\title{
Inhibition of Margination and Diapedesis of Neutrophils by Protein Synthesis Blockade
}

Phyllis V. Acquah

Virginia Commonwealth University

Follow this and additional works at: https://scholarscompass.vcu.edu/etd

Part of the Biochemistry, Biophysics, and Structural Biology Commons

(C) The Author

\section{Downloaded from}

https://scholarscompass.vcu.edu/etd/1439

This Thesis is brought to you for free and open access by the Graduate School at VCU Scholars Compass. It has been accepted for inclusion in Theses and Dissertations by an authorized administrator of VCU Scholars Compass.

For more information, please contact libcompass@vcu.edu. 


\section{Inhibition of Margination and Diapedesis of Neutrophils by Protein Synthesis Blockade}

A thesis submitted in partial fulfillment of the requirement for the degree of Master of Science in Biochemistry at Virginia Commonwealth University/Medical College of Virginia

\section{By}

Phyllis V. Acquah

BS Biology, University of Science and Technology, Ghana

George Mason University, Fairfax, Virginia

M Phil Microbiology, University of Science and Technology, Ghana

Director: Robert F. Diegelmann, Ph. D.

Professor, Department of Biochemistry

Virginia Commonwealth University

Richmond, Virginia

August, 2006 


\section{Acknowledgement}

I am highly indebted to several wonderful people, who contributed in diverse ways to make this project come this far. But, first I extend my gratitude to God, who endowed me with the courage to venture and the strength to carry on in this challenging pursuit. I also greatly appreciate and thank my family: my husband, Albert, whose love and support made it possible for me to undertake this study; my Mom, Nancy, whose unconditional love and selflessness in taking care of my children enabled me to concentrate on this research; my children, Nana and Kwaku, who did not quiet understand why Mommy had to be away most of the time, but hanged in there with me. I hope one day they will realize and be happy that their sacrifices benefited many lives.

Certainly, I couldn't have done this study without the unwavering support, guidance, and encouragement from my advisor, Dr. Diegelmann. He made a difficult problem seem manageable. Thanks for his direction through the "unchartered waters". I am also greatly indebted to Dr. Quincy Tran, who in spite of his busy schedule in the medical program, took time to train me and was never tired of my numerous questions. I thank Dr. Kevin Ward of the Emergency Department of VCU Health System for his passion for the prevention of ARDS and for funding the project through the generous support of VCURES (VCU Reamination, Engineering and Shock Center).

I thank Mr. Berny Fischer and Sonya Washington for their technical advice on difficult issues and for freely loaning me with some laboratory supplies. I am also very grateful to Frances White and Julie Farnsworth of the Flow Cytometry lab for patiently training me on the Flow Cytometer and helping me to analyze the data. I thank Steve Paugh, Kenneth Watterson, Carole Oskeritzian, Chas Easley, and Mike Maceyka, for the various technical assistance they gave to this research. I thank Dr. Hu Yang and several others mentioned here for willingly and generously helping out with sample collection. Jackie Shultz and Kristine Paccione's friendship and help in many different ways were invaluable. Finally, but certainly not the least, I would like to thank my committee members, Dr. Kevin Ward, Dr. Xiajun Fang, and Dr. Diegelmann, who took time off their tight schedule to meet with me. Their suggestions at every meeting were very helpful. 
Table of Contents

List of Tables..................................... $\mathrm{v}$

List of Figures................................. vi

List of Abbreviations.............................. viii

Abstract........................................... $\quad x$

Literature Review................................... 1

Introduction....................................... 1

Neutrophils..................................... 3

Description...................................... 3

Maturation \& Fate of Neutrophils.................. 3

Activities of Neutrophils........................... 4

Neutrophil Amory $. . . \ldots \ldots \ldots \ldots \ldots \ldots \ldots \ldots \ldots \ldots . . . \ldots, \quad 9$

Oxidative Mechanisms......................... 9

Non-oxidative Mechanisms.................... 11

Protein Synthesis Inhibitors....................... 13

The Hypothesis................................... 15

Materials and Methods.................................. 17

Results.......................................... 27

Discussion....................................... 49 
Conclusion....................................... 56

Recommendations for Future Studies.................. 56

References......................................... 58

Appendices.................................... 64 


\section{List of Tables}

\section{Table}

1 Effect of LPS on Myeloperoxidase Assay............................... 29 


\section{List of Figures}

Figure

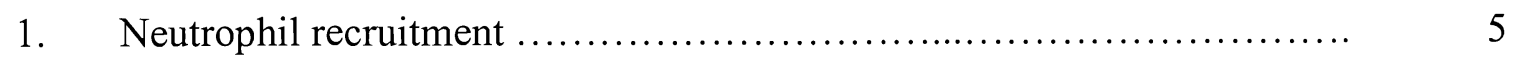

2. Neutrophil and endothelial cell Ligands ................................. 6

3. The structures of puromycin and aminoacyl -tRNA ..................... 13

4. The Structure of Anisomycin......................................... 14

5. MAP Kinase Signaling.............................................. 15

6. The structures of puromycin and aminoacyl -tRNA ….......................... 16

7. An in vitro model of the blood vessel-tissue in an in vivo system ........... 18

8. HMEC-1 Monolayer .................................................... 25

9. Time( in days) for HMEC-1 Monolayer Development ….................. 26

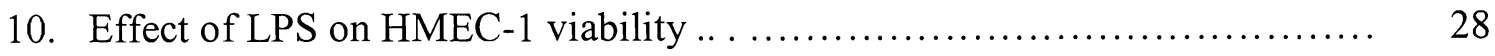

11. The inhibitory effect of LPS on PMN transmigration ............. 29

12. LPS induces neutrophil degranulation on contact $\ldots \ldots \ldots \ldots \ldots \ldots \ldots \ldots . . \ldots \ldots$

13. Comparing the direct effect of LPS, PSI, LPS-PSI on PMNs ...... 31

14. The effect different TNF $\alpha$ concentrations on PMN transmigration ........... 32

15. Inhibition of PMN transmigration by PSI in the presence of $10 \mathrm{ng} / \mathrm{ml} \mathrm{TNF} \alpha \ldots \quad 36$

16. A time course of PSI's effect on cell viability .................... 37

17. Analysis of endogenous E-selectin expression in HMEC-1 ................... 39

18. Growth pattern of HMEC-1 cultured in different growth media.............. 41 
19. HMEC-1 growth response to $0.2 \%$ serum after serum starvation..............

20. Low concentration of Serum exposure induces lower levels of E-selectin in HMEC-1 ..................................................... 44

21. Lack of serum induces apoptosis in HMEC-1 ......................... 45

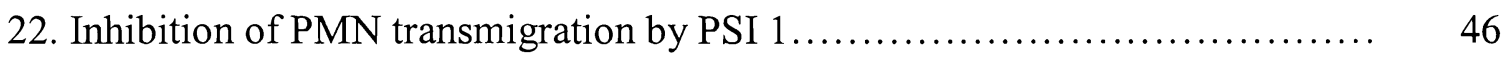

23. Inhibition of PMN transmigration by PSI $2 \ldots \ldots \ldots \ldots \ldots \ldots \ldots \ldots . . \ldots 7$

24. Analysis of E-selectin induced by $2 \%$ serum exposure.................... 48

25. A comparison of E-selectin levels induced by Serum: $20 \%$ vs. $2 \% \ldots \ldots \ldots \ldots \ldots \ldots . . . . . . .48$ 


$\begin{array}{ll}\text { ARDS } & \text { Acute Respiratory Distress Syndrome } \\ \text { MOF } & \text { Multiple Organ Failure } \\ \text { PMN } & \text { Polymorphonuclear Leukocytes } \\ \text { IL-1 } & \text { Interleukin }-1 \\ \text { IL-8 } & \text { Interleulin-8 } \\ \text { TNF } \alpha & \text { Tumor Necrosis Factor } \alpha \\ \text { LPS } & \text { Lypopolysaccharide }\end{array}$

PAF Platelet Activation Function

LFA-1 Lymphocyte-associated Function Antigen-1

Mac-1 Macrophage Antigen-1

ICAM Intercellular Adhesion Molecule

PECAM-1 Platelet Endothelial Cell Adhesion Molecule-1

C5a Complement Protein

fMLP formyl - Methionyl-Leucyl-Phenylalanine

LTB4 Leukotriene B4

NADPH Nicotine Adenine Dinucleotide Phosphate

MPO Myeloperoxidase

ROI Reactive Oxygen Intermediates

RNI Reactive Nitrogen Intermediates

OmpA Outer membrane proteins

MMPs Matrix Metalloproteinases

HMEC-1 Human Microvascular Endothelial Cells-1

FITC Fluorescein isothiocyanate

PBST Phosphate Buffered Saline $+0.05 \%$ Tween 20 
DPBS Dubelco's Phosphate Buffered Saline 


\begin{abstract}
INHIBITION OF MARGINATION AND DIAPEDESIS OF NEUTROPHILS BY PROTEIN SYNTHESIS BLOCKADE
\end{abstract}

By Phyllis V. Acquah, BS, M.Phil

A thesis submitted in partial fulfillment of the requirements for the degree of Master of Science in Biochemistry at Virginia Commonwealth University.

Virginia Commonwealth University, 2006

Major Director: Dr. Robert Diegelmann, Ph.D

Professor, Department of Biochemistry

Acute Respiratory Distress Syndrome (ARDS), an age-old clinical problem facing the Emergency Department and Intensive Care Units of all health systems, is a common debilitating lung condition consequent upon severe systemic inflammation. Although several studies have gone into understanding the epidemiology and pathogenesis of the disease thus making way for new advances in treatment strategies, there seems to be no known study tailored to its prevention. Neutrophil extravasation within the tissues during inflammation is the hallmark of this syndrome. Our study, sought to block excessive neutrophil infiltration by inhibiting the biosynthesis of some essential proteins necessary for the process. In this initial study, neutrophil transmigration was successfully reduced by $66 \%$ using protein synthesis inhibitors, a combination of puromycin and anisomycin. Our strategy, if fine-tuned, could form the basis of a new clinical strategy for the prevention of ARDS.

Funded by: VCURES (Dr. Kevin R. Ward) 


\section{Introduction}

\section{Literature Review}

Neutrophils, or polymorphonuclear leukocytes (PMN), are indispensable in mammalian host defense during infection. They are part of the innate immune system, which is very much involved in the first few hours of injury or infection before the adaptive immune system is activated. Although, the role of neutrophils is vital at the site of inflammation, their activities have also been implicated in the parthenogenesis of certain clinical conditions following their activation. An exaggerated neutrophil activation due to extensive tissue injury or shock causes systemic inflammatory response syndrome, which could lead to acute respiratory distress syndrome (ARDS) and subsequently, multiple organ failure (MOF) [1].

\section{Acute Respiratory Distress Syndrome (ARDS)}

Acute respiratory distress syndrome (ARDS) is a debilitating inflammatory condition resulting from an acute, severe lung injury to most or all of both lungs. Patients with ARDS experience severe shortness of breath and often require mechanical ventilation due to respiratory failure. The condition is characterized by fluid-filled alveoli and decreased lung compliance following extensive lung inflammation and small vessel injury[2]. ARDS is a syndrome not a specific disease, with predisposing factors like sepsis, trauma, and/or pneumonia. In ARDS, there is diffuse alveolar damage, resulting from structural changes in the alveolocapillary unit. Injury to the alveolocapillary membrane inevitably disrupts the endothelial barrier leading to the development of noncardiogenic pulmonary edema through increased vascular permeability. As the air spaces fill with fluid, the gas-exchange and mechanical properties of the lung deteriorate[3]. 
ARDS was first described in 1967 by Ashbaugh and collaborators, who observed 12 of 272 patients treated for respiratory failure, with the following unique features: cyanosis refractory to oxygen therapy, decreased lung compliance, and diffused infiltrates evident on chest radiograph that distinguished them from the others[4]. Initially, the condition was called adult respiratory distress syndrome but, in 1994, the AmericanEuropean Consensus Committee on ARDS standardized the definition and renamed it "acute" rather than "adult" because it occurs in all ages[5].

The incidence rate of ARDS ranges from 1.5 to 71 per 100,000 persons and affects about 150,000 each year in the United States. This syndrome is a major cause of morbidity, death, and cost in intensive care units [6]. The mortality rate of ARDS has been estimated to be approximately $30-40 \%,[7-10]$ with the deaths usually resulting from multi-system organ failure rather than lung failure alone[2]. The majority of ARDS patients who survive will make a full recovery; however, some will have lasting damage to their lungs. According Herridge and colleagues, survivors of ARDS may experience persistent functional disability even one year after discharge from the intensive care unit, mostly muscle wasting and weakness [11]. Thus, ARDS affects not only the patient, but also family members by way of stress and cost.

Patients who experience severe trauma or sepsis are at increased risk for the development of ARDS with an onset between 24 and 72 hours of injury. In an event of severe infection or trauma, neutrophils are activated and recruited to the site of injury. This is the body's initial immune response to foreign invasion. The immune response to trauma is often exaggerated and the activated neutrophils extravasate not only to the site of infection, but also to distant tissues. Thus, the immunoactivation, though of benefit at 
the site of injury, has the potential to cause cell-mediated damage at remote organs[1]. In normal circulation, neutrophils constitute about $60 \%$ of leukocytes, but in ARDS total percentage can be as high as $90 \%$ in the lungs alone. The principal players involved in ARDS are cytokines, neutrophils, endothelium, and reactive oxygen species [12].

\section{Neutrophils}

Neutrophils are described as the "first line of defense" in the body's immune response because they are the first to be recruited to the sites of inflammation. At the site, their targets include bacteria, fungi, protozoa, viruses, viral- infected cells and tumor cells. Like macrophages, neutrophils are called professional phagocytes, because, they hunt and kill microbes by ingesting them.

\section{Description}

Neutrophils are small cells, measuring about $9-10 \mu \mathrm{m}$ in diameter. They are the most abundant leukocyte (50\% $-60 \%$ of leukocytes) in blood, with mean concentration of $4.4 \times 10^{6}$ cells $/ \mathrm{ml}$. They differ from the other leukocytes by their characteristic segmented nuclei (2-5 lobes), however, $5 \%$ of them have "banded" nuclei. They also possess a large quantity of storage granules in the cytoplasm and glycogen in the cytosol. Functionally,

the granules are divided into three types: azurophils (primary granules), specific (secondary) granules, and storage granules.

\section{Maturation and Fate of Neutrophils}

Neutrophils begin their two-week lifespan in the bone marrow, where they differentiate and proliferate. During this period, they undergo six morphological stages: myeloblast, promyeloblast, myelocyte, metamyelocyte, non-segmented (band) neutrophil, 
and segmented neutrophil. The segmented neutrophil is terminally differentiated and a fully functionally active cell. It is during the mitotic phase of the promyelocytic stage that neutrophils begin to produce azurophil granules, which contain enzymes such as myeloperoxidase and elastase. In addition, in human neutrophils, the azurophil granules contain cationic antibacterial protein 37 and azurocidin[13, 14]. The azurophil granules are called "primary granules" because they are the first to appear in differentiation. Specific granules appear next and are called "secondary granules". They are made in the "myelocyte" stage (near the end of the mitotic stage). Specific granules contain lactoferin and lysozme and they outnumber (120-140 granules/cell) the azurophils (60-70 granules/cell).

Most of the neutrophils formed in the bone marrow never enter circulation; instead they are phagocytosed by bone macrophages. The few that are released from the bone marrow after maturation circulate in the bloodstream in a non-activated state, having a half-life of approximately 4-10 hours. Thereafter, the neutrophils enter the tissue pools, where they survive for another 1 to 2 days after which time they are cleared from circulation. Their viability is however greatly shortened in patients suffering from infections or acute inflammatory diseases, in whom tissue requirement for newly recruited neutrophils becomes overwhelmingly higher.

\section{Activities of Neutrophils}

Under normal physiologic conditions, non- activated neutrophils stay in constant circulation and occasionally probe the vascular endothelium for the opportunity to transmigrate. Leukocyte recruitment has an important endothelial cell-dependent 
component and involves a series of adhesion steps: margination, rolling, activation and firm adhesion, and diapedesis (Fig.1).

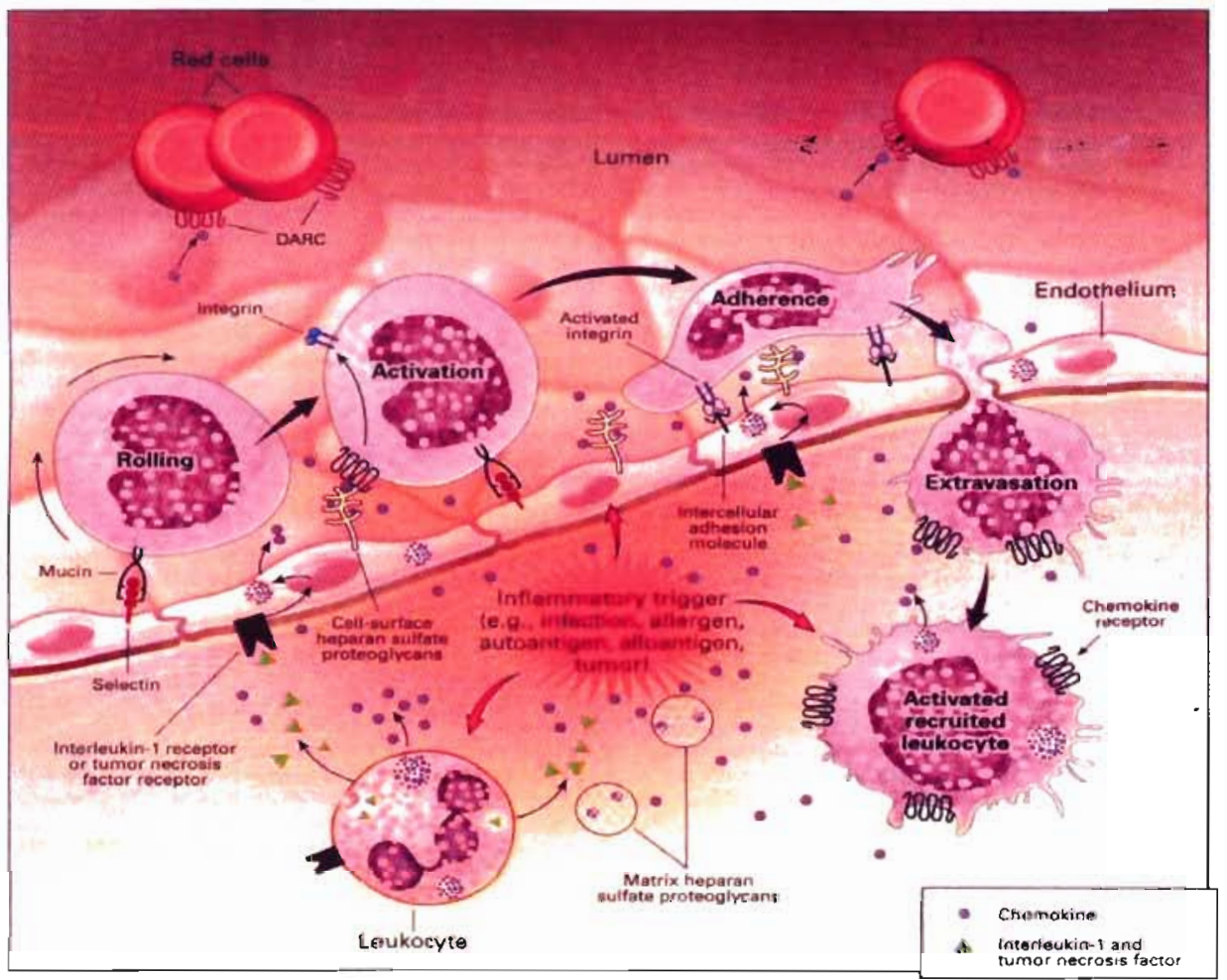

Picture adapted from: www.bio.davidson.edu/courses/immunology

Figure 1: Neutrophil recruitment. A schematic showing the four steps in neutrophil migration into the tissues and the chemokines that aide the process.

During inflammation, the endothelial cells become activated by cytokines such as interleukin-1 (IL-1), Tumor Necrosis Factor $\alpha$ (TNF- $\alpha)$, and bacterial products such as endotoxin (lipopolysaccharide, LPS) leading to the up-regulation of cell surface adhesion molecules[15-17] (Fig. 2). 




Figure 2: Neutrophil and endothelial cell Ligands. The different types of adhesion molecules expressed during neutrophil recruitment. [Picture adapted from Journal of Pharmacol Rev. 52(3): 349-374 (2000)]

The first group of adhesion molecules expressed is the selectins, specifically, E, L and P- selectins. They are vital to our body's immune response by recruiting and directing leukocytes and lymphocytes to sites of infection. In an event of an infection or injury, macrophages release TNF- $\alpha$ which stimulates the endothelial cells lining blood vessels to express P-selectin first, then, E-selectin (Janeway et al. 2005). P- selectins are pre-formed in vesicles called Weibel-Palade bodies near the cell surface of endothelial cells (Janeway, et al 2005). The activation of TNF- $\alpha$ or LPS receptors on endothelial cells causes these vesicles to fuse with cell membrane, resulting in P-selectin expression within minutes of cytokine recognition. The story, however, is different for E- selectins, which have to be transcribed, translated and transported to the cell surface to be expressed. Thus, it takes about two hours after endothelial cell activation for E-selectins to be expressed, with peak expression between 6-12 hours after cytokine recognition [18]. 
L -selectin, on the other hand, is constitutively expressed on the surface of neutrophils.

With endothelial cell activation, the neutrophils flowing in the center stream of the blood vessel begin to move towards the periphery, where they tether to the endothelial cells via the selectins. This initial attachment is called margination, and is a very important first step in the inflammatory cascade resulting in neutrophil rolling on the vessel wall.

Rolling is mediated by low-affinity interactions between the selectins family (E/L/P-selectins) and sialyl Lewis ${ }^{\mathrm{x}}$ glycans $\left(\mathrm{sLew}^{\mathrm{x}}\right)$ [19-21]. Both $\mathrm{E}$ and $\mathrm{P}$-selectins are known to interact with sLew ${ }^{x}$ glycans, which are constitutively expressed on the surface of neutrophils, but the actual role of L-selectin in rolling is yet to be fully elucidated. In trying to understand the roles of the three selectins in leukocyte rolling, Collins et al[22] studied double-null selectin $(\mathrm{E} / \mathrm{P})$ and triple-null selectin $(\mathrm{E} / \mathrm{L} / \mathrm{P})$ mice in infections. They noted that while the E/P-mutant mice developed both skin and pulmonary infections, the triple (E/L/P-selectins)- mutants did not. They therefore concluded that L-selectin deficiency alters the inflammatory response in E/P mutants. In another study, King and colleagues [23] also showed that the L-selectin receptors on neutrophils become clustered into a cap during rolling fostering a lower velocity movement than in cells with uniformly distributed L-selectin.

The slow rate acquired by neutrophils is integral in the transition to firm adhesion step by a second group of molecules called integrins. Prior to firm adhesion, chemokines such as interleukin- 8 (IL-8) and platelet activation function (PAF) stimulate neutrophils to upregulate $\beta_{2}$-integrins, which are Lymphocyte -associated Function Antigen-1, LFA1, (CD11a/CD18), Macrophage antigen- 1, Mac-1 (CD11b/CD18), and p150/ 95 $(\mathrm{CD} 11 \mathrm{c} / \mathrm{CD} 18)$ as well as the vascular endothelium to express inter-cellular adhesion 
molecules (ICAM- 1 and 2), which belong to the immunoglobulin superfamily. On neutrophils, the distribution of LFA-1 is greater than the rest and has a higher affinity for ICAM-1 (CD54), but less affinity for ICAM-2[17, 24-26]. The binding of $\beta_{2}$-integrins to the ICAMs arrests the rolling motion of neutrophils and ensures a firm adhesion, a phenomenon vital to leukocyte transmigration. According to one report [27] following IL-8 exposure, neutrophils shed their L-selectins to allow firm adhesion to take place.

Firm adhesion of neutrophils to activated endothelium is an important step preceding diapedesis (transmigration) and also enables neutrophils to probe the vascular endothelium for an intercellular barrier. Platelet-Endothelial Cell Adhesion Molecule-1 (PECAM-1 or CD31), another immunoglobulin superfamily localized at the intercellular borders of endothelial cells mediates the process. PECAM-1 acts as glue that holds the adjoining cells together. Recent reports $[28,29]$ indicate that leukocyte-derived azurocidin induces alteration of vascular permeability to permit diapedesis. The first assertion that azurocidin might play a role in endothelial permeability regulation was made by Ostergaard and Flodgaard [30] when they observed that fibroblast and endothelial monolayers treated with purified azurocidin exhibited reversible disruption of barrier function by cell contraction and the formation of large gaps between cells. However, for transmigration to proceed, the firmly adhered neutrophil must first flatten before squeezing between the adjoining cells to enter the tissues. In the tissues, chemotactic factors like complement protein (C5a), PAF, leukotriene $\mathrm{B}_{4}\left(\mathrm{LTB}_{4}\right)$, bacterial peptides, f-Met-Leu-Phe (fMLP), or IL-8 [31] guide the transmigrated neutrophil to the site of inflammation for degranulation or phagocytosis to occur. 


\section{Neutrophil's Armory}

Neutrophils have an incredible potent antimicrobial arsenal both within their granules and by their ability to produce reactive oxygen species. This array of weaponry is grouped as oxidative and non-oxidative "weapons" and they include oxidants, proteinases, and cationic peptides.

\section{Oxidative Microbicidal Mechanisms}

\section{Free Radical Production}

There are two forms of free radicals produced by neutrophils (and other cells): reactive oxygen species and reactive nitrogen intermediates. The reactive oxygen intermediates are produced by the phagocyte NADPH oxidase, and are microbicidal [32]. Upon activation, neutrophils and mononuclear phagocytes increase their oxygen consumption, a process called respiratory burst. During this respiratory burst, the NADPH oxidase, an electron transport chain, reduces oxygen to superoxide anion or its protonated form, perhydroxyl radical, according to the equation below to form hydrogen peroxide.

$\mathrm{O}_{2}+\dot{\mathrm{e}}+\mathrm{H}^{+} \rightarrow \mathrm{HO}_{2} \cdot \rightarrow \cdot \mathrm{O}^{-}{ }_{2}+\mathrm{H}^{+}$

$\cdot \mathrm{O}_{2}^{-}+\cdot \mathrm{O}_{2}^{-}+2 \mathrm{H}^{+} \rightarrow \mathrm{O}_{2}+\mathrm{H}_{2} \mathrm{O}_{2}$

The hydrogen peroxide so formed interacts with myeloperoxidase to produce hypochlorous acid, which is antibacterial and cytotoxic. The hydroxyl radical $(\bullet \mathrm{OH})$ can be formed in several ways, but the decomposition of $\mathrm{H}_{2} \mathrm{O}_{2}$ catalyzed by $\mathrm{Fe}^{2+}$ (Fenton reaction) is the most important.

\section{Fenton Reaction:}

$\mathrm{Fe}^{2+}+\mathrm{H}_{2} \mathrm{O}_{2} \rightarrow \mathrm{Fe}^{3+}+\mathrm{OH}^{\cdot}+\mathrm{OH}^{-}$ 
Reactive nitrogen intermediates (RNI) are the second group of free radicals formed by neutrophils. They originate from an oxidative pathway in which an unstable nitric oxide (NO•) is derived from the guanido nitrogen in the conversion of L-arginine to L- citrulline catalyzed by $\mathrm{NO} \bullet$ synthase. It appears the antimicrobial activity is ROI dependent in normal neutrophils, but RNI may play a role in cells with deficiences in NADPH oxidase/MPO pathways. Nitric oxide may also contribute to the microbicidal activity of neutrophils by reacting with ROI to form secondary cytotoxic species such as peroxynitrite.

Myeloperoxidase (MPO) the most abundant protein in neutrophils is a green lysosomal enzyme localized in the azurophil granules [33]. It catalyzes the reaction of hydrogen peroxide and chloride to hypochlorous acid [33-36], which is a potent antibactericidal [37]. This enzyme is considered a very important component of the neutrophil's antimicrobial armory.

MPO plays a central role in infection and inflammation [36] and neutrophils require it to kill a variety of microorganisms [34]. It is released in phagocytosis during neutrophils' attack. Myeloperoxidase has also been implicated in promoting tissue damage in numerous inflammatory diseases including rheumatoid arthritis[38], ARDS [39], multiple sclerosis [35], cystic fibrosis[40], and neonatal lung injury [41]. Recent reports further indicate that MPO triggers arterosclerosis by oxidizing low-density lipoproteins[42] and is implicated in acute myeloid leukemia[43], and lung cancer [44]. 


\section{Non- Oxidative Microbicidal Mechanisms}

This category includes many components found in the granules, which are described as follows:

Defensins are small, cysteine-rich cationic polypeptides, which exhibit powerful antimicrobicidal activities against a broad spectrum of microorganisms [45]. Their toxicity may involve the disruption of cell membrane of target cell leading to an increase in permeability and leakage of small molecules[46]. A Recent study has also linked defensins with tissue damage[47].

Bacterial Permeability- Increasing (BPI) protein is a $59 \mathrm{kDal}$ cationic protein localized in azurophil granules of neutrophils. It does not require enzymatic activity to function and belongs to a class of proteins, which transport or bind cholesterol esters and lypopolisaccharides [48, 49]. It exerts its antimicrobial activity by permeabilizing bacterial membrane [50].

Elastase, Cathepsin G, Proteinase 3, and Azurocidin are serine proteases (described as Neutral Serine Protease, NSP, family). They are highly cationic glycoprotein and are potent antibactericidal[51-53]. Both elastase and cathepsin G appear to kill bacteria by two distinct mechanisms - enzyme-dependent and an enzyme independent manner[54]. Elastase has also been known to specifically digest bacteria by degrading the outer membrane proteins, OmpA[55]. Azurocidin, however, has been found to be synergistic with elastase in killing bacteria [54]. Of these proteases, Proteinase 3 is the only one whose mechanism of killing still remains unclear. However, studies have also shown that these proteases when released can cause irreparable damage 
to tissues $[56,57]$. Proteinase 3 is the only other NPS that has been implicated in the immunopathogenesis of emphysema.

Lactoferrin, which localizes in the specific granules, is an iron-binding glycoprotein belonging to the transferrin family. Lactoferrin sequesters free iron with high affinity thereby preventing the growth of ingested microorganisms that survive the killing process and increase permeability to lysozyme[58]. This is one more strategy of neutrophil's host defense mechanism. Another report also suggests Lactoferrin's bactericidal activities, which are independent of iron binding [59].

Matrix Metalloproteinases (MMPs) are a family of enzymes that is responsible for degradation of extracellular matrix components. Of these, MMP-8, a neutrophil collagenase, is of special interest to this research. By its remodeling action, MMP-8 facilitates leukocyte trafficking through endothelial barriers and solid organs. MMP-8 like other metalloproteinases is stored in the specific granules and is rapidly liberated in response to inflammatory mediators[60].

Each of these antimicrobial agents of neutrophil has, besides its microbicidal function, the capability also to damage the surrounding tissues. Many of previous studies have centered on the treatment of ARDS consequent upon neutrophil's damaging activity. However, this study seeks to use protein synthesis inhibitors as a strategy to prevent transmigration of neutrophils by inhibiting margination and/or diapedesis. This is an in vitro study, which uses Puromycin and Anisomycin combined to inhibit protein biosynthesis. 


\section{Protein Synthesis Inhibitors}

Puromycin is an aminonucleoside antibiotic produced by Streptomyces alboniger. It inhibits protein biosynthesis by incorporating itself into a growing polypeptide chain at the A site and causes its premature termination. Because Puromycin resembles the aminoacyl terminus of an aminoacyl-tRNA (Fig. 3), it's amino group joins the carbonyl group of the growing polypeptide chain to form an adduct, which dissociates from the ribosome and becomes stable due to the amide group rather than an ester linkage (Berg et al, 2002).

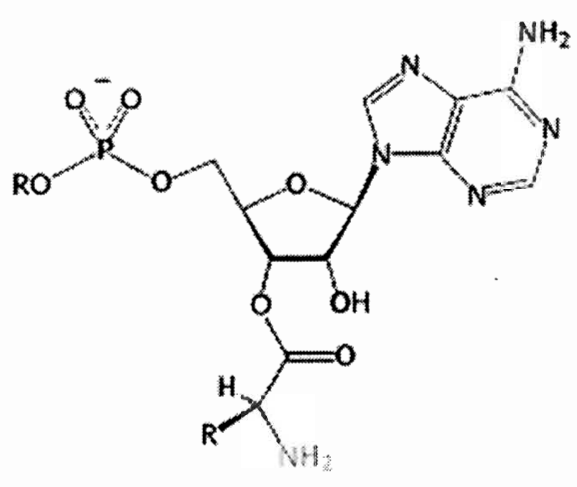

Aminosch-tRNA

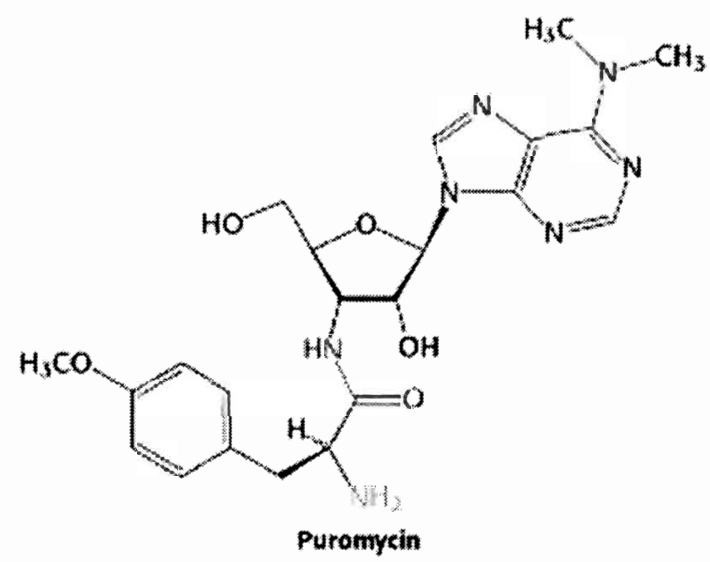

Diagram adapted from Figure 29.34. Biochemistry (C) 2002 by W. H. Freeman and Company

Figure 3: An illustration of the structural similarity between puromycin and the aminoacyl terminus of an aminoacyl-tRNA that makes it possible to incorporate itself into the growing polypeptide.

Anisomycin is an antibiotic isolated from Streptomyces griseolus with a structure established as 2-p-methoxyphenylmethyl-3-acetoxy-4-hydropyrrolidine (Fig. 4). It is known to inhibit protein synthesis by binding to $80 \mathrm{~S}$ ribosomal subunits and blocking peptide bond elongation causing polysome stabilization[61]. Its action is described as potent, structurally specific, and reversibly inhibits protein biosynthesis in certain yeast and mammalian cells. In his study on the Mode of Action of Anisomycin, Grollman[62], 
reported a partial inhibition of DNA synthesis in Hela cells at anisomycin concentration which also produced $95 \%$ inhibition of protein synthesis. He also noted that the onset was rapid and reversible. Another effect of anisomycin on cells classified as stress, has been reported to strongly activate p38 and c-Jun N-terminal kinase (JNK) MAPK pathway[63] (Fig. 5). However, studies show that activation of MAPK pathway, which occurs at subtrailslational inhibitory concentration, is dissociable from the translational arrest-related components $[64,65]$.

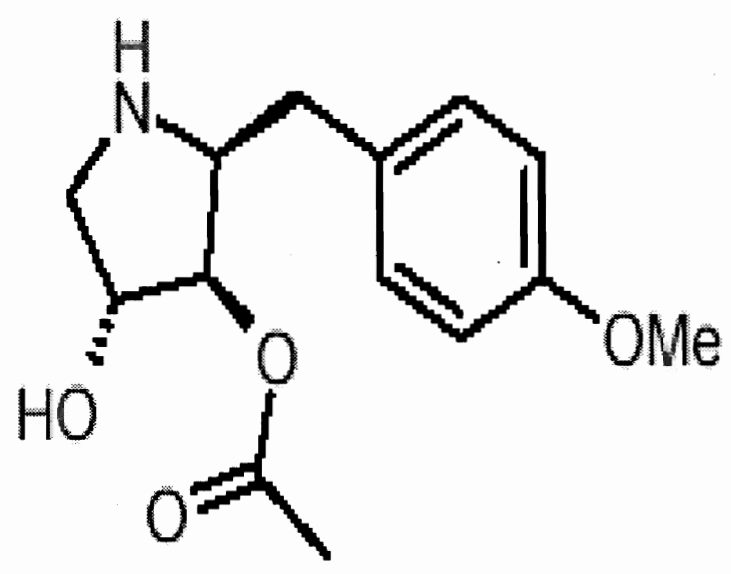

Figure 4: The structure of Anisomycin 


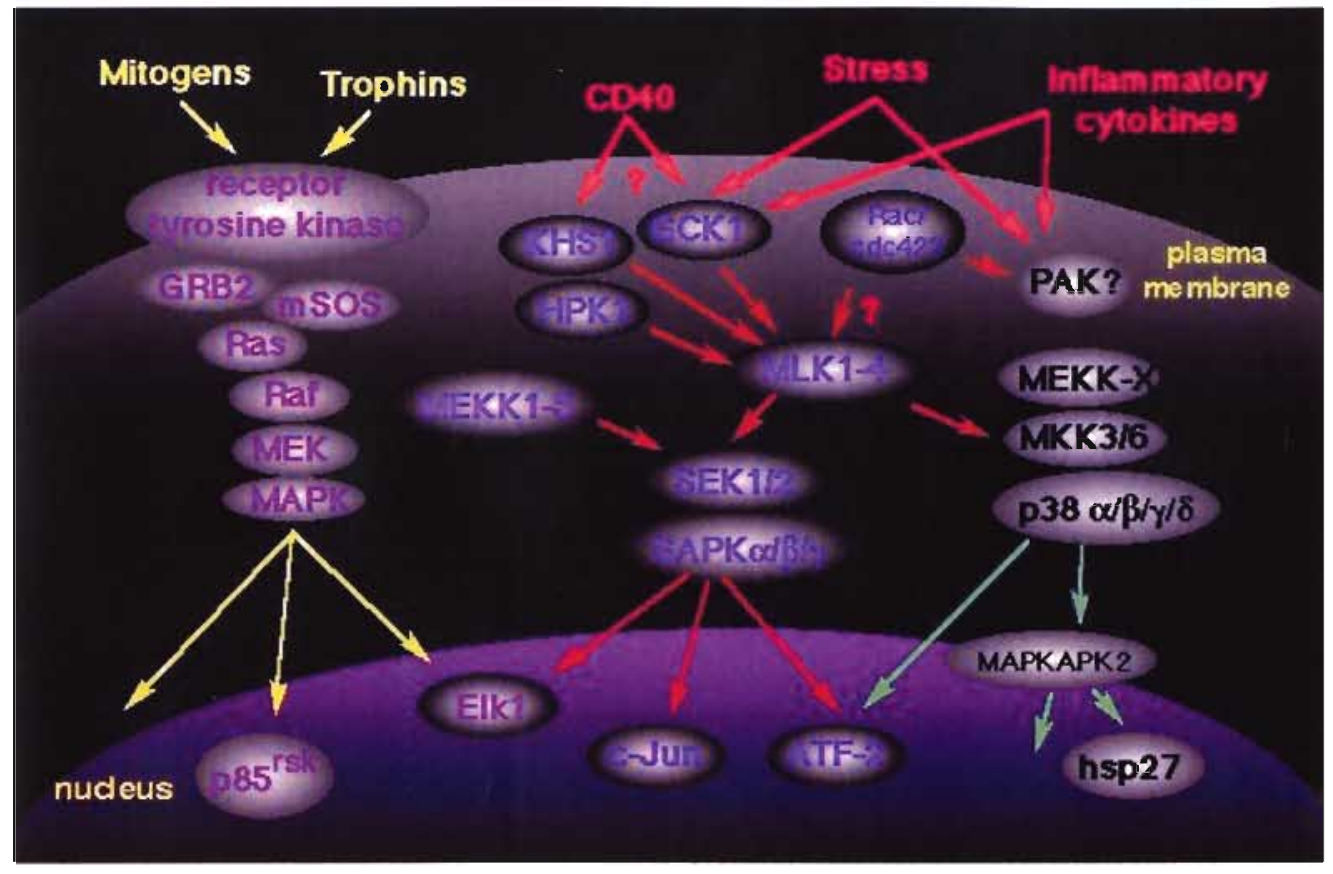

Adapted from: http://kinase.uhnes.utoronto.ca/media/signallingmap.html

Figure 5: MAP Kinase signaling. A schematic showing stress-activated c-Jun and p38 pathways.

\section{The Hypothesis}

Protein synthesis inhibitors can be used as a novel strategy to inhibit neutrophil transmigration and could form a basis for a therapy to prevent ARDS. 


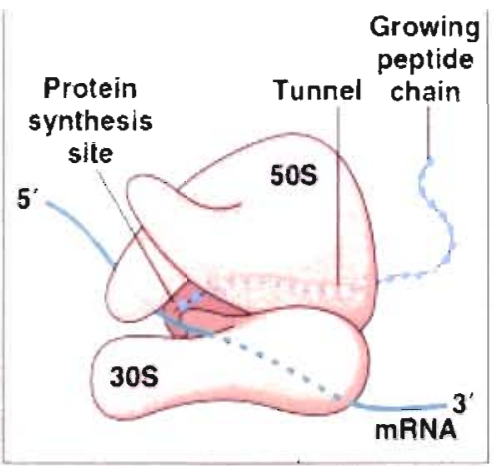

(a) Three-dimensional detail of the protein synthesis site showing the $30 \mathrm{~S}$ and $50 \mathrm{~S}$ subunit portions of the 705 prokaryotic ribosome.

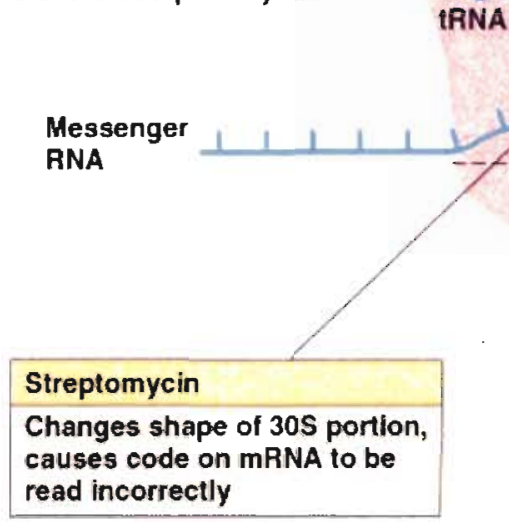

Growing polypeptide

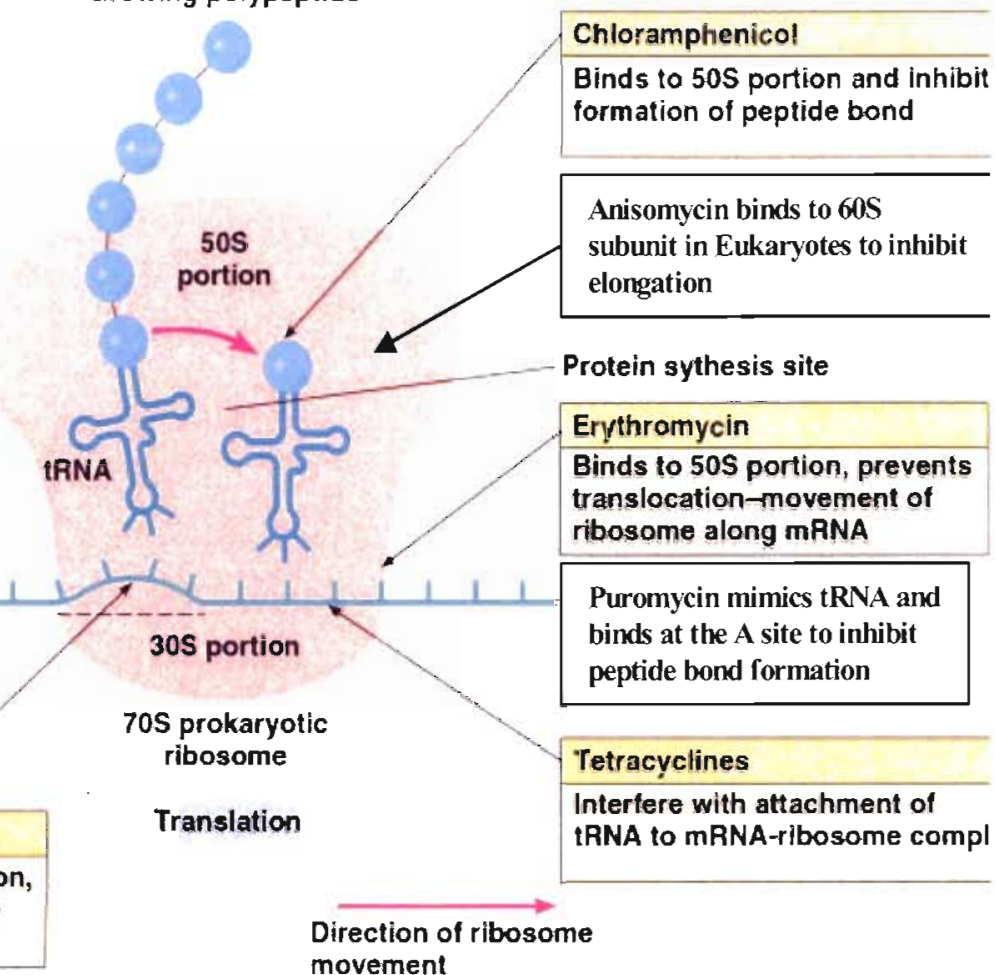

Copyright 2004 Pearson Education Inc. publishings as Benjamin Cummings.

Figure 6: Mechanism of Protein Synthesis Inhibitors. An illustration of some protein synthesis inhibitors including anisomycin and puromycin [Picture adapted from an unknown location of the Internet] 


\section{Materials and Methods}

\section{Cell Culture}

The cell line, Human Microvascular Endothelial Cells (HMEC-1), used was a gift from the Center for Disease Control and Prevention (CID-R053413-00)[Atlanta, GA]. The cells were initially cultured in MDCB 131 medium [Gibco, Grand Island, NY] supplemented with $20 \%$ Fetal Bovine Serum (Gibco, Grand Island, NY), $1 \%$ AntibioticAntimycotic (Penicillin, Streptomycin, and Amphotericin B) [Gibco: Grand Island, NY], 1\% L-Glutamine (Gibco: Grand Island, NY), 40ng/ml rh Epidermal Growth Factor (Invitrogen: Carlsbad, CA), and 1ug/ml Hydrocortisone (Sigma: St. Louis, MO). Later on, culture media with reduced serum were used and were prepared from $1 \%$ or $2 \%$ Fetal Bovine Serum, 1\% Insulin-Transferrin-Selenium (see Appendix 2 for formulations) [Gibco, Grand Island, NY] 1\% Antibiotic-Antimycotic (Penicillin, Streptomycin, and Amphotericin B), and 1\% L-Glutamine.

\section{Setting up an in vitro model}

A test model, which mimics the in vivo system of endothelium of the blood vessel and the tissue milieu, was adapted (Fig. 7). The model consisted of a 6.5 diameter transwell insert (Costar: Corning, NY) with polycarbonate membrane pore size of $3 \mu \mathrm{m}$ placed in a 24-multiwell plate (Cellstar \#662160) with medium. The transwell inserts were first coated with $6.6 \mathrm{ug} / \mathrm{ml}$ of fibronectin (Fisher Scientific: Newark, DE) and allowed to incubate at room temperature under the laminar hood for one hour. After the incubation period, excess fibronectin liquid was discarded and the coated inserts were washed one 
time in sterile 1X Dubelco's PBS (Gibco: Grand Island, NY). 100 $\mu 1$ of growth medium containing 20,000 human microvascular endothelial cells (HMEC-1) were seeded onto the fibronectin coated inserts. Then $500 \mu \mathrm{l}$ of growth medium was placed in the well and the seeded transwell insert was placed in it. The cells were allowed to grow to confluence for up to 7 days at $37^{\circ} \mathrm{C}$ and $5 \% \mathrm{CO}_{2}$ and fresh growth medium was replaced every other day. The monolayer formed represented the lining of the blood vessel.

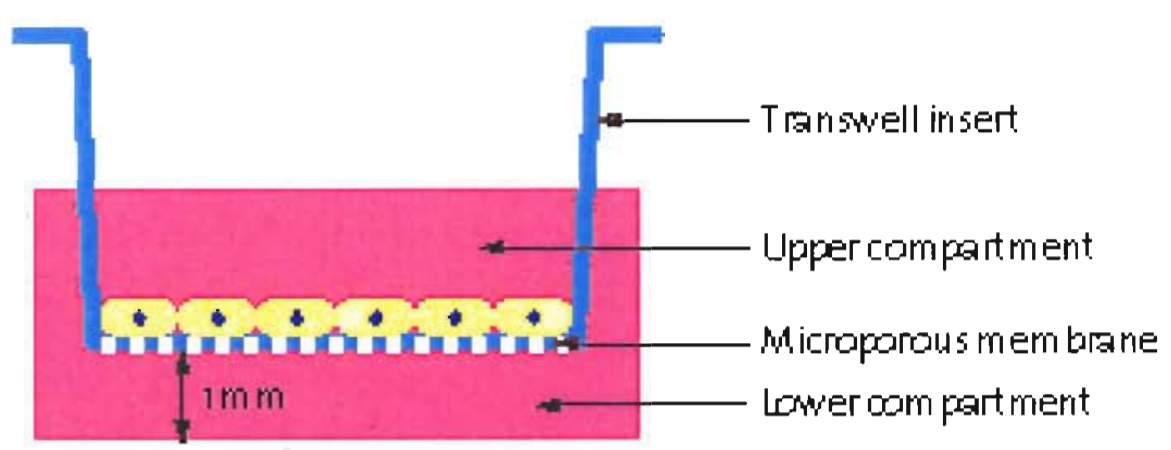

Figure 7: An in vitro model of the blood vessel- tissue system in vivo. The upper compartment depicts the blood vessel with a monolayer of endothelial cells and the lower compartment represents the surrounding tissue into which the neutrophil migrate.[ Diagram adapted from the internet. Location: unknown]

\section{Determining the Integrity of HMEC-1 Monolayer}

Each day starting from the third day of growth, the integrity of monolayer was tested using the Bradford Protein assay. The inserts were removed from the incubator and washed twice in DPBS to remove traces of serum from the monolayer. $100 \mu \mathrm{l}$ of $10 \mu \mathrm{g} / \mathrm{ml}$ of BSA (Bio-Rad: Hercules, CA) in MCDB 131 was placed in the transwell inserts and $500 \mu 1$ of basic MCDB 131 in the lower chamber. A control was included in each day's experiment. The control consisted of a transwell insert without a monolayer and was 
placed in a well containing $500 \mu \mathrm{l}$ of medium; $100 \mu \mathrm{l}$ of $10 \mu \mathrm{g} / \mathrm{ml} \mathrm{BSA}$ was then placed in the upper chamber. Triplicates of each set up were done and were incubated at $37^{\circ} \mathrm{C}$ and $5 \% \mathrm{CO}_{2}$ for 45 minutes. After the incubation, the bottoms of the inserts were rinsed with the contents of the lower chamber and $200 \mu 1$ of the contents was transferred into a labeled $1.5 \mathrm{ml}$ microcentrifuge tubes. $200 \mu 1$ of $1 \mathrm{X}$ Bradford Dye Reagent (Bio-Rad: Hercules CA) was added, vortexed, and incubated for 5 minutes at room temperature. $100 \mu \mathrm{l}$ of the suspension was transferred to a $96-$ well microplate and read at $595 \mathrm{~nm}$ on a microplate reader. Standards were prepared according to the manufacturer's instruction [Bio-Rad: Hercules, CA] with a linear range of $1.25-10 \mu \mathrm{g} / \mathrm{ml}$ of BSA. The standard curve developed was used to determine the amount of albumin that had gone through the monolayer. By measuring each day's total protein leakage up to 7 days, it was possible to determine when the monolayer was ready for future transmigration experiments.

\section{Testing Lypopolyssachrides' Reaction with Myeloperoxidase ELISA Assay}

Standard myeloperoxidase solutions ranging from $0 \mathrm{ng} / \mathrm{ml}-100 \mathrm{ng} / \mathrm{ml}$ were prepared according to the manufacturer's protocol (Calbiochem, La Jolla, CA) [Appendix 5]. Later on, three concentrations of MPO, $0 \mathrm{ng} / \mathrm{ml}, 5 \mathrm{ng} / \mathrm{ml}$ and $100 \mathrm{ng} / \mathrm{ml}$, were prepared in buffer (MCDB 131) with or without $1 \mathrm{ng} / \mathrm{ml}$ of lypopolysacchride, LPS (Sigma: St. Louis, MO). A blank, made up solely of the buffer was included. Both the standard solutions and the samples were tested with the ELISA assay [Appendix 5]. MPO activity was measured at $450 \mathrm{~nm}$ on a microplate reader. The standard curve was developed and used to calculate the amount of MPO activity seen with both the buffer and LPS. 


\section{Investigating LPS Direct Effect on Neutrophils}

Approximately 500,000 purified PMNs (obtained from healthy volunteers) were added to $1 \mathrm{ng} / \mathrm{ml}$ LPS in a $1.5 \mathrm{ml}$ microcentrifuge tubes and incubated for 0,15 and 30 minutes at $37^{\circ} \mathrm{C}$ and $5 \% \mathrm{CO}_{2}$. At the end of the incubation, the PMN suspensions were vortexed and 100ul transferred into a required number of strips of a 96-well polystyrene plate coated with antibody for MPO ELISA assessment. The presence of myeloperixidase was measured at $450 \mathrm{~nm}$ using a microplate reader.

\section{Investigating LPS's and PSI's Individual and Combined Effect on PMNs}

To determine if PSI could prevent neutrophil degranulation with LPS activation, 500,000 neutrophils were placed in four separate $1.5 \mathrm{ml}$ microcentrifuge tubes and either LPS ( $1 \mathrm{ng} / \mathrm{ml})$, PSI ( $0.5 \mathrm{uM}$ puromycin and $0.12 \mathrm{uM}$ anisomycin), both, or nothing (control) was added. The neutrophils that received both reagents were first pre-treated with PSI for one hour followed by LPS for an additional hour. All samples were incubated at $37^{\circ} \mathrm{C}$ and $5 \% \mathrm{CO}_{2}$. Immediately after incubation, the suspensions were centrifuged at $18,000 \mathrm{xg}$ at $4^{\circ} \mathrm{C}$ for 15 minutes to pellet the PMNs. After centrifugation, $450 \mu \mathrm{l}$ of the supernatant was discarded and $500 \mu \mathrm{l}$ of cytobuster extraction protein (Novagen: Canada) was added and incubated on ice for another 15 minutes to lyse the PMNs. Following PMN lysis, MPO ELISA assay was performed to assess the amount of myeloperoxidase released. 


\section{Determining Cell Viability With LPS or PSI Exposure}

Cell viability was tested after LPS and PSI separate exposures. Viable cell numbers were measured using 3-[4,5-dimethylthiazol-2-yl]-2,5 diphenyltetrazolium bromide (MTT)[Sigma: St. Louis, MO] assay. Approximately 50,000 HMEC-1 were cultured to confluence for 3 days in a 96-well plate. The medium was aspirated and the cells were washed two times with 1 X DPBS to remove all traces of serum. A dose response on cell viability was tested with LPS. To do this, $100 \mu$ l of different LPS concentrations, $0 \mathrm{ng} / \mathrm{ml}, 0.25 \mathrm{ng} / \mathrm{ml}, 0.5 \mathrm{ng} / \mathrm{ml}$ and $1 \mathrm{ng} / \mathrm{ml}$, were added to designate wells with cells and incubated for four hours. While cultures were incubating, MTT working solution was prepared by adding 3ml of MCDB 131 medium to a vial of MTT lyophilized reagent. After LPS treatment, the cultures were removed and $10 \mu l$ of the MTT reconstituted solution was added to all wells and re-incubated for 2 hours. A purple precipitate (formazan) resulted from a reaction between mitochondria and MTT reagent. $100 \mu \mathrm{l}$ of MTT Solubilization solution was added to dissolve the precipitate. Dissolution of crystals was expedited by carefully triturating the mixture with a micropipette. Two absorbance readings at $570 \mathrm{~nm}$ and $690 \mathrm{~nm}$ were taken. The latter reading at $690 \mathrm{~nm}$, which is the background absorbance, was deducted from the absorbance at $570 \mathrm{~nm}$ to obtain a measure of cell viability.

In the case of PSI, a time-course of HMEC-1 exposure to a single dose of PSI $(0.5 \mu \mathrm{M}$ Puromycin $+0.12 \mu \mathrm{M}$ Anisomycin) was tested. The cells were exposed to PSI for different time periods at one hour intervals up to five hours and then analyzed by MTT assay for viability or cytotocity. 


\section{Determination of TNF $\alpha$ 's Optimal Concentration for PMN Transmigration}

In subsequent experiments, it became necessary to replace LPS with TNF $\alpha$ as a stimulant for PMN transmigration. And to determine the appropriate concentration for the assay, various TNF $\alpha$ concentrations, were tested on PMN transmigration. HMEC-1 monolayer preparations were exposed to TNF $\alpha$ concentrations of $2 \mathrm{ng} / \mathrm{ml}, 5 \mathrm{ng} / \mathrm{ml}$, and $10 \mathrm{ng} / \mathrm{ml}$ for 4 hours. The length of time (4 hours) for TNF $\alpha$ to exert maximal effect was selected according to the method by Chen et. al[66] .

Meanwhile, PMNs were isolated from whole blood of healthy volunteers by density gradient separation (Appendix 3 ) using polymorphprep solution (Polymorphprep: Oslo, Norway). The purified PMNs were re-suspended in MCDB medium and the density was determined using a Coulter cell counter [Coulter Electronics Ltd., Luton, England]. The purified PMNs were kept on ice until needed. At the end of the monolayer treatment period, all inserts were washed two times in DPBS and placed in a 24-well plate containing $600 \mu \mathrm{l}$ of $0.1 \mathrm{ng} / \mathrm{ml}$ of interleukin -8 ( Sigma: St. Louis, MO). $100 \mu \mathrm{l}$ of $10^{6} \mathrm{PMNs}$ was also placed in all inserts. The sets were incubated at $37^{\circ} \mathrm{C}$ and $5 \% \mathrm{CO}_{2}$ for 90 minutes. After that, cultures were removed from the incubator and the bottoms of the inserts were rinsed with the lower chamber contents to ensure no transmigrated PMN was sticking to the bottom. $475 \mu 1$ of the lower chamber contents from each well was transferred into labeled micro-centrifuge tubes to which $25 \mu 1$ of 20X Sample Buffer (Calbiochem, La Jolla, CA) was added and vortexed to ensure careful mixing. Following this, the MPO ELISA assay [Appendix 5] was performed to quantify transmigrated PMNs by measuring the presence of myeloperoxidase. The results obtained were recorded. 


\section{Transmigration of PMNs after TNF- $\alpha$ and PSI treatment of Monolayer}

Triplicates of four categories of inserts with intact HMEC-1 monolayers were prepared. The experiment was designed and grouped as follows: Negative Control (\#1), TNF- $\alpha$-treated only (\#2), PSI -treated only (\#3), and PSI pre-treatment plus TNF- $\alpha$ cotreatment (\#4). The Protein Synthesis Inhibitors (PSI) used was a combination of $0.5 \mu \mathrm{M}$ Puromycin (Sigma \# P8833, St. Louis, MO) and 0.12 $\mu \mathrm{M}$ Anisomycin (Sigma \#A9789, St. Louis, MO). The combined concentration is also referred to in this study as $0.5 \mathrm{X}$. This dosage of PSI was selected based on preliminary in vitro studies done in the lab by Quincy Tran on the reversibility effects of different concentrations of PSI on HMEC-1 viability [Appendix 6]. From his experiments, $0.5 \mathrm{X}$ PSI was the optimum dose that showed an inhibitory effect as well as a $95 \%$ cell recovery (in 48 hours).

To begin the experiment, all sets were washed two times in 1X DPBS by carefully submerging to remove traces of serum. The experimental wells, \#4, were first pre-treated with $0.5 \mathrm{X}$ PSI for one hour by placing $100 \mu \mathrm{l}$ of PSI in the upper chamber and $500 \mu \mathrm{l}$ in the lower chamber. Then $\mathrm{TNF} \alpha(10 \mathrm{ng} / \mathrm{ml})$ was added during the second hour for a total treatment time of 5 hours. Other monolayers were treated as appropriate.

After the incubation, the treated monolayers were washed two times in 1X DPBS and the inserts were placed in wells containing $600 \mu \mathrm{l}$ of $0.1 \mathrm{ng} / \mathrm{ml} \mathrm{IL-8.} 100 \mu \mathrm{l}$ of $10^{6}$ PMN suspensions was placed in all inserts and incubated for 90 minutes at $37^{\circ} \mathrm{C}$ and $5 \%$ $\mathrm{CO}_{2}$. After incubation, the bottoms of the transwell inserts were rinsed with the lower chamber contents and set aside. The contents of the lower chamber were carefully mixed and $475 \mu \mathrm{l}$ was transferred into $1.5 \mathrm{ml}$ microcentrifuge tubes to which $25 \mu \mathrm{l}$ of $20 \mathrm{X}$ Sample buffer was added and vortexed for 30 seconds. $100 \mu \mathrm{l}$ of the suspension was transferred to 96-wells (Calbiochem: La Jolla, CA) for MPO ELISA analysis of 
myeloperoxidase (Appendix 5). The presence of myeloperoxidase was measured at $450 \mathrm{~nm}$ on a microplate reader and the results were analyzed.

\section{FACS Analysis}

\section{Measuring E-selectin}

Approximately $10^{6} \mathrm{HMEC}-1$ cells were cultured in $75 \mathrm{~cm}^{2}$ tissue culture flasks for 4 days to confluence. Cells were exposed to various treatments as follows: Negative Control (no treatment), TNF- $\alpha$ treatment only, PSI treatment only, and PSI-TNF- $\alpha$ cotreatment. PSI treatment was for a total incubation time of 5hours and TNF- $\alpha$ treatment, where applicable, was for a total time of 4 hours. After treatment, cells were washed one time with DPBS and harvested by scraping with cell lifters (Costar: Corning, NY). When the cells had detached from the bottom of the flasks, the suspension was transferred into a $15 \mathrm{ml}$ Falcon tube and triturated with pipette to loosen any clumped cells. The cell suspensions were centrifuged at $250 \mathrm{xg}$ for 5 minutes to pellet and then washed one time in PSB+ $0.05 \%$ Tween (PBST). The washing was followed by a blocking step for which the cell pellet was incubated for 15 minutes with $1 \%$ FBS in PBS to reduce non-specific binding.

Later on, the cells were stained with monoclonal anti-human CD62E, FITC conjugate (Sigma: F0674, St. Louis, MO) for E-selectin analysis. In addition to that, a negative control for staining was set up to ensure a successful blocking step. For that purpose, approximately 200,000 cells treated with TNF $\alpha$ were stained with mouse IgG1, к- FITC conjugate isotype control (Sigma, \# F6397). All cells were then washed in PBS $+0.05 \%$ Tween 20 (PBST) and re-suspended in medium for immediate flow cytometer 
analysis. Cells (control, treated and/or antibody incorporated) were analyzed using fluorescence-activated cytometer (Beckman Coulter Excel). Cells were gated using forward light scatter by side scatter absorbance. The analysis produced was based on 10,000 events within the gated region. The percentages of cells with or without E-selectin were displayed on both dot-plots and histograms for analysis.

\section{Measuring Apoptosis after HMEC-1 Exposure to TNF $\alpha$ and LPS}

Cells were exposed to the various treatment conditions: no treatment, TNF $\alpha$ (10ng/ml), PSI, and PSI-TNF $\alpha$. After treatment, the cells were immediately harvested with $3 \mathrm{ml}$ of Trypsin-EDTA for $2-5$ minutes at $37^{\circ} \mathrm{C}$. Cell harvesting with Trypsin-EDTA for this study was preferred to scraping since the latter appeared to permeabilize cells leading to increased cell death in HMEC-1. When cells had lifted off the flask, $5 \mathrm{ml}$ of growth medium was added to neutralize trypsin's enzymatic reaction. The cell suspension was centrifuged at $250 \mathrm{x}$ g for 5 minutes to isolate the cells. The cell -pellets were washed twice in ice cold DPBS. Meanwhile, $1 \mathrm{X}$ annexin- binding buffer and 100ug/ml Propidium Iodide (PI) working solutions were prepared from stock solutions provided in Vybrant Apoptosis Assay Kit (Molecular Probes: Eugene, Oregon) according to the manufacturer's protocol. After the last washing, the cells were re-suspended in $1 \mathrm{X}$ annexin-binding buffer and cell density was determined with the aide of a Coulter Cell Counter. For annexin positive control analysis, 5ul of Alexa Fluor 488(Molecular Probes: Eugene, Oregon) was added to every 100,000 cells in solution. Similarly, for PI positive control analysis, $1 \mu \mathrm{l}$ of $100 \mathrm{ug} / \mathrm{ml}$ propidium iodide was added per 100,000 cells. For each category of cells (control and treated) a combination of annexin and PI was added to 
determine total apoptosis induced. Staining was accomplished by incubating the cells with the stains in the dark for 15 minutes after which $400 \mu$ l of annexin-binding buffer was added to every $100 \mu 1$ of 100,000 - cell suspension. The stained cells were maintained on ice and immediately analyzed by flow cytometry as before.

\section{Analysis of the Effect of Lack of Serum on HMEC-1}

The effect of three types of growth media: $20 \%$ FBS, Serum - free, and InsulinTranferrin-Selenium-A (ITS) media, on HMEC-1 cell- proliferation was investigated. The serum-free medium was made from 1\% L-Glutamine [Gibco: Grand Island, NY], $1 \%$ Antibiotic-Antimycotic (Penicillin, Streptomycin, and Amphotericin B) [Gibco: Grand Island, NY]. The ITS medium was also prepared from $1 \%$ ( 100X) Insulin-TransferrinSelenium-A (Gibco: Grand Island, NY) $1 \%$ ( 200mM), L-Glutamine (Gibco Grand Island, NY), $1 \%$ ( 100X) Antibiotic-Antimycotic (Gibco: Grand Island, NY) and MCDB 131. First, 100,000 cells were seeded in 6-well plates and were grouped as control and experimental. A triplicate of each category was set up. The control set was cultured in 20\% FBS medium, and the experimental category had either serum-free or ITS medium. Growth pattern was monitored every 24 hours up to 5 days. After 4 days of growth when visual observation indicated severely impaired cell growths, $0.2 \%$ serum was added to cells receiving ITS only to see if serum would produce any change in growth pattern. All changes observed within 24 hours thereon were noted and carefully documented.

The statistical method used in analyzing the data was student t-test with a 5\% level of significance. 


\section{Results}

\section{Determining HMEC Monolayer Readiness}

The experiments begun by estimating if a well-formed monolayer was intact for subsequent transmigration experiments. Approximately, 20,000 HMEC-1 cells were seeded in transwell inserts and one extra well with no insert for monitoring cell growth. The cultures were allowed to grow to confluence for seven days. Each day following the day of seeding, cell growth was visually monitored in the well with no insert to determine when a monolayer may have formed. It was observed that, on the averàge, from the third day of growth cells formed a cobblestone pattern indicative of an intact monolayer formation (Fig. 8).

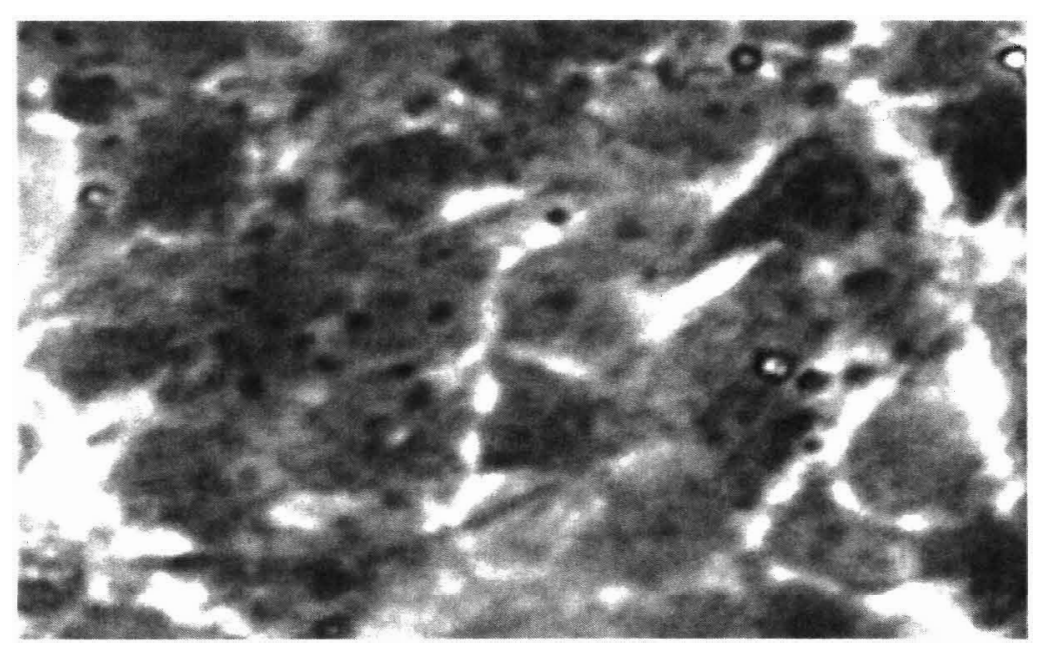

Figure 8: HMEC-1 Monolayer. A cobblestone- pattern of cells typical of HMEC-1 cell line after three days of growth. Magnification: 200X. 
The integrity of the monolayer was measured using the Bradford Protein Assay. A standard curve was first created and later used to calculate the amount of protein (albumin) that leaked through the monolayer on each day starting from day 3 of cell growth. The data in Figure 9 show the growth trend. Also, the data show that 20,000 cells could form an intact monolayer between 5-7 days of growth.

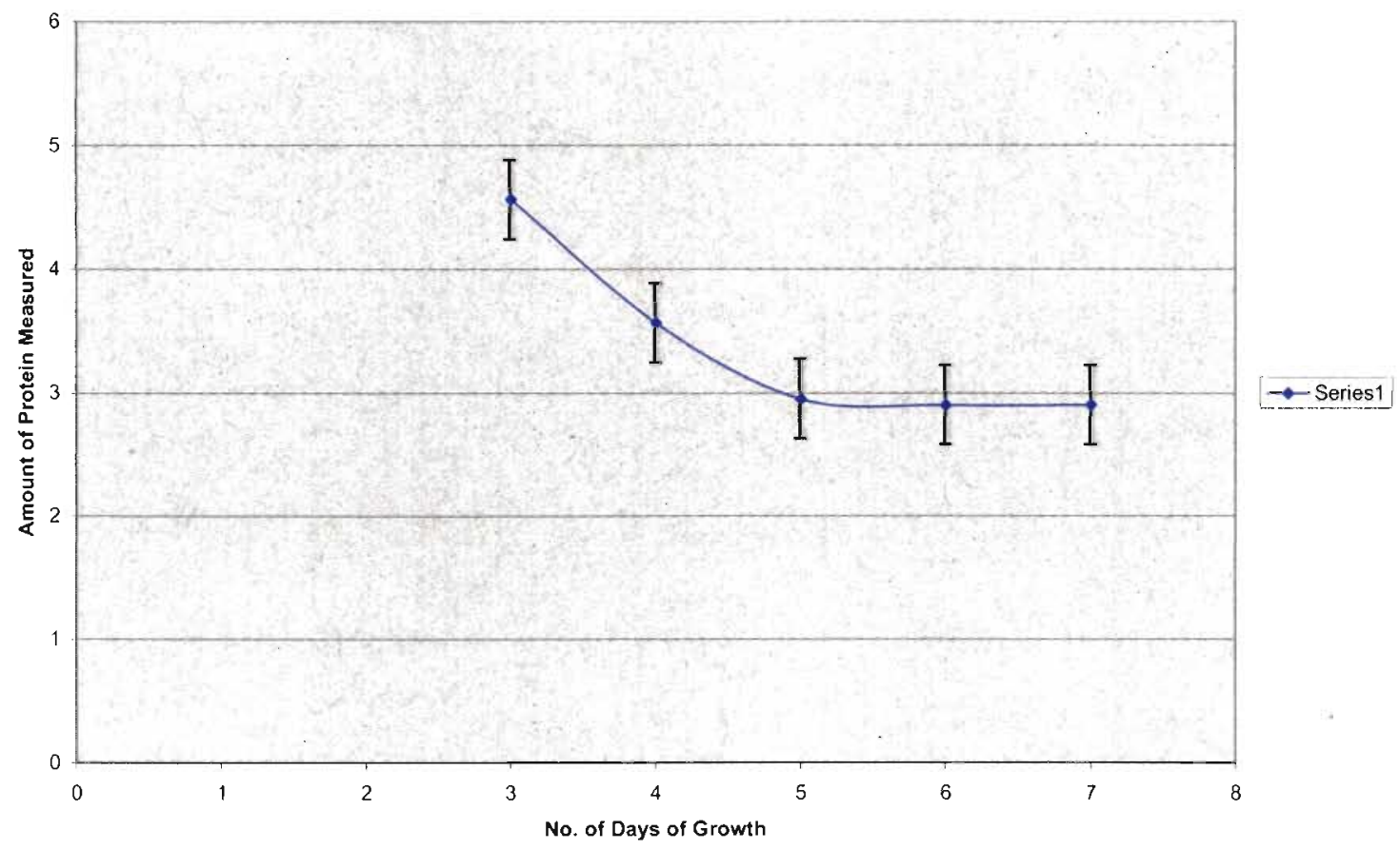

Figure 9: Time( in days) for HMEC-1 Monolayer Development. A plot showing an intact monolayer formation between 5-7 days of cell proliferation when 20,000 cells were seeded in a transwell insert. The inhibition of albumin leakage into the bottom chamber was used as an indication of a functional and intact monolayer. The data represent means of triplicates of three independent experiments. 


\section{Does LPS Affect the Myeloperoxidase (MPO) Assay?}

To ensure that LPS does not negatively impact the experimental results its effect on the MPO ELISA assay was tested. To do this, an experiment was done to compare the background buffer (control) and LPS in buffer (experiment) on different concentrations of myeloperoxidase. A standard curve was developed using standard myeloperoxidase solution provided in the commercial kit. The results listed in Table 1 demonstrate that at the various concentrations of myeloperoxidase listed, LPS is comparable to the control (buffer). Hence, LPS has no negative effect on MPO ELISA assay. The data were means of replicated experiment of three in two independent experiments $(\mathrm{N}=6+/-$ S.D.).

Table 1: Testing the Effect of LPS on MPO Assay to Rule out Possible Interference

\begin{tabular}{|c|c|c|}
\hline Experimental Conditions & $\begin{array}{l}\text { Mean Protein } \\
\text { Measured (ng/ml) }\end{array}$ & Standard Deviation \\
\hline 100ng/ml MPO & 58.5 & $+/-4$ \\
\hline 5ng/ml MPO & 13.0 & $+/-1.6$ \\
\hline 0ng/ml MPO & 0 & 0 \\
\hline & & \\
LPS (1 ng/ml) in Buffer & & $+/-4.3$ \\
\hline 100ng/ml MPO & 54.0 & $+/-2$ \\
\hline 5ng/ml MPO & 13.0 & $+/-0.08$ \\
\hline 0ng/ml MPO & 0.12 & \\
\hline
\end{tabular}

\section{What is LPS's Effect on HMEC-1 Viability?}

In an effort to determine LPS's effect on HMEC-1, a viability test was performed using the MTT-based assay, which was developed by Mosmann (1983) and quantifies the mitochondrial activity of cells as a measure of cell viability[67]. Cells were treated with 
different concentrations of LPS ranging from $0 \mathrm{ng} / \mathrm{ml}$ to $1 \mathrm{ng} / \mathrm{ml}$ for one hour (Fig. 10). All three LPS concentrations had a stimulatory effect on HMEC-1 as compared with the control $(\mathrm{P}<0.05)$. In another experiment by Dr. Tran (data unavailable), cells exposed up to $100 \mathrm{ng} / \mathrm{ml}$ LPS for 4 hours were still viable. Thus, LPS enhances HMEC-1 cell line's activity and sustains their viability.

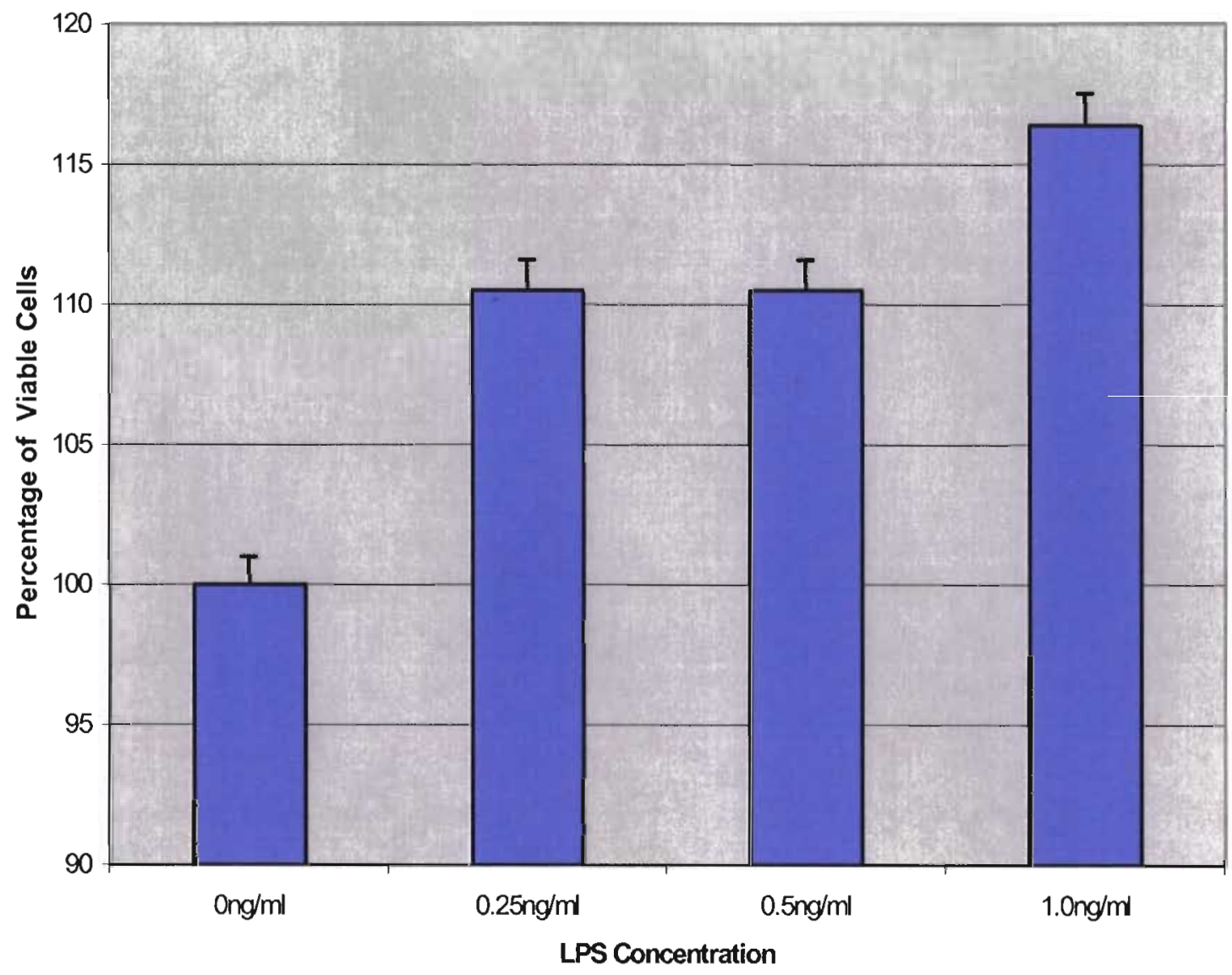

Figure 10: Effect of LPS on HMEC-1 viability. HMEC-1 cells exposed to different LPS concentrations, $0.25 \mathrm{ng} / \mathrm{ml}, 0.5 \mathrm{ng} / \mathrm{ml}$, and $1 \mathrm{ng} / \mathrm{ml}$ for one hour show a continuous increase in viability $(\mathrm{P}<0.05)$. 
PMN Transmigration in the presence of LPS and Protein Synthesis Inhibitors (PSI)

An investigation of inhibition of PMNs transmigration across the HMEC-1

monolayer was performed. LPS $(1 \mathrm{ng} / \mathrm{ml})$ was used to stimulate transmigration while PSI $(0.5 \mu \mathrm{M}$ Puromycin $+0.12 \mu \mathrm{M}$ Anisomycin) was used to inhibit transmigration. The preliminary data (Figure 11) showed approximately $60 \%$ less transmigration in both the positive control (LPS only) and the experimental model compared to the control.

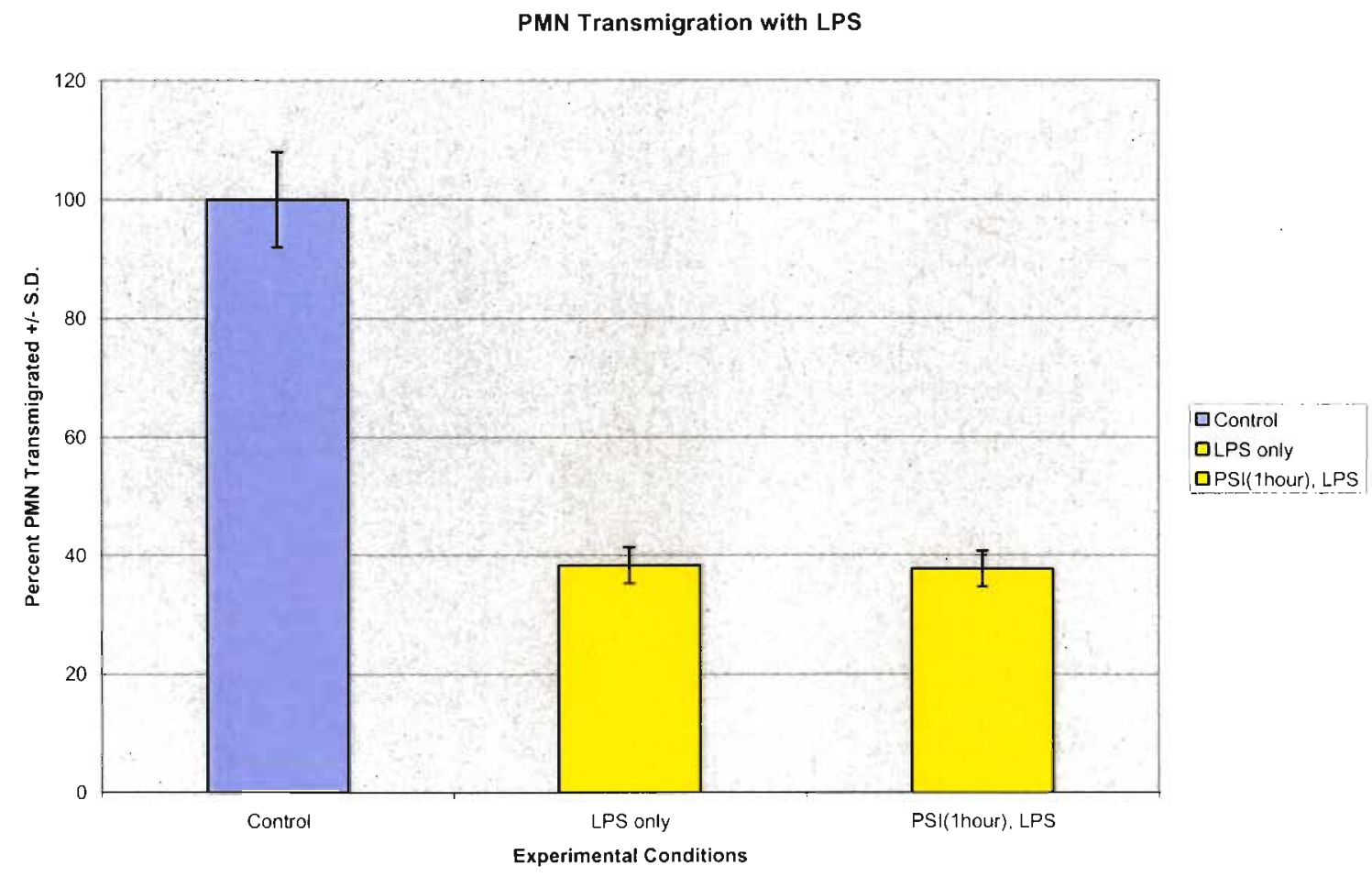

Figure 11: The inhibitory effect of LPS on PMN transmigration. The positive control (LPS only) shows an inhibition of PMN transmigration compared with the control $(\mathrm{P}<0.05)$. The data represent the means $+/-1$ standard deviation of duplicates of two independent experiments $(\mathrm{N}=4)$. 


\section{LPS Causes PMN to degranulate on Contact}

Following these unexpected observations with LPS's effect on transmigration experiment, LPS's direct effect on PMNs was tested to determine the effect should the two ever come into contact anytime during the experiment. $1 \mathrm{ng} / \mathrm{ml}$ LPS was added directly to PMNs and then the effect on myeloperoxidase release was determined starting from 0 to 30 minutes. The findings in Figure 12 show degranulation of PMNs occurred within seconds of "zero time" when exposed to LPS. In another experiment, PMNs were exposed to LPS, PSI, and LPS-PSI for 30 minutes. The suspension was centrifuged at $18000 \mathrm{x}$ g for 15 minutes at $4^{\circ} \mathrm{C}$ to pellet the PMN. The PMNs were lysed with cytobuster and then the MPO ELISA assay was perfomed on the suspension. There was a $20 \%$ loss of myeloperoxidase with LPS compared with the control (Figure 13) Interestingly, it appeared the presence of PSI prevented the release of MPO by LPSmediated degranulation. These data (Figures 12 and 13) gave a possible explanation for our observations in Fig. 11, which indicates a possible residual LPS in the transwell inserts could interfere with the transmigration assay. The findings led us to switch from using LPS to activate PMN transmigration through endothelial cells to TNF $\alpha$. 
LPS Causes PMN Degranulation On Contact

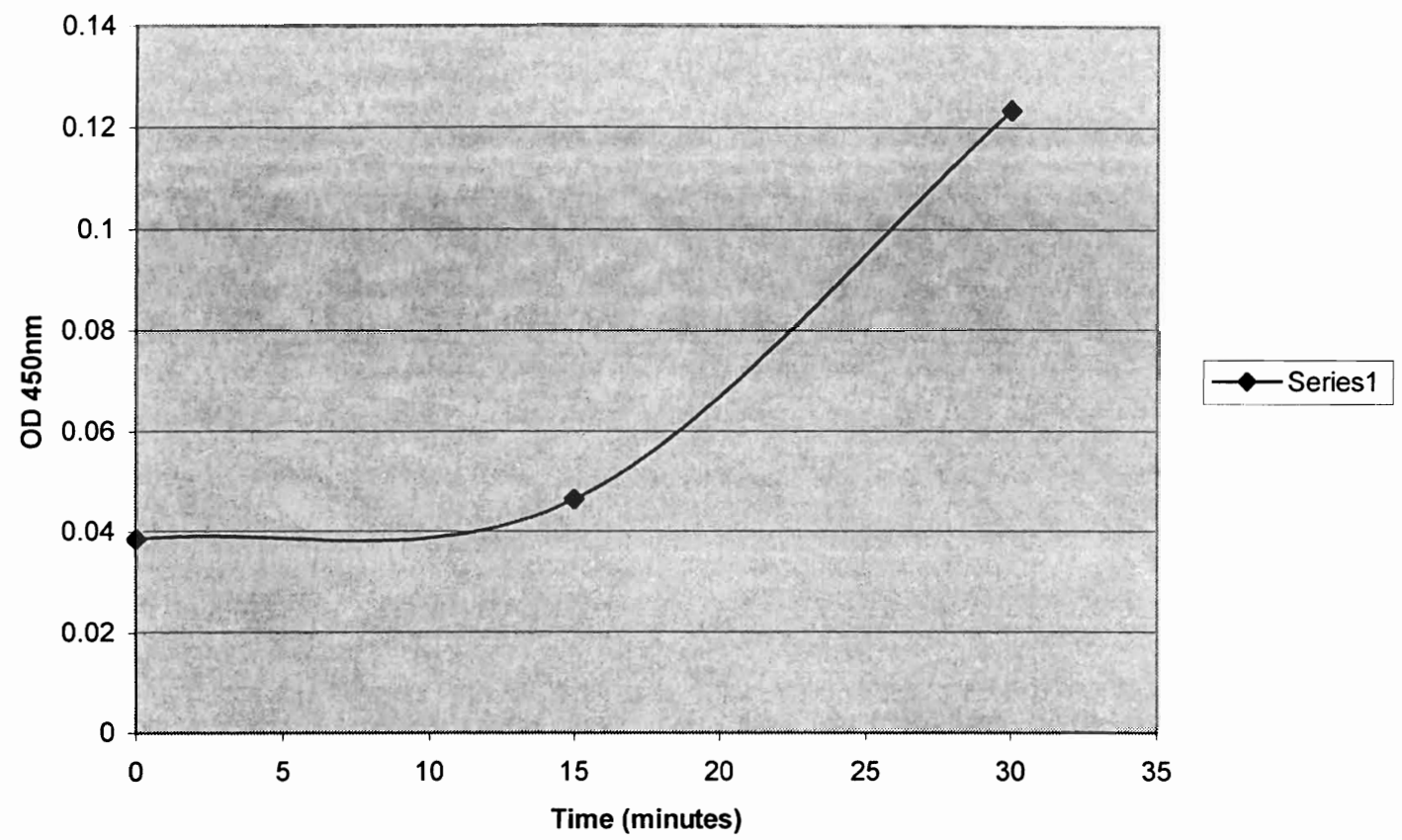

Figure 12: LPS induces neutrophil degranulation on contact when added directly to PMNs. Myeloperoxidase activity was measured even at zero minutes and steadily increases at 30 minutes. 


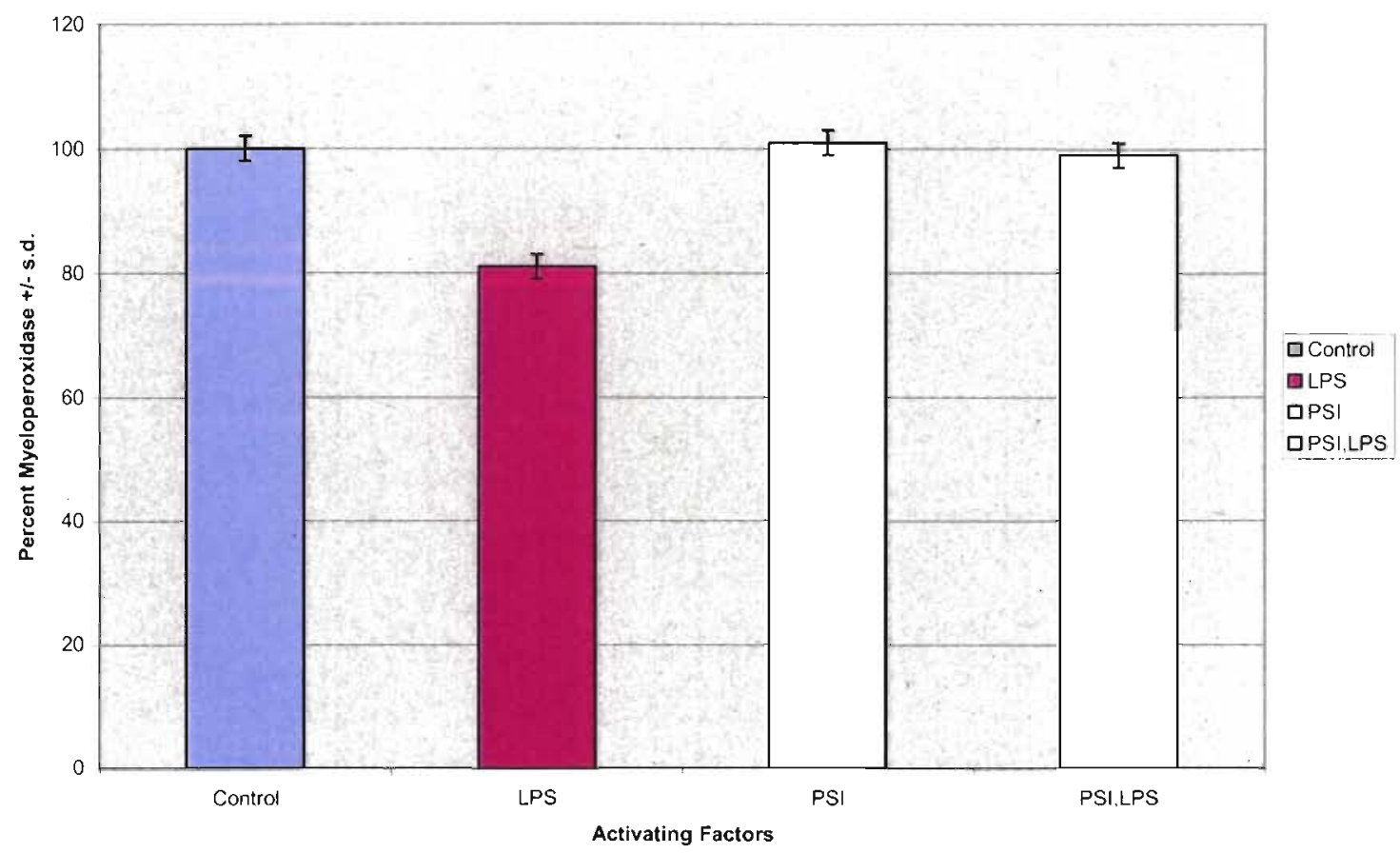

Figure 13: Comparing the direct effect of LPS, PSI, LPS-PSI on PMNs. There was loss of myeloperoxidase in LPS treatment compared with the control $(\mathrm{P}<0.05)$. PSI prevents PMN degranulation when added alone or with LPS. Experiment was in duplicate of two independent experiments.

\section{Determination of the TNF $\alpha$ Concentration Required for Optimal Transmigration}

Initial efforts were made to determine the appropriate TNF $\alpha$ concentration for the PMN transmigration assay by exposing separate endothelial cell preparations to $0 \mathrm{ng} / \mathrm{ml}$, $2 \mathrm{ng} / \mathrm{ml}, 5 \mathrm{ng} / \mathrm{ml}$, and $10 \mathrm{ng} / \mathrm{ml} \mathrm{TNF} \alpha$ respectively for 4 hours. Then a transmigration test o was performed on the treated PMN to determine which TNF $\alpha$ concentration would produce the maximum transmigration. Comparing the three concentrations used with the baseline, $10 \mathrm{ng} / \mathrm{ml}$ of TNF $\alpha$ treatment for four hours (Figure 14) enhanced maximum $\mathrm{PMN}$ transmigration with $\mathrm{P}<0.05$. The data were means values of triplicate of two separate experiments $+/$ - standard deviation of $9 \%$. 


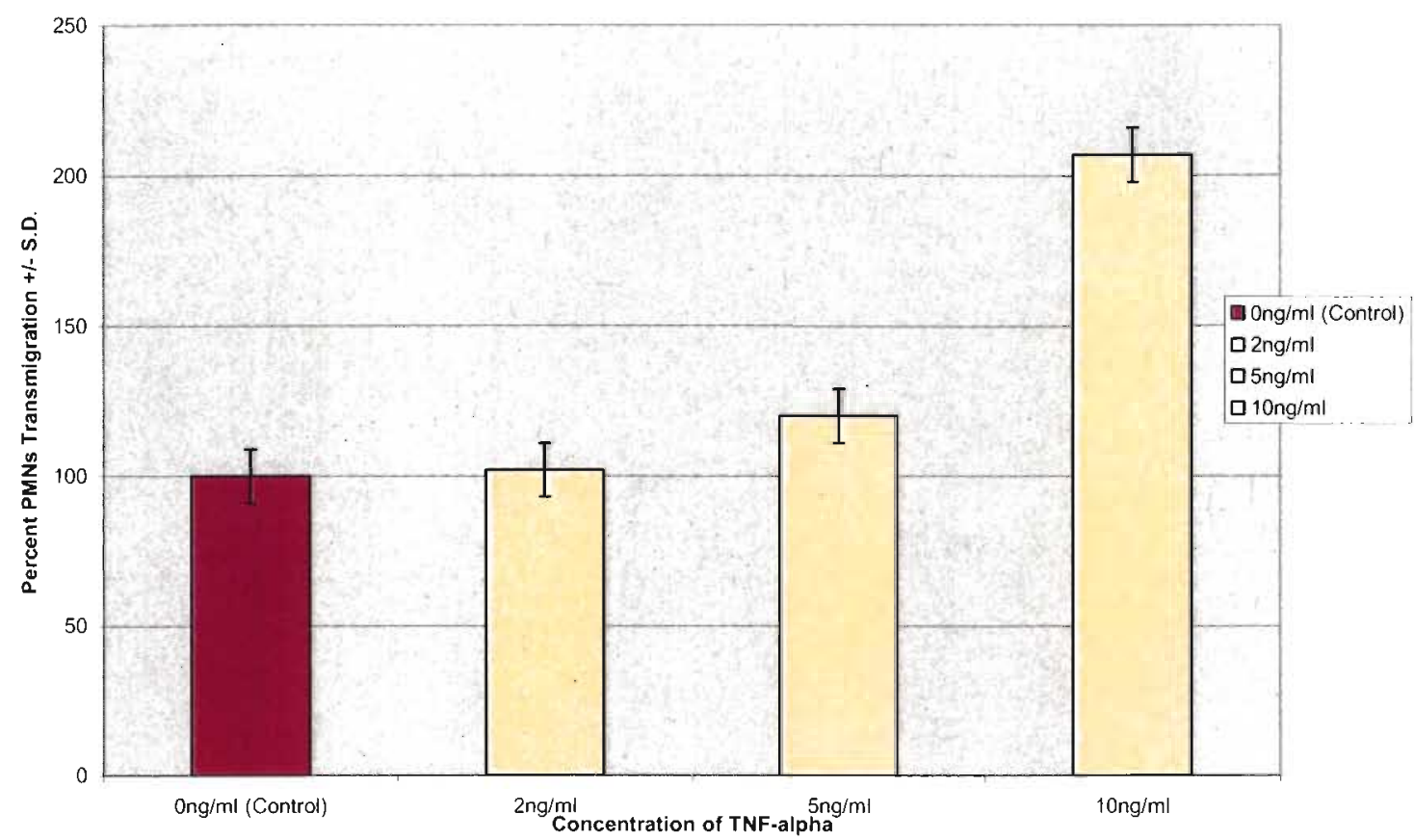

Figure 14: The effect different TNF $\alpha$ concentrations on PMN transmigration. TNF $\alpha$ $(10 \mathrm{ng} / \mathrm{ml})$ show significant transmigration compared to the control $(0 \mathrm{ng} / \mathrm{ml}), 2 \mathrm{ng} / \mathrm{ml}$, and $5 \mathrm{ng} / \mathrm{ml}(\mathrm{P}<0.05)$.

\section{Determination of PSI's Effect on PMN Transmigration in the Presence of TNFa}

Having successfully established a workable TNF $\alpha$ concentration for our transmigration assay it was necessary to determine if PMN transmigration would be inhibited by the PSI cocktail at that TNF $\alpha$ concentration. Controls, TNF $\alpha$, PSI and PSITNF $\alpha$ (experimental) were set up. For the experimental models, the monolayers were pre-treated with PSI for one hour and then TNF $\alpha$ was added for an additional four hours giving a total time of 5 hours for PSI and 4 hours for TNF $\alpha$. The results indicate PSI 
wells, with or without TNFa, show about $80 \%$ increase in transmigration compared to the negative control (Fig. 15). To rule out a possible effect of a "high" TNFa concentration (10ng/ml) counteracting PSI's ability to inhibit PMN transmigration, the experiment was therefore repeated with a lower TNF $\alpha$ concentration of $5 \mathrm{ng} / \mathrm{ml}$. Once again, the data (Figure 15b) gave similar results with an even higher (120\% more than control) PMN transmigration in the experimental wells. Figures 15 represents the mean values of PMN transmigration $+/$ - standard deviations.

PSI's Inhibition of PMN Transmigration with $10 \mathrm{ng} / \mathrm{ml}$ TNF-alpha

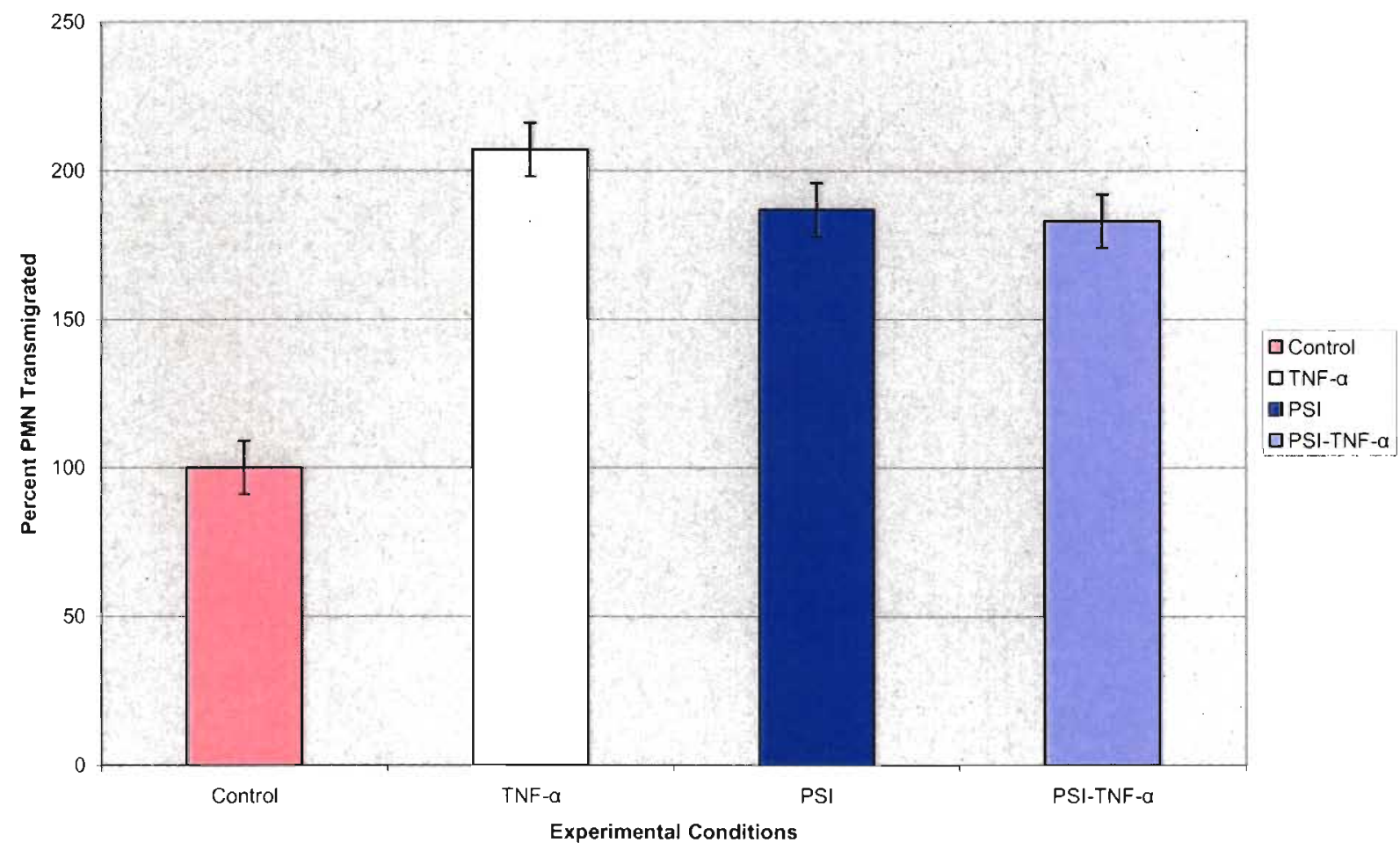

Figure 15: Inhibition of PMN transmigration by PSI in the presence of $10 \mathrm{ng} / \mathrm{ml}$ TNF $\alpha$. PMNs were inhibited with PSI-TNF $\alpha$ compared with TNF $\alpha$ alone $(\mathrm{P}>0.05)$. PSI showed a significant increase in $\mathrm{PMN}$ transmigration compared with the control $(\mathrm{P}<$ $0.05)$. The experiment was in triplicate $(n=3)+/-$ S.D. 


\section{Is PSI treatment for 5 hours too long?}

To answer this question, a time course experiment was performed on the effect of PSI's on HMEC-1 for up to 5 hours. Cell viability after exposure to PSI was measured using the MTT-based assay, which uses mitochondrial activity as an index of cell viability. The result of the experiment illustrated in Figure 16 shows that within the first hour of PSI exposure, HMEC-1 increases in metabolic activity up to $40 \%$ above the control. However, with two hours of PSI exposure HMEC-1 loses $25 \%$ metabolic activity and then gradually bounces back with $110 \%$ viability at 4 hours. At 5 hours of PSI treatment, the cells lost $20 \%$ viability.

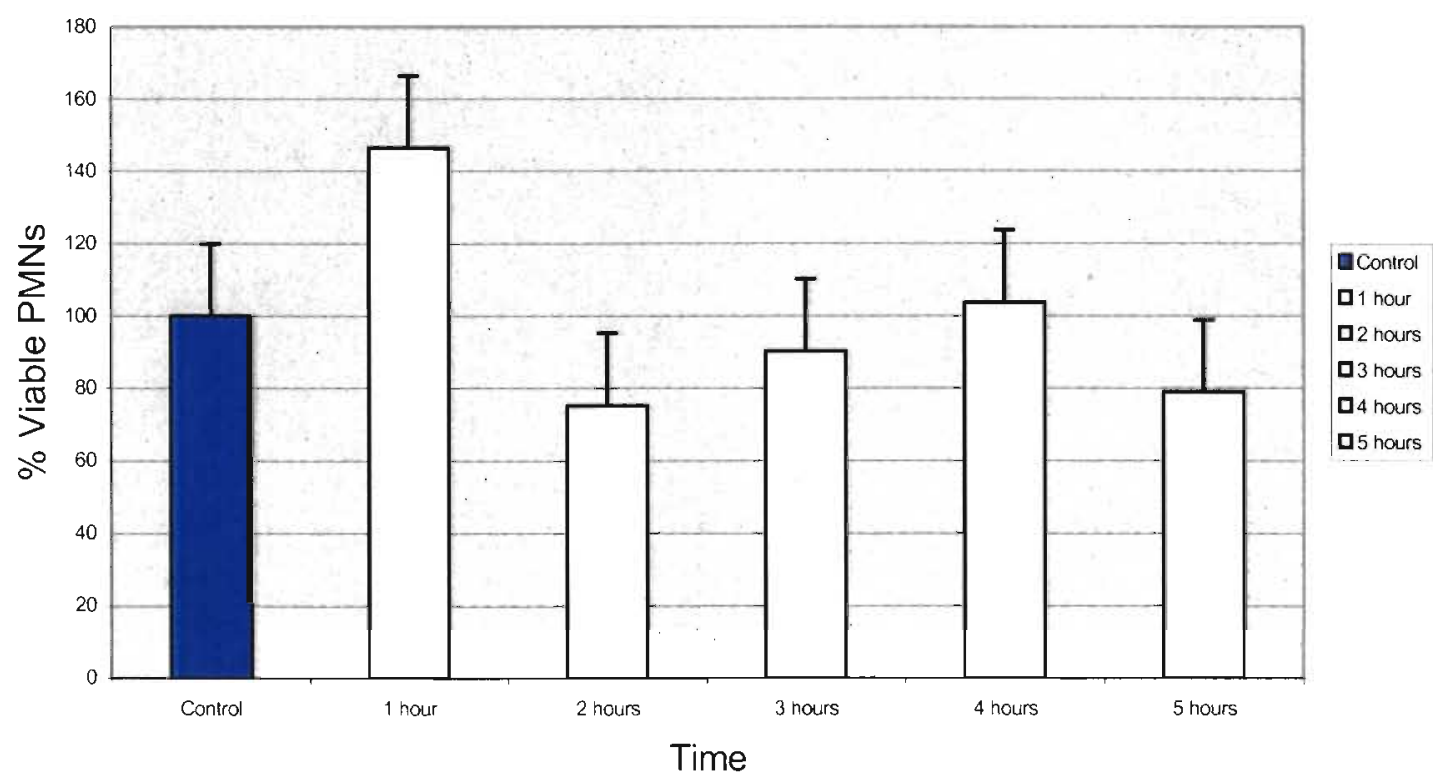

Figure 16: A time course of PSI's effect on cell viability. Mitochondrial activity was the measure of cell viability. The first hour shows a significant increase in mitochondrial metabolic activity $(\mathrm{P}<0.05)$, while the fifth hour show a loss in viability $(\mathrm{P}<0.05)$. The data represent means of triplicate experiments +/-1 S.D. 


\section{Determination of the Effect of TNFa and PSI on E-selectin expression in HMEC-1}

The ability of TNF $\alpha$ to stimulate E-selectin and PSI's ability to repress their expression in our assay was investigated. Four groups of HMEC-1 cells were treated with TNF $\alpha$ and /or PSI pius a negative cr ntrol in the absence of serum. After treatment, cells were stained with anti-E-selectin antibody and the samples analyzed by flow cytometry. E- selectin was expressed in all groups. Below are illustrations of the results of the control cells (34\%) and TNFa -treated cells (72\%) showing E-selectin expression (Fig. 17 a \& b). The complete results obtained are summarized in Figure $17 \mathrm{c}$ with $37 \%$ of PSItreated cells and $60 \%$ of PSI-TNF $\alpha$ treated cells showing E-selectin expression. Although, E-selectin is endogenously expressed in all groups, TNF $\alpha$ activation doubles the E-selectin expression compared to the control $(\mathrm{P}<0.05)$. Also, PSI-TNF $\alpha$ treated cells show 12\% decrease in E-selectin expression compared with the expression with TNFa activation. The data represent the means $+/-1$ S.D. of triplicate samples per treatment of three experiments. 
(a)

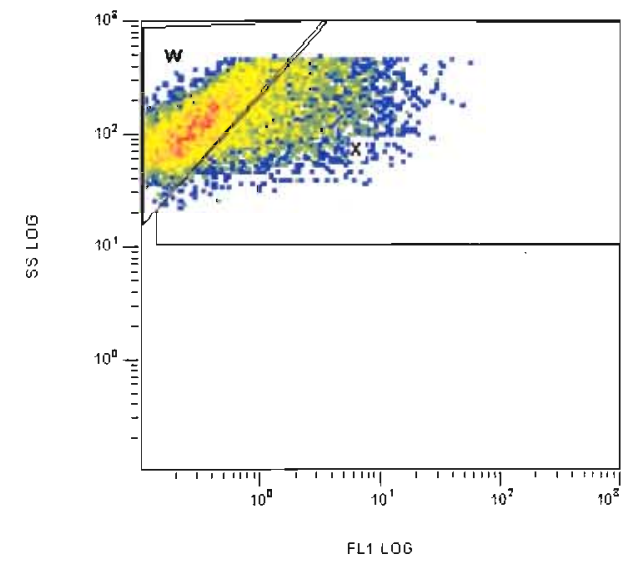

(b)

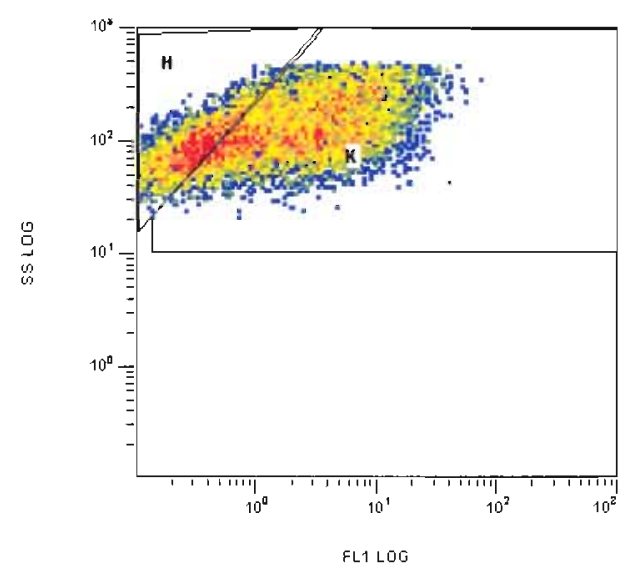

(c)

HMEC-1 Endogenously Express E-Selectin

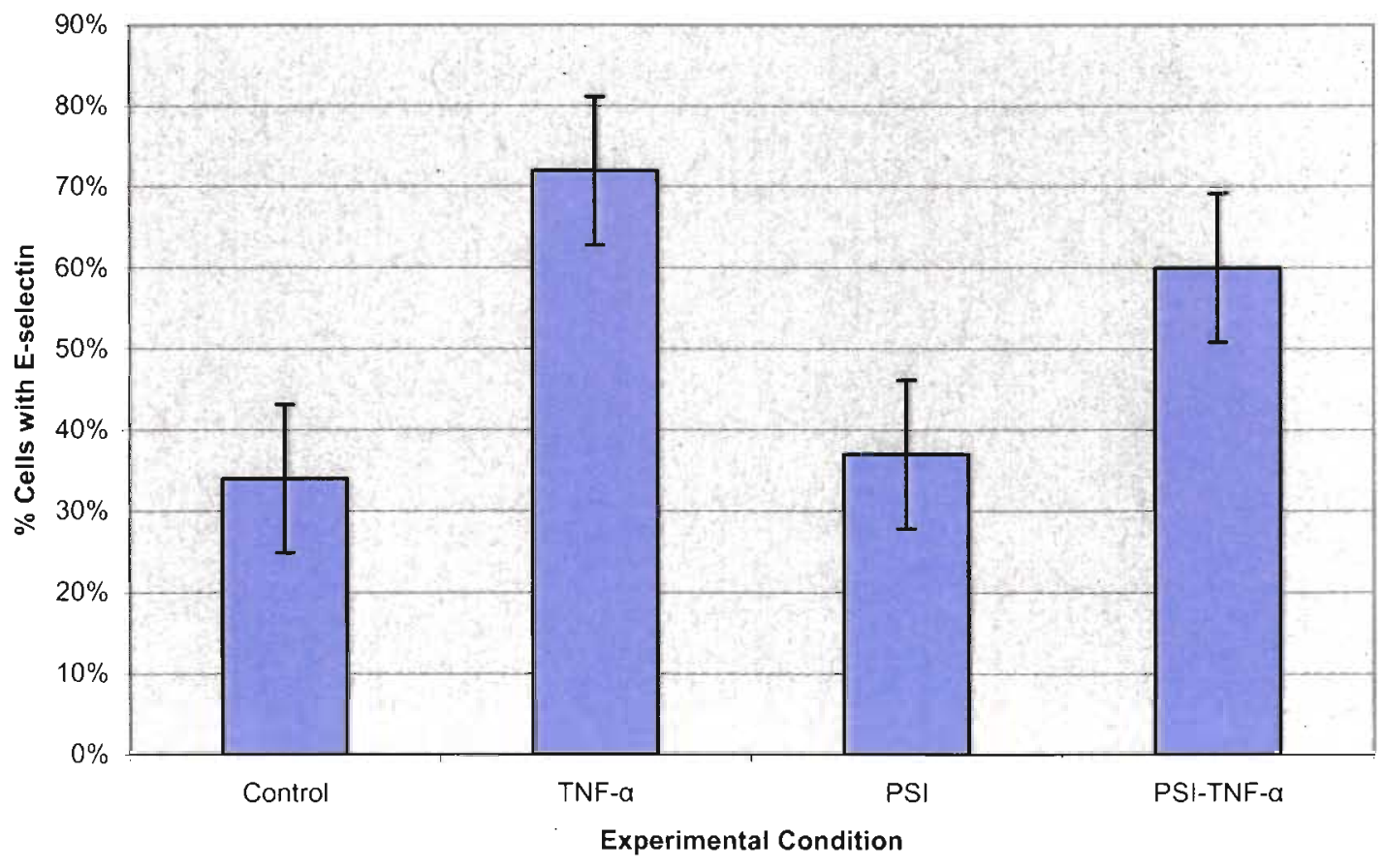

Figure 17: Analysis of endogenous E-selectin expression in HMEC-1. (a) An illustration of Control cells with E-selectin shown in the X -region (b) An illustration of TNF $\alpha$ - treated cells with E-selectin shown in the K-region. (c) A graphical presentation of the percent levels of E-selectin in the HMEC-1 exposed to different experimental conditions. 


\section{Does Serum Induce E-selectin Expression in HMEC-1?}

Of all the conditions exposed to HMEC-1 in the study, serum was the condition common to all cells. The next question that needed to be addressed was does serum then induce E-selectin in HMEC-1? In order to investigate serum's ability to induce E-selectin in HMEC-1, it was necessary to determine the effect of lack of serum on cell growth. Therefore, an investigation to determine the importance of serum to HMEC-1 growth was performed. One group of cells was cultured in medium with $20 \%$ FBS (control), a second group of cells was grown in a serum-free medium, and a third group of cells was grown in a medium with Insulin-Transferrin-Selenium-A (ITS). The experiment was inspired by a similar study with bovine calf chondrocytes (Kisiday et al 2005). Control cells had a robust growth forming a cobblestone-shaped pattern by 96 hours (Figure 18). For cell groups cultured in both serum-free and ITS media, cells established growth within 24 hours but showed a decline till by 96 hours, growth was sparse with increase in dead cells in the serum-free category and stunted growth with ITS medium (Figure 18). When $0.2 \%$ serum was added to the dying cells in ITS medium on day five of growth, cell began to show characteristics of healthy growth in as little as 24 hours (Figure 19a \& b). 
First 24 hours of Cell Growth

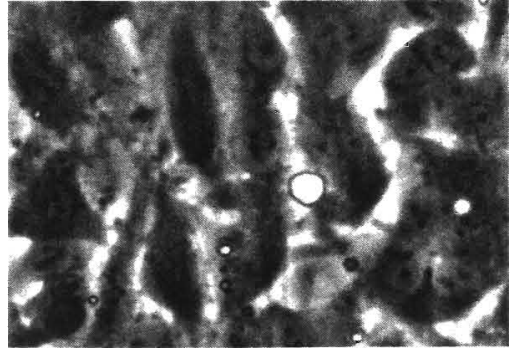

(a) Control- 20\%FBS

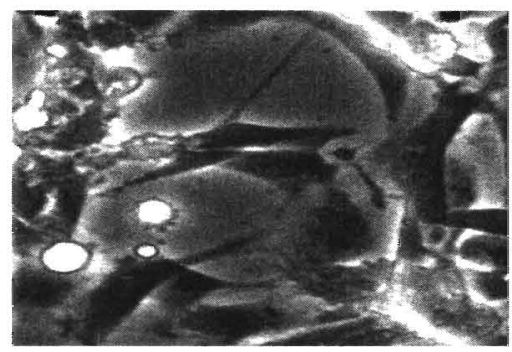

(b) Serum-free growth medium

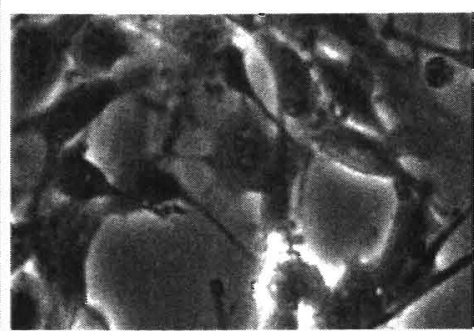

(c) ITS growth medium

\section{6 hours of Growth}

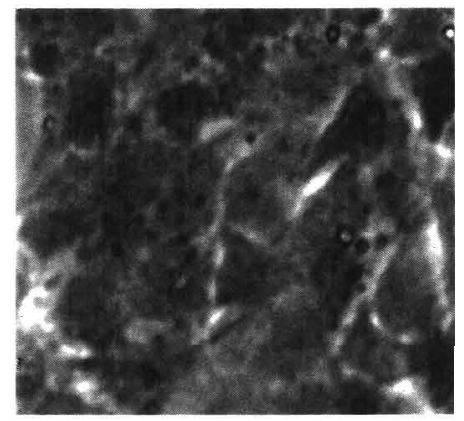

(d) Control

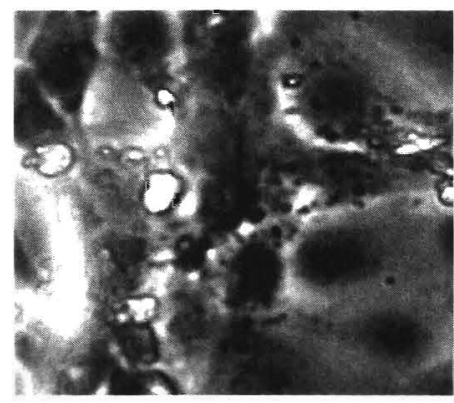

(e) Serum-free

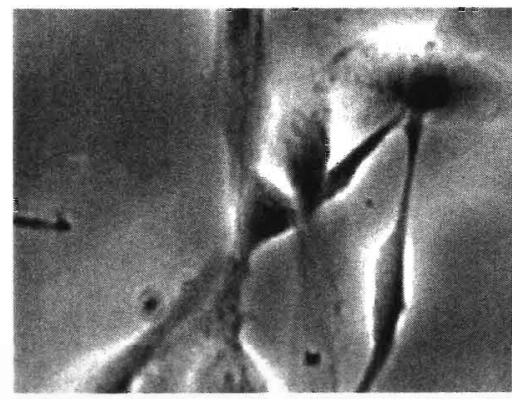

(f) ITS

Figure 18: Growth pattern of HMEC-1 cultured in different growth media.

(a) Control cells at 24 hours (b) Serum-free cells at 24 hours (c) ITS cells at 24 hours (d)

(d) Control cells show compact, cobblestone- shaped cells at 96 hours (e) Serum -free cells show a lot of floating (dead) cells at 96 hours (f) ITS cells show sparse and malnourished at 96 hours 
(a)

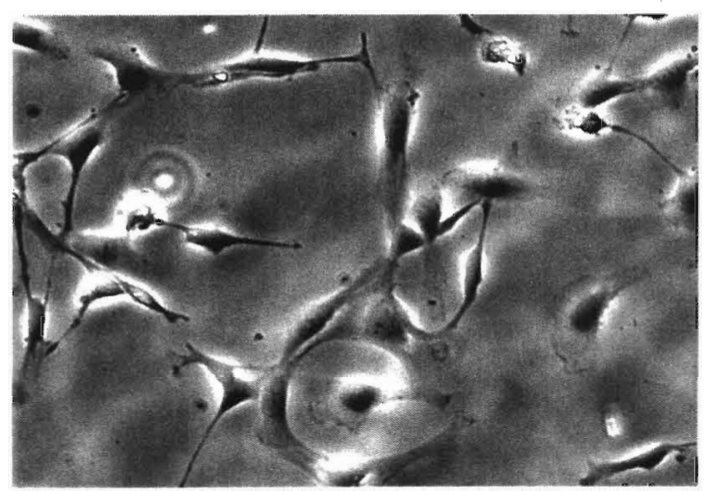

(b)

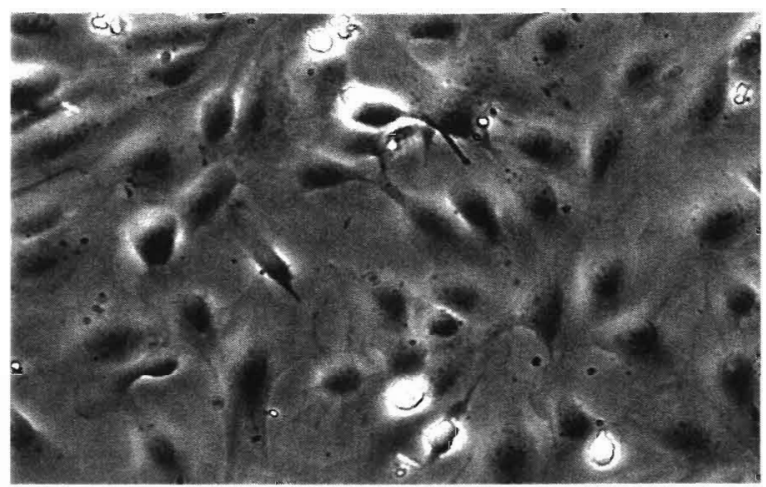

Figure 19: HMEC-1 growth response to $0.2 \%$ serum after serum starvation. (a) Stunted growth after 5 days with serum -free ITS- supplemented medium. (b) HMEC-1 return to healthy growth within 24 hours of $0.2 \%$ serum addition.

\section{Analyzing Endogenous E-selectin Expression level with Reduced Serum in Growth Medium}

After establishing the importance of serum to HMEC-1 growth, the effect of low serum concentrations on E-selectin expression in control cells (no treatment) investigated. Since ITS $+0.2 \%$ serum showed a positive growth response, HMEC-1 were exposed to different media combinations of ITS plus $0.2 \%, 1 \%$, and $2 \%$ serum concentrations and the corresponding level of E-selectin expressed were investigated. A FACS analysis of the various serum concentrations indicated the following: cells cultured in growth medium with $0.2 \%$ serum had $4 \%$ of cells expressing E-selectin. Also cells grown in medium with $1 \%$ and $2 \%$ serum had $7 \%$ and $9 \%$ respectively of cells expressing E-selectin. 
1. Cells grown in $0.2 \%$ serum

(a) negative control

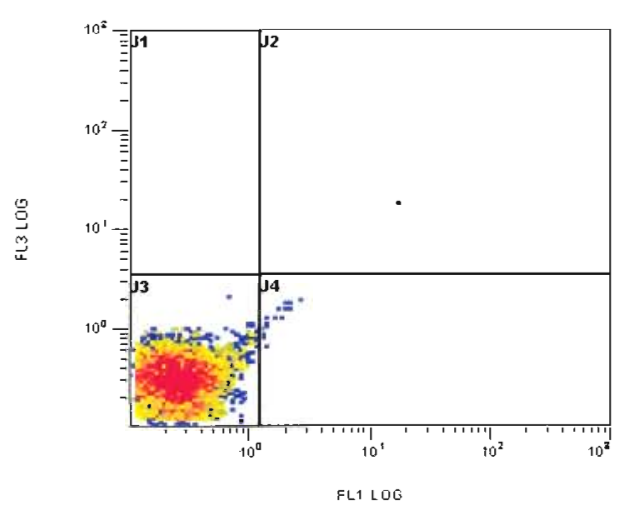

2. Cells grown in $1 \%$ serum

(c) negative control only

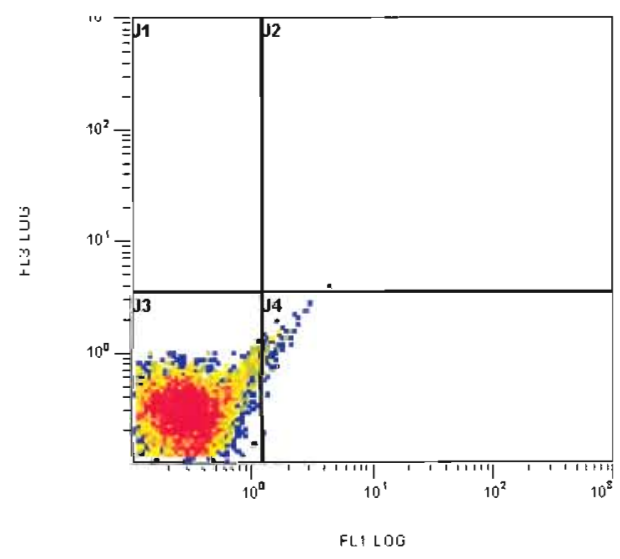

(b) $4 \%$ control cells has E-selectin

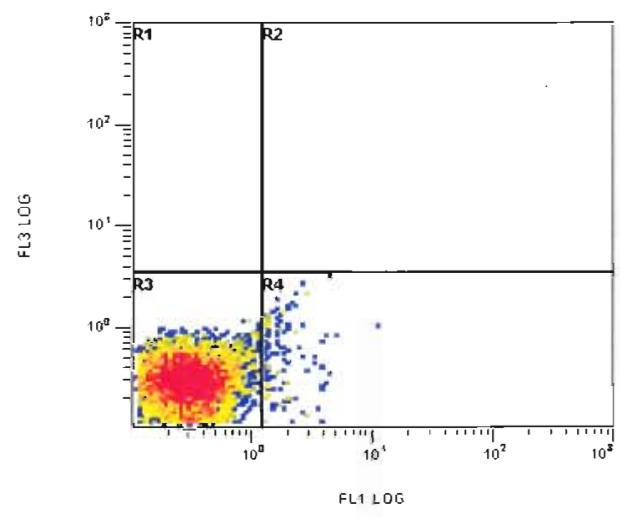

(d) $7 \%$ control cells has $E$-selectin

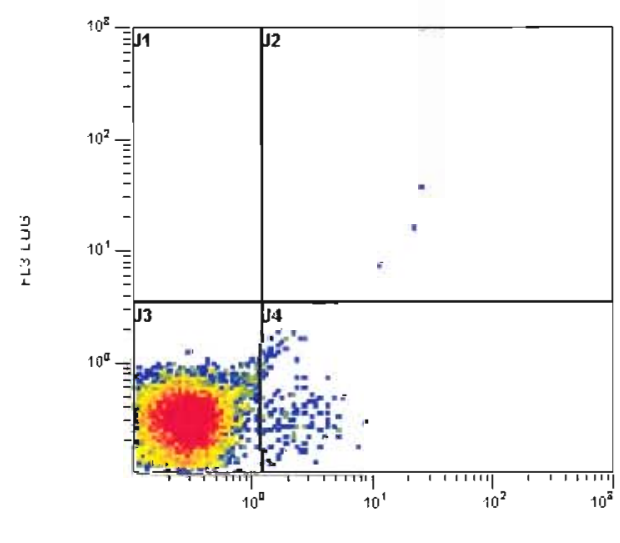


3. Cells grown in $2 \%$ serum

a. negative control cells

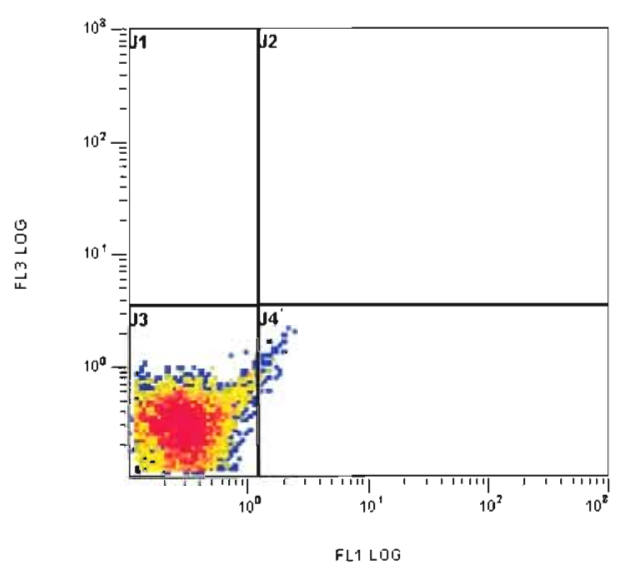

b. control cells have $9 \%$ E-selectin

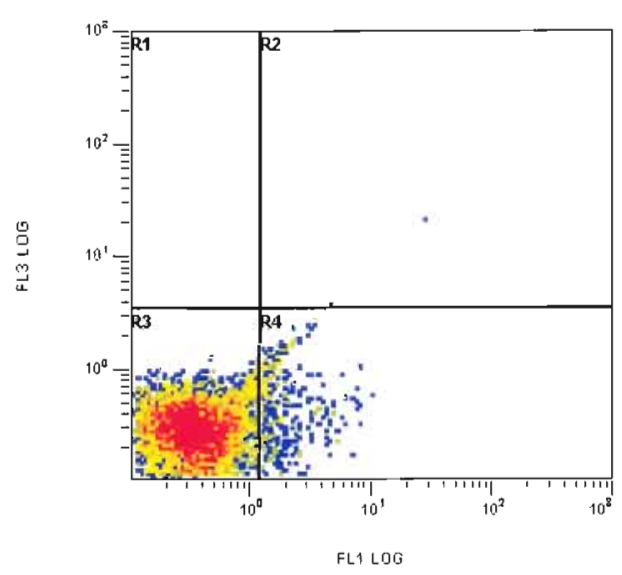

Figure 20: Low concentration of Serum induces lower levels of E-selectin in HMEC1.(a) cells in $0.2 \%$ serum (b) cells in $1 \%$ serum (c) cells in $2 \%$ serum. The E-selectins are expressed in the fourth quadrant(J4).

\section{Does Apoptosis Occur in HMEC-1 during Treatment With or Without Serum?}

Two groups of HMEC-1 cells were exposed to TNF $\alpha$, PSI, PSI-TNF $\alpha$, and no treatment (control). One was provided with serum during treatment and the other received treatment in the absence of serum. They were both analyzed by flow cytometry for apoptosis. The data show in the presence of serum apoptosis was prevented in $50 \%$ or more cells. Cells that did not receive serum during treatment showed total apoptosis of $80 \%$ or more. 


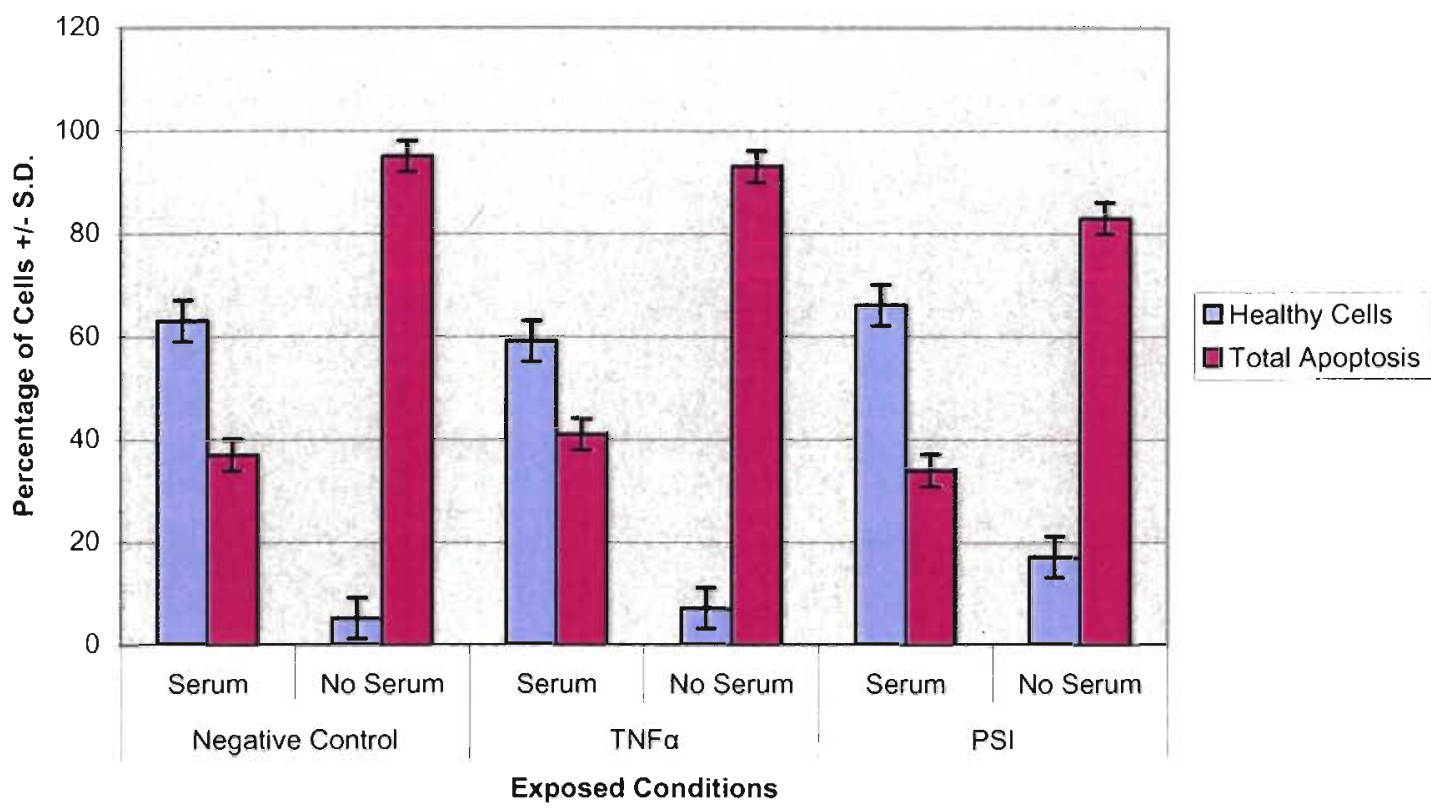

Figure 21: Lack of serum induces apoptosis in HMEC-1. Measurement of apoptosis in HMEC-1 during TNF $\alpha$ and PSI treatments in the presence of or lack of serum. The addition of serum during treatments improved the number of healthy cells available for transmigration.

\section{Determination of PMN Transmigration through HMEC-1 Exposed to Low Serum Concentration}

Inhibition of PMN transmigration by PSI was performed with cells exposed to

ITS $+1 \%$. Other modifications considered were: the one-hour PSI pre-treatment was

eliminated to prevent cell over-exposure to PSI and to allow enough time for TNFa to stimulate adhesion molecules expression necessary for transmigration. In addition, IL-8 was replaced with $10 \%$ serum not only to serve as chemoattractant, but also to restore serum back to HMEC-1 cells after serum starvation during the treatment period. With $1 \%$ serum supplement in the growth medium the data show that PMN transmigration was inhibited by $16 \%$ with PSI compared to the transmigration with TNF $\alpha$ activation (Figure 22). Due to the low number of replicates $(\mathrm{N}=2)$ used in this experiment, the statistics 
could not be adequately performed. The results, however, indicated a trend, which was honed by a slight experimental modification. Cells were exposed to $2 \%$ serum in growth medium instead of $1 \%$. With this additional modification, PMN transmigration was inhibited by $66 \%$ in PSI-TNF $\alpha$ cotreated monolayers with $\mathrm{P}<0.05$ (Figure 23 ).

Inhibition of PMN Transmigration

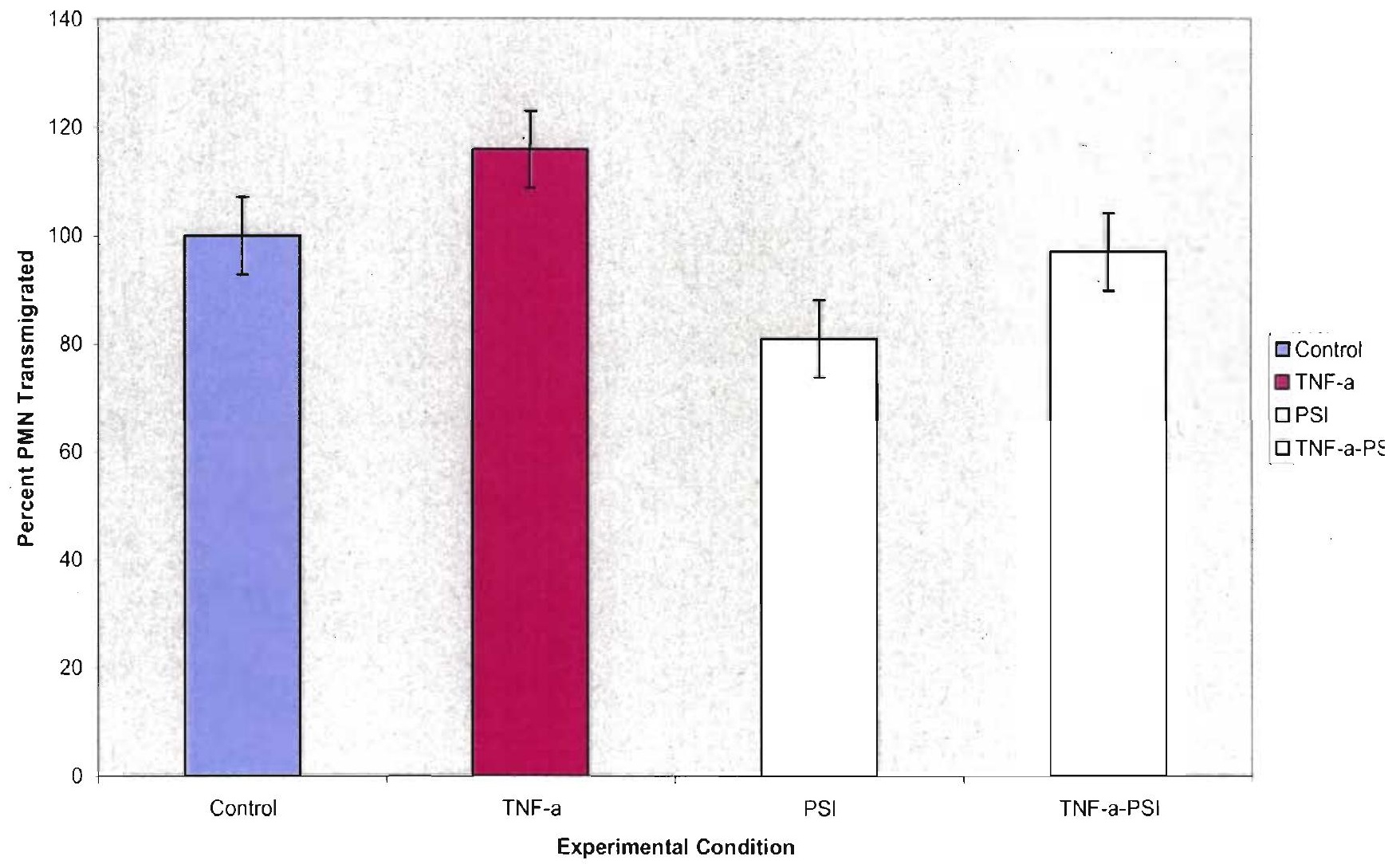

Figure 22: Inhibition of PMN transmigration by PSI 1. PSI inhibits PMN transmigration compared with activity in TNF $\alpha$ treated monolayer. The data represent mean values of $\mathrm{N}=2+/-\mathrm{S}$.D. The statistics could not be done due to the small sample size, but data show an interesting trend. 
Inhibition of PMN Transmigration by PSI

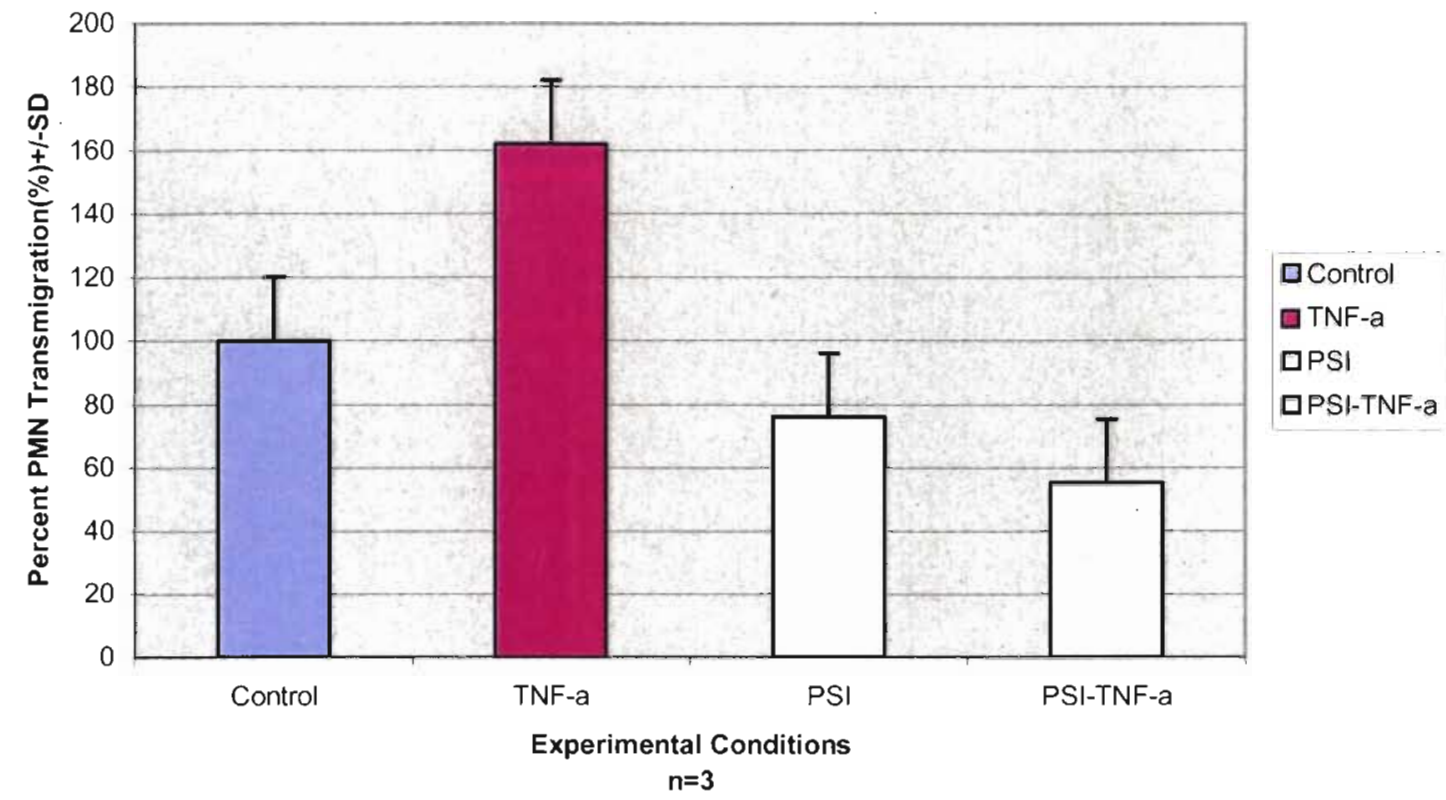

Figure 23: Inhibition of PMN transmigration by PSI 2. PSI inhibits PMN transmigration in PSI-TNF $\alpha$ compared with TNF $\alpha$ control. PSI alone also significantly inhibits PMN transmigration compared with the control $(\mathrm{P}<0.05, \mathrm{~N}=3$ + - S.D.).

\section{HMEC-1 Exposed to 2\% Serum Reflects Low E-selectin Expression}

Flow cytometry analysis of the E-selectin associated with $2 \%$ serum cultured HMEC-I cells exposed to the various treatment conditions, show expressed percent E-selectin as follows: Control (22\%), TNF $\alpha(29 \%)$, PSI (14\%), and TNF $\alpha$-PSI $(10 \%)$. The data represents means of two readings from two experiments (Figure 24 and Appendix 7). Figure 25 also compares E-selectin induced by $20 \%$ serum with that by $2 \%$. 


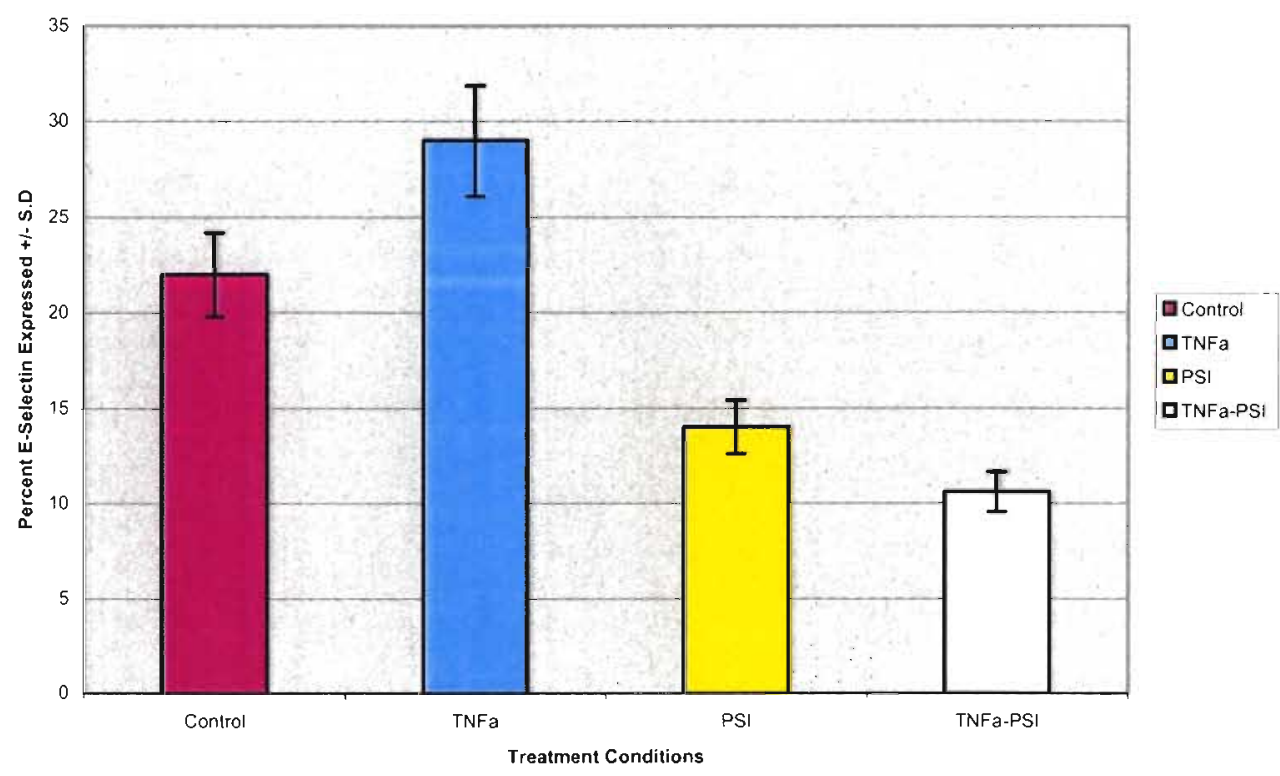

Figure 24: Analysis of E-selectin induced by $2 \%$ serum exposure. Data represents means $+/-1$ S.D. of analyses from two independent experiments

Comparing E-selectin Induced with Serum Concentration



Figure 25: A comparison of E-selectin levels induced by Serum: $20 \%$ versus $2 \%$ serum. A FACS analysis of cells exposed to $20 \%$ serum yields higher E-selectin levels than cells exposed to $2 \%$ serum $(\mathrm{P}<0.05)$. 


\section{Discussion}

Acute respiratory distress syndrome (ARDS), an imminent sequel of severe trauma has a mortality rate of up to $40 \%$. However, there is no known study regarding prevention of this syndrome. Our current study on the inhibition of neutrophil transmigration sets the stage for a possible future intervention of ARDS. The purpose of the project, therefore, was to inhibit neutrophil transmigration by repressing the biosynthesis of adhesion molecules, which are indispensable for transmigration, on endothelial cells using Protein Synthesis Inhibitors (PSI). The expectation is that in the presence of PSI stimulating cytokines such as TNF $\alpha$ or a bacterial peptide like LPS will fail to enhance neutrophil transmigration.

In order to ascertain the efficacy of the assay, an in vitro model, which mimics the natural in vivo system of blood vessel and tissue compartment, was developed (Figure 7). Specifically, the upper chamber of the model with a coat of monolayer of cells represented the lumen and the endothelium of the microvascular capillary. The lower chamber, which was made up of a well from a 24-multiwell plate containing a chemoattractant, represented the tissue milieu. Human microvascular endothelial cells (HMEC-1) produced from human lung tissues were used for the experiments. It was established that the model system requires 20,000 HMEC-1 seeded in $6.5 \mathrm{~mm}$ diameter transwell inserts for 5-7 days to develop sufficiently intact monolayer for the assay (Figure 9). Throughout the experiment, no leakage problems were observed with this monolayer density. 
Originally the endotoxin, lypopolysaccharide (LPS) was selected as an inflammatory stimulus. However, previous reports $[68,69]$ had indicated that LPS affects pulmonary endothelium in diverse and complicated manner. Furthermore, LPS' effect varies both in vivo and in culture and between species and cellular origin. It was, therefore, necessary to rule out any interference that LPS might have in the experiment. Thus, LPS' effect on the MPO ELISA assay was investigated by testing various concentrations of myeloperoxidase standard solution against LPS. The data showed no negative effect of LPS on the MPO assay (Table 1), an indication that LPS would not interfere with the MPO assay. Next, LPS' effect on HMEC-1 was tested and the results showed that HMEC- 1 was viable with the LPS concentrations of $0.25 \mathrm{ng} / \mathrm{ml}, 0.5 \mathrm{ng} / \mathrm{ml}$ and $1 \mathrm{ng} / \mathrm{ml}$ (Figure 10). Furthermore, in a previous study, Dr. Quincy Tran (personal communication) recorded HMEC-1's viability with LPS concentrations of up to $100 \mathrm{ng} / \mathrm{ml}$. From these data, it was concluded that LPS does not cause HMEC-1 damage or death. An assertion, which Hu et al support[70].

Equipped with this information, the transmigration of neutrophils through LPSactivated monolayer was preformed. In another set up of the same experiment, protein synthesis inhibitors $(0.5 \mu \mathrm{M}$ Puromycin and $0.12 \mu \mathrm{M}$ Anisomycin) were used to prevent the transmigration. Unexpectedly, the results showed $60 \%$ inhibition of PMN transmigration even in the LPS (positive) control. This observation was very interesting and it supported the fact that LPS might be inhibiting rather than enhancing PMN transmigration. To examine this possibility, an investigation into the nature of LPS' effect on PMNs was conducted. The myeloperoxidase activity data in Figure 12 suggested that within seconds of zero time LPS caused an instant degranulation of PMN following 
contact. In another experiment, the direct effects of LPS and LPS- PSI on PMNs were tested. The experiment recorded that as much as $20 \%$ loss of the total myeloperoxidase content with associated with LPS treatment (Figure 13) while PSI-LPS treated PMNs had myeloperoxidase content comparable with the control. Based on the findings of the experiment, a reason attributable to the loss of myeloperoxidase in the LPS -treated neutrophil is early degranulation of PMN following contact with LPS. Some of the myeloperoxidase released may have been lost to the supernatant after a centrifugation. Hence, the significantly low PMN transmigration observed in LPS-activated endothelial cells $(\mathrm{P}<0.05)$ may have resulted from residual LPS in the monolayer. Khan et. al suggested LPS impaired neutrophil emigration and chemotaxis is due to a p38 MAPKmediated inhibition of neutrophil responses to endogenous chemokines [71].

Following this finding, TNF $\alpha$ was substituted for LPS as an endothelial cell stimulant. It was established in the experiment that a 4-hour treatment time of $10 \mathrm{ng} / \mathrm{ml}$ TNF $\alpha$ was necessary to stimulate HMEC-1 to up- regulate the necessary adhesion molecules to allow significant PMN transmigration (Figure 14). However, when PSI was tested for its ability to block PMN transmigration, an unexpected finding was observed. In PSI- and PSI-TNF $\alpha$-treated monolayers, PMN transmigration was enhanced to $80 \%$ compared to the control $[\mathrm{P}<0.05]$ in the presence of $10 \mathrm{ng} / \mathrm{ml} \mathrm{TNF}-\alpha$ (Figure 15). However, a look at PSI control suggested that PSI rather than TNF $\alpha$ might be inducing transmigration.

A viability test (MTT assay) on HMEC-1 with PSI was done to determine the time dependent effect of PSI on HMEC-1. With one hour PSI exposure, cell viability was up by $40 \%$ over the control $(\mathrm{P}<0.05)$, but the numbers dropped by the second hour $75 \%$ 
and gradually increased to about $105 \%$ (comparable with the control) and plummeted again to $80 \%$ in the fifth hour. While there is no immediate explanation for the fluctuation in cell viability with PSI exposure over the five-hour period, $20 \%$ loss in cells number after the five hours of PSI treatment was significant to consider reducing the total HMEC-1 exposure time to PSI. Thus, in subsequent transmigration tests PSI exposure time was reduced to four hours.

Since the goal of the project was to target protein biosynthesis, E-selectin, an adhesion molecule synthesized de novo [18] became the focus of the research. So an investigation was conducted to determine E-selectin expression with TNF $\alpha$ activation of endothelial cells and a possible blockade with PSI. Flow cytometry analysis of all categories of cells (treated and non-treated) revealed the biggest surprise yet. The data revealed E-selectin expression in all cell groups regardless of their treatment status (Figure 17 and Appendix 7). Control (untreated) cells alone showed 34\% E-selectin expression, which was doubled (72\%) with $10 \mathrm{ng} / \mathrm{ml}$ TNF $\alpha$ activation. Also, PSI- and TNF $\alpha$-PSI- treated cells indicated $37 \%$ and $60 \%$ of cells respectively with E-selectin (Figure 17c). The two-fold increase in E-selectin expression with TNF $\alpha$ activation however, confirms TNFa's ability to up-regulate adhesion molecules on the surface of the endothelial cells.

These unexpected findings of endogenous E-selectin expression initiated an investigation of what may have caused it. A quick look at the various experimental conditions exposed to HMEC-1 indicated serum as the common denominator to all groups of cells. Thus, selecting serum as the focus of investigation to determine the cause of the endogenous expression of E-selectin production and it is consistent with other 
investigators reports of serum's ability to induce various proteins in eukaryotic cells [72, 73].

The effect of lack of serum on HMEC-1's growth was then studied to determine if HMEC-1 could still function well in the absence of serum. Three categories of HMEC-1 cells were cultured in three separate growth media: 20\% FBS- supplemented medium (control), Serum-free medium, and Insulin-Transferrin-Selenium-A (ITS) medium. The data indicated that after four days of growth, while the control cells were well formed and looked healthy, growth was severely impaired in cells supplied with the two other media (Figure 18). However, when shrunken cells resulting from ITS diet were supplied with as little as $0.2 \%$ serum, normal growth resumed and cells began to look healthier within 24 hours (Figure 19). From these observations, it was obvious that eliminating serum from the growth medium interfered with HMEC-1's ability to function adequately.

In another experiment to determine how vital serum is to HMEC-1's optimal performance, apoptosis was investigated in cells that continue to receive serum during the various treatment conditions versus cells that did not receive any serum in the treatment period. Figure 21 show that regardless of the type of treatment received, apoptosis was induced at higher percentages in cells that had no serum during treatment period than in cells that continued to receive serum during treatment. Additionally, cells that received serum had $50 \%$ or more healthy cells for subsequent transmigration. Another interesting finding was that cells receiving TNF $\alpha$ without serum registered $93 \%$ apoptosis. This rather strange observation could imply TNF $\alpha$ may induce apoptosis in HMEC-1 in the absence of serum. In general, although, the number of healthy cells was 
improved with serum addition during treatment, $50 \%$ of cells lost to both apoptosis quiet disturbing and could hurt our goal of greatly inhibiting PMN transmigration.

Since serum exposure seemed to play a big role in the transmigration assay, it became necessary that the appropriate serum concentration required to support HMEC-1 growth without interfering with the expected results, be determined. To do this, cells grown in $11 \mathrm{~S}$ medium with different serum concentrations of $0.2 \%, 1 \%$, or $2 \%$, were analyzed for E-selectin expression by flow cytometry technique. The data revealed a dose-dependent serum tied to the percentage of E-selectin expressed. Thus, non-treated (control) cells exposed to serum concentrations of $0.2 \%, 1 \%$, and $2 \%$ had $4 \%, 7 \%$, and 9\% respectively of E-selectin expression (Figure 20). These findings proved to a large extent that, serum actually induces E-selectin in HMEC-1. Although, 0.2\% serum exposure induced the least E-selectin in the cells, cells cultured in medium with $1 \%$ or $2 \%$ serum were used in the transmigration assay. The choice made was based on a visual observation of cell growth, which indicated a longer time (9-10 days) for cells grown in $0.2 \%$ serum to develop a monolayer as opposed to cells grown in either $1 \%$ or $2 \%$ serum, which required between 5-7 days for the desired monolayer to form. Following this observation, the subsequent transmigration assay was tested on HMEC-1 grown in $1 \%$ serum. In addition, for the next transmigration assay a few modifications were made. The modifications included the elimination of one-hour PSI pre-treatment reducing the treatment period to a total time of 4 hours; $\mathrm{IL}-8$ was also replaced with $10 \%$ serum in the bottom well and served as both chemoattractant and restored serum to the monolayer after the short period of starvation. With these adjustments, a $16 \%$ inhibition of PMNs transmigration was observed in TNF $\alpha$-PSI co-treated monolayer. In addition, PSI- 
treated cells recorded 20\% less PMN transmigration compared to the baseline (Figure 22).

The current results continue to make serum concentration an important factor to closely monitor. A further increase of serum was adapted and HMEC-1 for the subsequent transmigration assay was cultured in $2 \%$ serum (a $1 \%$ increase). The increase in serum supply to HMEC-1 surely made a difference: a $66 \%$ inhibition of PMN transmigration was observed in TNF $\alpha$-PSI monolayer compared to TNF $\alpha$ activated transmigration $[\mathrm{P}<0.05]$ Also PSI treated cells show a $24 \%$ inhibition compared with control $[\mathrm{P}<0.05]$ (Figure 23). This latter data is very exciting and indicates that with proper serum adjustment greater PMN inhibition in transmigration with protein synthesis inhibitors can be achieved. The results at this point definitely show an inhibitory trend and are significant $(\mathrm{P}<0.05)$. However, repeated experiments with larger the sample sizes will be helpful. It is also recommended that future experiments include serum adjustments to obtain the optimal concentration for HMEC- 1 at which higher inhibition could be achieved with reduced endogenous E-selectin expression, which interferes with the data. When HMEC-1 exposed to $2 \%$ serum was analyzed for E-selectin, the data (Figure 24) show E-selectin proportions, which compares favorably with the trend of PMN transmigration observed in Figure 23. For example, TNF $\alpha$-PSI treated cells with the least proportion of E-selectin $(10.6 \%)$ also has the least PMN transmigration or the most inhibition $(\mathrm{P}<0.05)$. In comparing E-selectin expressed with concentration of serum made available to the growing cells, it was obvious that $20 \%$ serum induces much higher E-selectin in HMEC-1 than did 2\% serum (Figure 25). This data clearly show that Eselectin endogenously expressed by serum in HMEC-1 is dose-dependent. 


\section{Conclusion}

From our current experiments the following observations can be concluded:

1. It takes 5-7days for 20,000 HMEC-1 seeded in inserts of $6.5 \mathrm{~mm}$ diameter, and $3 \mu \mathrm{m}$ pore- sized polycarbonate membrane to develop a good monolayer intact enough for the transmigration experiment.

2. The Serum conundrum: while the presence of high concentrated serum induces endogenous E-selectin, total serum removal induces apoptosis in HMEC-1. The data support that at least $2 \%$ serum is optimal to satisfy the maintenance requirement of HMEC-1, but yet not over induce E-selectin.

3. In this experiment it will require $10 \mathrm{ng} / \mathrm{ml} \mathrm{TNF} \alpha$ treatment for four hours to allow significant PMN transmigration.

4. A four - hour co-treatment of PSI and TNF $\alpha$ resulted in a greater inhibition of PMN transmigration than a one- hour PSI pre-treatment followed by TNF $\alpha$ treatment.

5. Finally, these studies support our hypothesis that Protein Synthesis Inhibitors can be used to block neutrophil transmigration during inflammation.

\section{Recommendation for Future Studies}

1. Additional work is recommended to further define the optimal serum concentration needed to ensure HMEC-1 stability and good health for the period of the experiment.

2. The separate dose-response effects of puromycin and anisomycin on PMN transmigration will be necessary. 
3. Studies on the reversible effect of these protein synthesis inhibitors is recommended to ensure cell functions are not permanently impaired.

4. We also recommend that since using PMNs from a daily blood source is a point of variability, a transfected or stable PMN cell line should be considered in future studies. 


\section{References}

1. Timlin, M., et al., Fracture hematoma is a potent proinflammatory mediator of neutrophil function. J Trauma, 2005. 58(6): p. 1223-9.

2. Udobi, K.F., E. Childs, and K. Touijer, Acute respiratory distress syndrome. Am Fam Physician, 2003. 67(2): p. 315-22.

3. Kollef, M.H. and D.P. Schuster, The acute respiratory distress syndrome. N Engl J Med, 1995. 332(1): p. 27-37.

4. Ashbaugh, D.G., et al., Acute respiratory distress in adults. Lancet, 1967. 2(7511): p. 319-23.

5. Bernard, G.R., et al., The American-European Consensus Conference on ARDS. Definitions, mechanisms, relevant outcomes, and clinical trial coordination. Am J Respir Crit Care Med, 1994. 149(3 Pt 1): p. 818-24.

6. Piantadosi, C.A. and D.A. Schwartz, The acute respiratory distress syndrome. Ann Intern Med, 2004. 141(6): p. 460-70.

7. Lewandowski, K., et al., Incidence, severity, and mortality of acute respiratory failure in Berlin, Germany. Am J Respir Crit Care Med, 1995. 151(4): p. 1121-5.

8. Luhr, O.R., et al., Incidence and mortality after acute respiratory failure and acute respiratory distress syndrome in Sweden, Denmark, and Iceland. The ARF Study Group. Am J Respir Crit Care Med, 1999. 159(6): p. 1849-61.

9. Bersten, A.D., et al., Incidence and mortality of acute lung injury and the acute respiratory distress syndrome in three Australian States. Am J Respir Crit Care Med, 2002. 165(4): p. 443-8.

10. Thomsen, G.E. and A.H. Morris, Incidence of the adult respiratory distress syndrome in the state of Utah. Am J Respir Crit Care Med, 1995. 152(3): p. 965-71.

11. Herridge, M.S., et al., One-year outcomes in survivors of the acute respiratory distress syndrome. N Engl J Med, 2003. 348(8): p. 68393. 
12. Granger, D.N. and P. Kubes, The microcirculation and inflammation: modulation of leukocyte-endothelial cell adhesion. J Leukoc Biol, 1994. 55(5): p. 662-75.

13. Gabay, J.E., et al., Antibiotic proteins of human polymorphonuclear leukocytes. Proc Natl Acad Sci U S A, 1989. 86(14): p. 5610-4.

14. Shafer, W.M., L.E. Martin, and J.K. Spitznagel, Cationic antimicrobial proteins isolated from human neutrophil granulocytes in the presence of diisopropyl fluorophosphate. Infect Immun, 1984. 45(1): p. 29-35.

15. Bevilacqua, M.P., Endothelial-leukocyte adhesion molecules. Annu Rev Immunol, 1993. 11: p. 767-804.

16. Carlos, T.M. and J.M. Harlan, Leukocyte-endothelial adhesion molecules. Blood, 1994. 84(7): p. 2068-101.

17. Springer, T.A., Traffic signals on endothelium for lymphocyte recirculation and leukocyte emigration. Annu Rev Physiol, 1995. 57: p. 827-72.

18. Leeuwenberg, J.F., et al., E-selectin and intercellular adhesion molecule-1 are released by activated human endothelial cells in vitro. Immunology, 1992. 77(4): p. 543-9.

19. Borges, E., et al., The P-selectin glycoprotein ligand-1 is important for recruitment of neutrophils into inflamed mouse peritoneum. Blood, 1997. 90(5): p. 1934-42.

20. Tedder, T.F., et al., The selectins: vascular adhesion molecules. Faseb J, 1995. 9(10): p. 866-73.

21. Zou, X., et al., PSGL-1 derived from human neutrophils is a highefficiency ligand for endothelium-expressed E-selectin under flow. Am J Physiol Cell Physiol, 2005. 289(2): p. C415-24.

22. Collins, R.G., et al., Dermal and pulmonary inflammatory disease in E-selectin and P-selectin double-null mice is reduced in tripleselectin-null mice. Blood, 2001. 98(3): p. 727-35.

23. King, M.R., et al., Rolling dynamics of a neutrophil with redistributed L-selectin. Math Biosci, 2005. 194(1): p. 71-9.

24. Staunton, D.E., M.L. Dustin, and T.A. Springer, Functional cloning of ICAM-2, a cell adhesion ligand for LFA-1 homologous to ICAM-1. Nature, 1989. 339(6219): p. 61-4.

25. Issekutz, A.C., D. Rowter, and T.A. Springer, Role of ICAM-1 and ICAM-2 and alternate CD11/CD18 ligands in neutrophil transendothelial migration. J Leukoc Biol, 1999. 65(1): p. 117-26.

26. Smith, C.W., et al., Cooperative interactions of LFA-1 and Mac-1 with intercellular adhesion molecule-1 in facilitating adherence and 
transendothelial migration of human neutrophils in vitro. J Clin Invest, 1989. 83(6): p. 2008-17.

27. Kuhns, D.B., D.A. Long Priel, and J.I. Gallin, Loss of L-selectin (CD62L) on human neutrophils following exudation in vivo. Cell Immunol, 1995. 164(2): p. 306-10.

28. Edens, H.A. and C.A. Parkos, Neutrophil transendothelial migration and alteration in vascular permeability: focus on neutrophil-derived azurocidin. Curr Opin Hematol, 2003. 10(1): p. 25-30.

29. Gautam, N., et al., Heparin-binding protein (HBP/CAP37): a missing link in neutrophil-evoked alteration of vascular permeability. Nat Med, 2001. 7(10): p. 1123-7.

30. Ostergaard, E. and H. Flodgaard, A neutrophil-derived proteolytic inactive elastase homologue ( $\mathrm{HHBP}$ ) mediates reversible contraction of fibroblasts and endothelial cell monolayers and stimulates monocyte survival and thrombospondin secretion. J Leukoc Biol, 1992. 51(4): p. 316-23.

31. Wagner, J.G. and R.A. Roth, Neutrophil migration mechanisms, with an emphasis on the pulmonary vasculature. Pharmacol Rev, 2000. 52(3): p. 349-74.

32. Moraes, T.J., J.H. Zurawska, and G.P. Downey, Neutrophil granule contents in the pathogenesis of lung injury. Curr Opin Hematol, 2006. 13(1): p. 21-7.

33. Kettle, A.J. and C.C. Winterbourn, A kinetic analysis of the catalase activity of myeloperoxidase. Biochemistry, 2001. 40(34): p. 10204-12.

34. Klebanoff, S.J., Myeloperoxidase. Proc Assoc Am Physicians, 1999. 111(5): p. 383-9.

35. Nagra, R.M., et al., Immunohistochemical and genetic evidence of myeloperoxidase involvement in multiple sclerosis. J Neuroimmunol, 1997. 78(1-2): p. 97-107.

36. Winterbourn, C.C., M.C. Vissers, and A.J. Kettle, Myeloperoxidase. Curr Opin Hematol, 2000. 7(1): p. 53-8.

37. Klebanoff, S.J., Iodination of bacteria: a bactericidal mechanism. J Exp Med, 1967. 126(6): p. 1063-78.

38. Edwards, S.W. and M.B. Hallett, Seeing the wood for the trees: the forgotten role of neutrophils in rheumatoid arthritis. Immunol Today, 1997. 18(7): p. 320-4.

39. Chabot, F., et al., Reactive oxygen species in acute lung injury. Eur Respir J, 1998. 11(3): p. 745-57. 
40. Regelmann, W.E., et al., Sputum peroxidase activity correlates with the severity of lung disease in cystic fibrosis. Pediatr Pulmonol, 1995. 19(1): p. 1-9.

41. Buss, I.H., B.A. Darlow, and C.C. Winterbourn, Elevated protein carbonyls and lipid peroxidation products correlating with myeloperoxidase in tracheal aspirates from premature infants. Pediatr Res, 2000. 47(5): p. 640-5.

42. Heinecke, J.W., Cellular mechanisms for the oxidative modification of lipoproteins: implications for atherogenesis. Coron Artery Dis, 1994. 5(3): p. 205-10.

43. Reynolds, W.F., et al., An allelic association implicates myeloperoxidase in the etiology of acute promyelocytic leukemia. Blood, 1997. 90(7): p. 2730-7.

44. London, S.J., T.A. Lehman, and J.A. Taylor, Myeloperoxidase genetic polymorphism and lung cancer risk. Cancer Res, 1997. 57(22): p. 5001-3.

45. Proud, D., The Role of Defensins in Virus-induced Asthma. Curr Allergy Asthma Rep, 2006. 6(1): p. 81-5.

46. Lehrer, R.I., et al., Interaction of human defensins with Escherichia coli. Mechanism of bactericidal activity. J Clin Invest, 1989. 84(2): p. 553-61.

47. Kougias, P., et al., Neutrophil antimicrobial peptide alpha-defensin causes endothelial dysfunction in porcine coronary arteries. J Vasc Surg, 2006. 43(2): p. 357-63.

48. Gray, P.W., et al., Cloning of the cDNA of a human neutrophil bactericidal protein. Structural and functional correlations. J Biol Chem, 1989. 264(16): p. 9505-9.

49. Schumann, R.R., et al., Structure and function of lipopolysaccharide binding protein. Science, 1990. 249(4975): p. 1429-31.

50. Weiss, J., et al., Purification and characterization of a potent bactericidal and membrane active protein from the granules of human polymorphonuclear leukocytes. J Biol Chem, 1978. 253(8): p. 266472.

51. Odeberg, H. and I. Olsson, Mechanisms for the microbicidal activity of cationic proteins of human granulocytes. Infect Immun, 1976. 14(6): p. 1269-75.

52. Shafer, W.M., et al., Tailoring an antibacterial peptide of human lysosomal cathepsin $G$ to enhance its broad-spectrum action against antibiotic-resistant bacterial pathogens. Curr Pharm Des, 2002. 8(9): p. 695-702. 
53. Cole, A.M., et al., Inhibition of neutrophil elastase prevents cathelicidin activation and impairs clearance of bacteria from wounds. Blood, 2001. 97(1): p. 297-304.

54. Miyasaki, K.T. and A.L. Bodeau, Human neutrophil azurocidin synergizes with leukocyte elastase and cathepsin $G$ in the killing of Capnocytophaga sputigena. Infect Immun, 1992. 60(11): p. 4973-5.

55. Weinrauch, Y., et al., Neutrophil elastase targets virulence factors of enterobacteria. Nature, 2002. 417(6884): p. 91-4.

56. Stefansson, S., et al., Mutants of plasminogen activator inhibitor-1 designed to inhibit neutrophil elastase and cathepsin $G$ are more effective in vivo than their endogenous inhibitors. J Biol Chem, 2004. 279(29): p. 29981-7.

57. Zimmermann, F., et al., Expression of elastase on polymorphonuclear neutrophils in vitro and in vivo: identification of CDI1 b as ligand for the surface-bound elastase. Shock, 2005. 23(3): p. 216-23.

58. Arnold, R.R., M.F. Cole, and J.R. McGhee, A bactericidal effect for human lactoferrin. Science, 1977. 197(4300): p. 263-5.

59. Farnaud, S. and R.W. Evans, Lactoferrin--a multifunctional protein with antimicrobial properties. Mol Immunol, 2003. 40(7): p. 395-405.

60. Sternlicht, M.D. and Z. Werb, How matrix metalloproteinases regulate cell behavior. Annu Rev Cell Dev Biol, 2001. 17: p. 463516.

61. Barbacid, M., M. Fresno, and D. Vazquez, Inhibitors of polypeptide elongation on yeast polysomes. J Antibiot (Tokyo), 1975. 28(6): p. 453-62.

62. Grollman, A.P., Inhibitors of protein biosynthesis. II. Mode of action of anisomycin. J Biol Chem, 1967. 242(13): p. 3226-33.

63. Shifrin, V.I. and P. Anderson, Trichothecene mycotoxins trigger a ribotoxic stress response that activates c-Jun $N$-terminal kinase and p38 mitogen-activated protein kinase and induces apoptosis. J Biol Chem, 1999. 274(20): p. 13985-92.

64. Kyriakis, J.M., et al., pp54 microtubule-associated protein-2 kinase requires both tyrosine and serine/threonine phosphorylation for activity. J Biol Chem, 1991. 266(16): p. 10043-6.

65. Edwards, D.R. and L.C. Mahadevan, Protein synthesis inhibitors differentially superinduce c-fos and c-jun by three distinct mechanisms: lack of evidence for labile repressors. Embo J, 1992. 11(7): p. 2415-24. 
66. Chen, X.L., et al., E-selectin gene expression in vascular smooth muscle cells. Evidence for a tissue-specific repressor protein. Circ Res, 1997. 80(3): p. 305-11.

67. Mosmann, T., Rapid colorimetric assay for cellular growth and survival: application to proliferation and cytotoxicity assays. $\mathrm{J}$ Immunol Methods, 1983. 65(1-2): p. 55-63.

68. Meyrick, B., L.C. Berry, Jr., and B.W. Christman, Response of cultured human pulmonary artery endothelial cells to endotoxin. Am J Physiol, 1995. 268(2 Pt 1): p. L239-44.

69. Pober, J.S. and R.S. Cotran, The role of endothelial cells in inflammation. Transplantation, 1990. 50(4): p. 537-44.

70. $\mathrm{Hu}, \mathrm{X}$., et al., Lipopolysaccharide induces the antiapoptotic molecules, A1 and A20, in microvascular endothelial cells. Blood, 1998. 92(8): p. 2759-65.

71. Khan, A.I., et al., Lipopolysaccharide: a p38 MAPK-dependent disrupter of neutrophil chemotaxis. Microcirculation, 2005. 12(5): p. 421-32.

72. Orlandini, M., et al., Protein kinase CK2alpha' is induced by serum as a delayed early gene and cooperates with Ha-ras in fibroblast transformation. J Biol Chem, 1998. 273(33): p. 21291-7.

73. Webster, M.K., et al., Characterization of sgk, a novel member of the serine/threonine protein kinase gene family which is transcriptionally induced by glucocorticoids and serum. Mol Cell Biol, 1993. 13(4): p. 2031-40. 
Appendix 1

A. Growth Media Preparation

1. $20 \%$ Fetal Bovine Serum

\begin{tabular}{|l|c|c|c|}
\hline Ingredient & Stock Conc. & Volume added & Working Conc. \\
\hline FBS & - & $100 \mathrm{ml}$ & $20 \%$ \\
\hline L-Glutamine & $200 \mathrm{mM}$ & $5 \mathrm{ml}$ & $2 \mathrm{mM}$ \\
\hline $\begin{array}{l}\text { Antibiotic- } \\
\text { Antimycotic }\end{array}$ & $100 \mathrm{X}$ & $5 \mathrm{ml}$ & $1 \mathrm{X}$ \\
\hline EGF & $100 \mu \mathrm{g} / \mathrm{ml}$ & $200 \mu \mathrm{l}$ & $40 \mathrm{ng} / \mathrm{ml}$ \\
\hline Hydrocortisone & $25 \mathrm{mg} / \mathrm{ml}$ & $20 \mu \mathrm{l}$ & $1 \mu \mathrm{g} / \mathrm{ml}$ \\
\hline MCDB 131 & $1 \mathrm{X}$ & $390 \mathrm{ml}$ & $1 \mathrm{X}$ \\
\hline \multicolumn{1}{|c|}{ Total Volume } & - & $500 \mathrm{ml}$ & - \\
\hline
\end{tabular}

Mix all ingredients under the lamina flow hood and filter with a filter system

2. Preparing an Insulin-Transferrin-Selenium -A (ITS) medium, a serum- free medium

\begin{tabular}{|l|c|c|c|}
\hline Ingredients & Stock Conc. & $\begin{array}{l}\text { Volume } \\
\text { added }\end{array}$ & $\begin{array}{l}\text { Working } \\
\text { Conc. }\end{array}$ \\
\hline ITS-100X (Gibco \#51300-044) & $100 \mathrm{X}$ & $5 \mathrm{ml}$ & $1 \%(1 \mathrm{X})$ \\
\hline $\begin{array}{l}\text { Antibiotic-Antimycotic } \\
\text { (Gibco\#15240-096) }\end{array}$ & $100 \mathrm{X}$ & $5 \mathrm{ml}$ & $1 \%(1 \mathrm{X})$ \\
\hline $\begin{array}{l}\text { L-Glutamine-200mM (Gibco \# } \\
\text { 25030-081) }\end{array}$ & $200 \mathrm{mM}$ & $5 \mathrm{ml}$ & $2 \mathrm{mM}$ \\
\hline Hydrocortisone & $25 \mathrm{mg} / \mathrm{ml}$ & $20 \mu \mathrm{l}$ & $1 \mu \mathrm{g} / \mathrm{ml}$ \\
\hline MCDB 131(Gibco \# 10372) & $1 \mathrm{X}$ & $485 \mathrm{ml}$ & $1 \mathrm{X}$ \\
\hline Total Volume & - & $500 \mathrm{ml}$ & - \\
\hline
\end{tabular}

Mix all ingredients under the hood and filter with a filtering system. 
3. Preparing $1 \%$ Serum plus Insulin-Transferrin-Selenium -A (ITS) medium,

\begin{tabular}{|l|c|c|c|}
\hline Ingredients & Stock Conc. & $\begin{array}{l}\text { Volume } \\
\text { added }\end{array}$ & $\begin{array}{l}\text { Working } \\
\text { Conc. }\end{array}$ \\
\hline ITS-100X (Gibco \#51300-044) & $100 \mathrm{X}$ & $5 \mathrm{ml}$ & $1 \%(1 \mathrm{X})$ \\
\hline $\begin{array}{l}\text { Antibiotic-Antimycotic } \\
\text { (Gibco\#15240-096) }\end{array}$ & $100 \mathrm{X}$ & $5 \mathrm{ml}$ & $1 \%(1 \mathrm{X})$ \\
\hline $\begin{array}{l}\text { L-Glutamine-200mM (Gibco \# } \\
\text { 25030-081) }\end{array}$ & $200 \mathrm{mM}$ & $5 \mathrm{ml}$ & $2 \mathrm{mM}$ \\
\hline Fetal Bovine Serum & - & $5 \mathrm{ml}$ & $1 \%$ \\
\hline Hydrocortisone & $25 \mathrm{mg} / \mathrm{ml}$ & $20 \mu \mathrm{l}$ & $1 \mu \mathrm{g} / \mathrm{ml}$ \\
\hline MCDB 131(Gibco \# 10372) & $1 \mathrm{X}$ & $480 \mathrm{ml}$ & $1 \mathrm{X}$ \\
\hline Total Volume & - & $500 \mathrm{ml}$ & - \\
\hline
\end{tabular}

Mix all ingredients under the hood and filter with a filtering system. 


\section{Appendix 2}

\section{Media Formulations}

\section{a. MCDB 131(Table was adapted from http://catalog.invitrogen.com)}

MCDB 131 Medium liquid (1X)

contains no L-glutamine.

MCDB 131 was orginially developed by Knedler and Ham as a reduced serum-supplemented medium for the culture of human microvascular endothelial cells. This formulation has been reported to support clonal growth of humanomental microvascular cells when supplemented with $0.7 \%$ dialyzed FBS, $10 \mathrm{ng} / \mathrm{ml} \mathrm{EGF}$, and $1 \mu \mathrm{g} / \mathrm{ml}$ hydrocortisone.

Catalog Number: 10372019

\begin{tabular}{|c|c|c|c|}
\hline COMPONENTS & Molecular Weight & Concentration $(\mathrm{mg} / \mathrm{L})$ & Molarity (mM) \\
\hline \multicolumn{4}{|l|}{ Amino Acids } \\
\hline Glycine & 75 & 2.3 & 0.0307 \\
\hline L-Alanine & 89 & 2.7 & 0.0303 \\
\hline L-Arginine hydrochloride & 211 & 63.2 & 0.300 \\
\hline L-Asparagine- $\mathrm{H} 2 \mathrm{O}$ & 150 & 15 & 0.1000 \\
\hline L-Aspartic acid & 133 & 13.3 & 0.1000 \\
\hline $\mathrm{L}$-Cysteine $2 \mathrm{HCl} . \mathrm{H} 2 \mathrm{O}$ & 176 & 35 & 0.199 \\
\hline L-Glutamic Acid & 147 & 4.4 & 0.0299 \\
\hline L-Histidine hydrochloride- $\mathrm{H} 2 \mathrm{O}$ & 210 & 42 & 0.200 \\
\hline L-Isoleucine & 131 & 66 & 0.504 \\
\hline L-Leucine & 131 & 131 & 1.000 \\
\hline L-Lysine hydrochloride & 183 & 182 & 0.995 \\
\hline L-Methionine & 149 & 15 & 0.101 \\
\hline L-Phenylalanine & 165 & 33 & 0.200 \\
\hline L-Proline & 115 & 11.5 & 0.1000 \\
\hline L-Serine & 105 & 32 & 0.305 \\
\hline L-Threonine & 119 & 12 & 0.101 \\
\hline L-Tryptophan & 204 & 4.1 & 0.0201 \\
\hline L-Tyrosine & 181 & 18.1 & 0.1000 \\
\hline L-Valine & 117 & 117 & 1.000 \\
\hline \multicolumn{4}{|c|}{ Vitamins } \\
\hline Biotin & 244 & 0.0073 & 0.0000299 \\
\hline Choline chloride & 140 & 14 & 0.1000 \\
\hline D-Calcium pantothenate & 477 & 12 & 0.0252 \\
\hline Folinic Acid Calcium salt & 512 & 0.6 & 0.00117 \\
\hline
\end{tabular}




\begin{tabular}{|c|c|c|c|}
\hline i-Inositol & 180 & 7.2 & 0.0400 \\
\hline Niacinamide & 122 & 61 & 0.0500 \\
\hline Pyridoxine hydrochloride & 206 & 2.1 & 0.0102 \\
\hline Riboflavin & 376 & 0.0038 & 0.0000101 \\
\hline Thiamine hydrochloride & 337 & 3.4 & 0.0101 \\
\hline Vitamin B12 & 1355 & 0.0136 & 0.0000100 \\
\hline \multicolumn{4}{|l|}{ Luorganic Salts } \\
\hline Ammonium Metavanadate $\mathrm{NaVO} 3$ & 121.93 & 0.0006 & 0.0000049 \\
\hline Ammonium Molybdate ((NH4)6Mo7O24-4H2O) & 1235 & 0.0037 & 0.0000030 \\
\hline Calcium Chloride $(\mathrm{CaCl} 2-2 \mathrm{H} 2 \mathrm{O})$ & 147 & 235 & 1.60 \\
\hline Cupric sulfate (CuSO4-5H2O) & 250 & 0.0012 & 0.0000048 \\
\hline Ferric sulfate (FeSO4-7H2O) & 278 & 0.283 & 0.00102 \\
\hline Magnesium Sulfate (MgSO4-7H2O) & 246 & 2464 & 10.02 \\
\hline Manganese Sulfate (MnSO4-H20) & 169 & 0.0002 & 0.0000012 \\
\hline Nickelous Chloride $\mathrm{NiCl} 26 \mathrm{H} 2 \mathrm{O}$ & 238 & 7.1 & 0.0000003 \\
\hline Potassium Chloride $(\mathrm{KCl})$ & 75 & 298 & 3.97 \\
\hline Selenious Acid $\mathrm{H}_{2} \mathrm{SeO} 3$ & 129 & 0.0038 & 0.0000295 \\
\hline Sodium Bicarbonate $(\mathrm{NaHCO} 3)$ & 84 & 1176 & 14.00 \\
\hline Sodium Chloride $(\mathrm{NaCl})$ & 58 & 6430 & 110.86 \\
\hline Sodium Meta Silicate $\mathrm{Na} 2 \mathrm{SiO} 39 \mathrm{H} 2 \mathrm{O}$ & 284 & 2.8 & 0.00986 \\
\hline Sodium Phosphate dibasic ( $\mathrm{Na} 2 \mathrm{HPO}-7 \mathrm{H} 2 \mathrm{O}$ ) & 268 & 134 & 0.500 \\
\hline Zinc Sulfate ( $\mathrm{ZnSO} 4-\mathrm{H} 2 \mathrm{O})$ & 288 & 0.0003 & 0.0000010 \\
\hline \multicolumn{4}{|c|}{ Other Components } \\
\hline Adenine & 135 & 0.135 & 0.001000 \\
\hline D-Glucose (Dextrose) & 180 & 1000 & 5.56 \\
\hline Lipoic Acid & 206 & 0.0021 & 0.0000102 \\
\hline Phenol Red & 376.4 & 12.4 & 0.0329 \\
\hline Putrescine $2 \mathrm{HCl}$ & 161 & 0.0002 & 0.0000012 \\
\hline Sodium Pyruvate & 110 & 110 & 1.000 \\
\hline Thymidine & 242 & 0.024 & 0.0000992 \\
\hline
\end{tabular}

\section{b. Insulin-Transferrin-Selenium-A (100X) Supplement Formulation (Gibco \# 15240-096, Grand Island, NY)}

\begin{tabular}{|l|c|}
\hline Component & Concentration \\
\hline Insulin & $1.0 \mathrm{~g} / \mathrm{L}$ \\
\hline Sodium Selenite & $0.67 \mathrm{mg} / \mathrm{L}$ \\
\hline Transferrin & $0.55 \mathrm{~g} / \mathrm{L}$ \\
\hline Sodium Pyruvate & $11.0 \mathrm{~g} / \mathrm{L}$ \\
\hline Ethanolamine & $0.2 \mathrm{~g} / \mathrm{L}$ \\
\hline
\end{tabular}




\section{Appendix 3}

\section{Flow Cytometer}

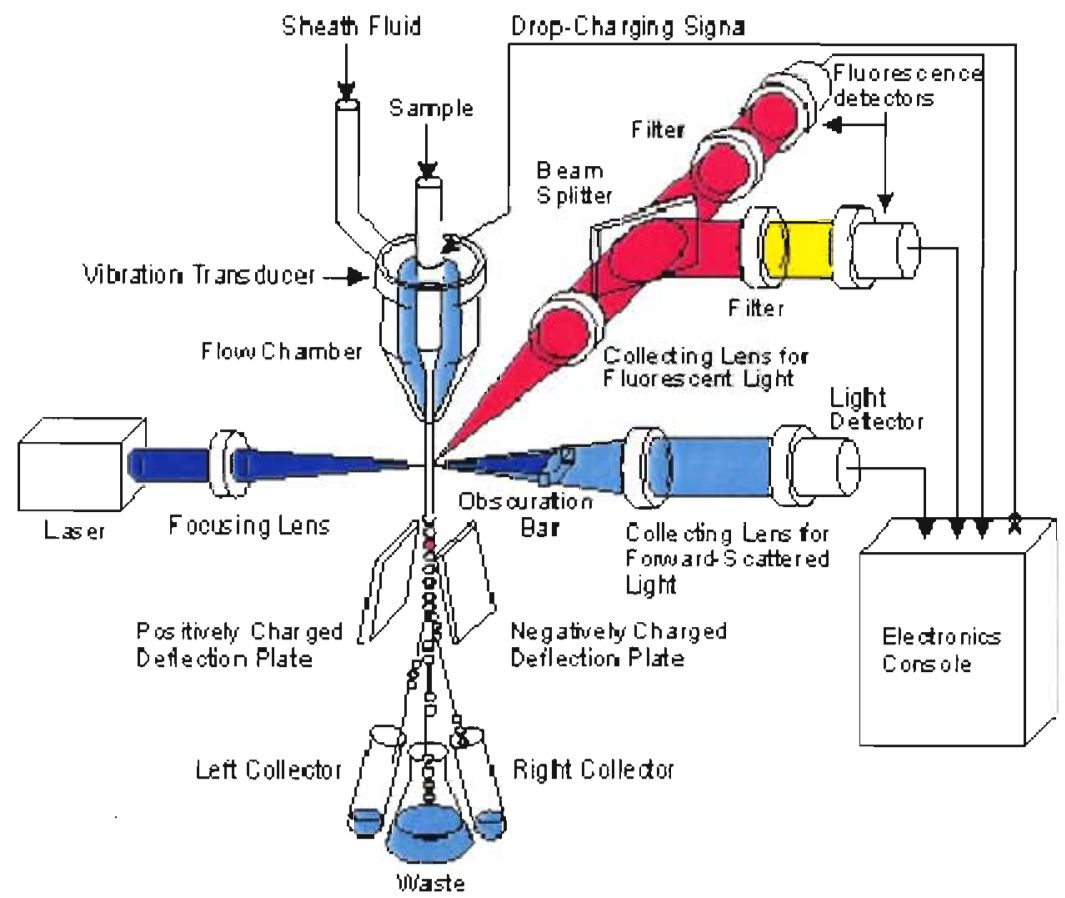

A. A schematic view of a flow cytometer and sorter with a jet-in-air configuration showing one forward light scatter and two fluorescence detectors.

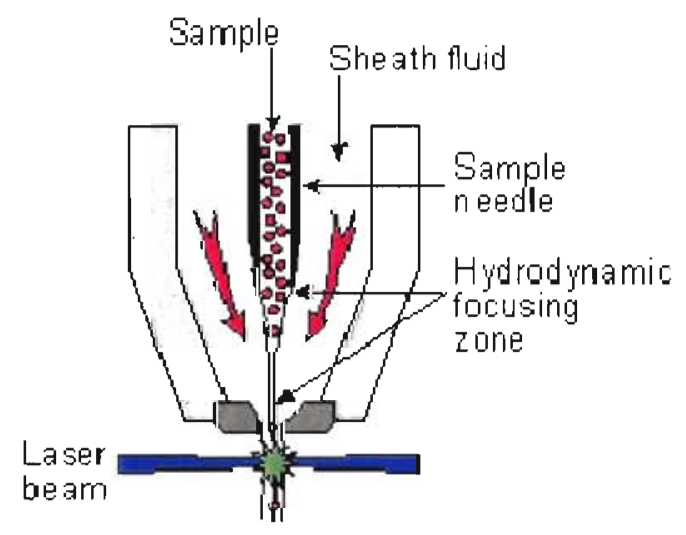

\section{A close up of the Flow Chamber}

Adapted from: www.ueb.cas.cz./.../Basic_principles.htm 
Appendix 4

Isolation of PMNs Schematic

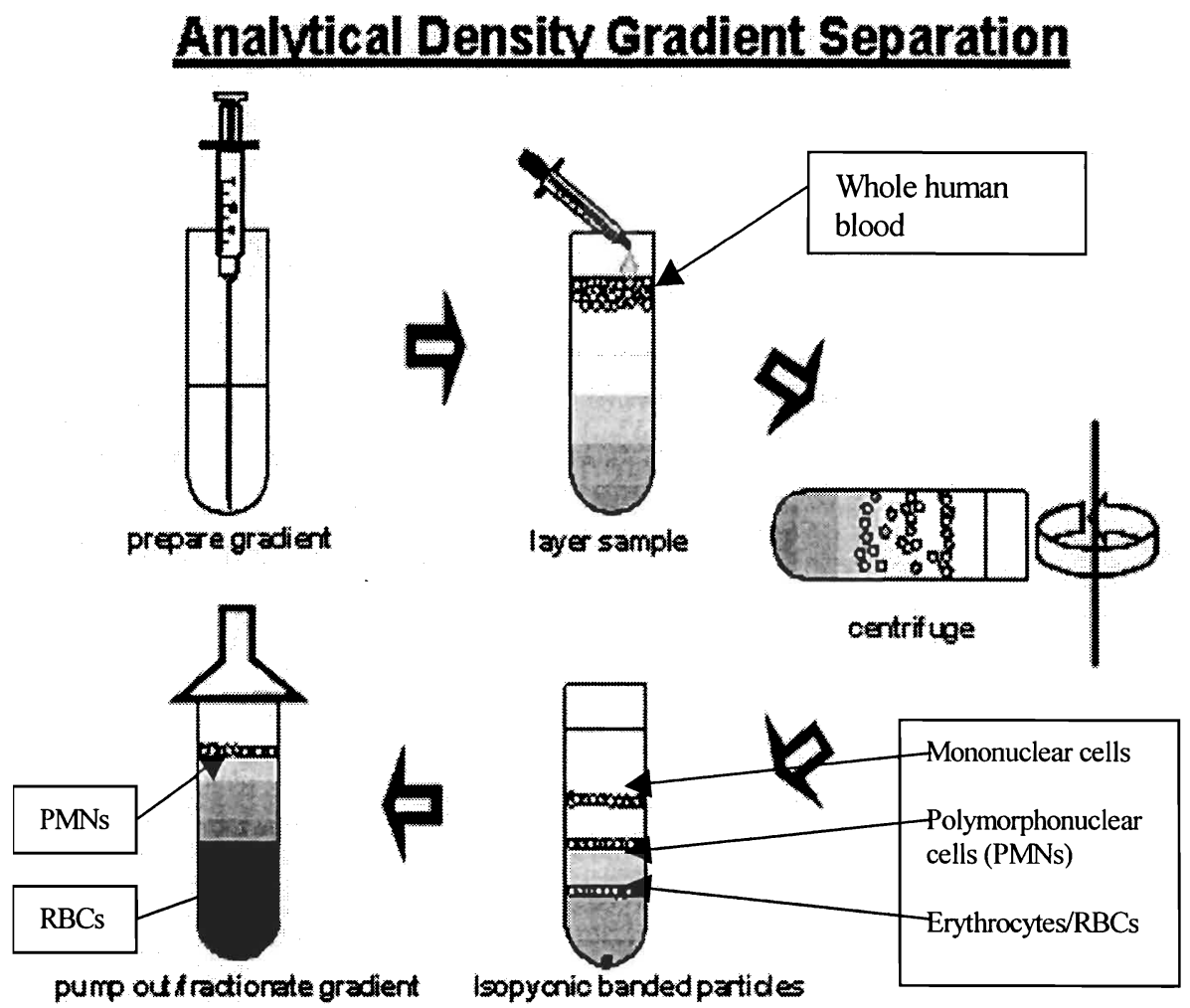

[Picture adapted from: chemistry.anl.gov/.../images/dgc-prep 1.jif]

\section{Procedure}

1. Remove Polymorphprep Solution from $4^{\circ} \mathrm{C}$ prior to blood separation to equilibrate to room temperature.

2. Obtain whole blood from healthy donors drawn and placed in sterile $3 \mathrm{ml}$ vacutainers with EDTA as anticoagulant.

3. Place $5 \mathrm{ml}$ of polymorphprep first in a $15 \mathrm{ml}$ Falcon tube and $5 \mathrm{ml}$ of anticoagulated whole blood carefully layered over it. Much care was taken not to mix the blood with the separation fluid.

4. Centrifuge the layered samples at 450-500 $\mathrm{xg}$ for 30-35 minutes in a swing-out rotor between $18-22^{\circ} \mathrm{C}$.(NB: blood from some individuals may require a higher 
centrifugal force to separate). For the first time with any individual's blood one may have to test spin to know the specific g-force required.

5. At the end of centrifugation, two distinct leukocyte bands will be visible. The top band at the medium interface is mononuclear cells and the lower band of polymorphonuclear cells. The bottom pellet is composed of erythrocytes. 


\section{Appendix 5}

\section{Myeloperoxidase ELISA Assay}

Materials (Innozyme ${ }^{\mathrm{TM}}$ Myeloperoxidase Activity Kit)[Calbiochem, La Jolla, CA]

1. 1X Sample Buffer $\rightarrow 1 \mathrm{ml}$ of $20 \mathrm{X}$ Sample Buffer $+19 \mathrm{ml}$ of $\mathrm{dH} 2 \mathrm{O}$

2. $0.3 \% \mathrm{H}_{2} \mathrm{O}_{2} \rightarrow 5 \mu \mathrm{l}$ of $30 \% \mathrm{H}_{2} \mathrm{O}_{2}+495 \mu$ l cold $\mathrm{dH}_{2} \mathrm{O}$

3. TMB Detection Reagent

4. ELISA Stop Solution

5. Assay Buffer

6. 96-well polystyrene plate coated with antibody

7. 20 X Sample Buffer

\section{Procedure}

1. Transfer $475 \mu$ l of PMN suspension after transmigration and $25 \mu$ l of $20 \mathrm{X}$ Sample Buffer into a sterile eppendorf tube. Vortex and dispense $100 \mu l$ to designated wells of a 96-well strips placed in a well holder (NB: these come in individual strips so the experiments can be tailored to the number of strips needed).

2. Cover with a plastic plate sealer provided in the kit

3. Incubate for 60 minutes by gentle shaking

4. Wash the plate 4 times with $400 \mu \mathrm{l}$ of $1 \mathrm{X}$ Sample Buffer. Following each wash discard the contents of the well by inverting with plate over the sink; tap the plate on a paper towel to remove residual liquid.

5. Add freshly prepared TMB working solution (see Table below for the number of strips used and the corresponding Working Solution) to each well and incubate at $37^{\circ} \mathrm{C}$ for $20-30$ minutes.

6. Add $100 \mu \mathrm{l}$ ELISA Solution to each well to stop the color development.

7. Read the absorbance at $450 \mathrm{~nm}$

\begin{tabular}{|c|l|l|l|l|}
\hline $\begin{array}{l}\text { \# of 8-well } \\
\text { Strips }\end{array}$ & $\mathrm{dH}_{2} \mathrm{O}$ & Assay Buffer & $\mathrm{TMB}$ & $0.3 \% \mathrm{H}_{2} \mathrm{O}_{2}$ \\
\hline 1 & $715 \mu \mathrm{l}$ & $200 \mu \mathrm{l}$ & $80 \mathrm{ul}$ & $4.0 \mathrm{ul}$ \\
\hline 2 & $1.43 \mathrm{ml}$ & $400 \mathrm{ul}$ & $160 \mathrm{ul}$ & $8.0 \mathrm{ul}$ \\
\hline 3 & $2.148 \mathrm{ml}$ & $600 \mathrm{ul}$ & $240 \mathrm{ul}$ & $12 \mathrm{ul}$ \\
\hline 4 & $2.86 \mathrm{ml}$ & $800 \mathrm{ul}$ & $320 \mathrm{ul}$ & $16 \mathrm{ul}$ \\
\hline 5 & $3.575 \mathrm{ml}$ & $1.00 \mathrm{ml}$ & $400 \mathrm{ul}$ & $20 \mathrm{ul}$ \\
\hline 6 & $4.31 \mathrm{ml}$ & $1.21 \mathrm{ml}$ & $480 \mathrm{ul}$ & $24 \mathrm{ul}$ \\
\hline 8 & $5.00 \mathrm{ml}$ & $1.41 \mathrm{ml}$ & $560 \mathrm{ul}$ & $28 \mathrm{ul}$ \\
\hline 10 & $5.73 \mathrm{ml}$ & $1.60 \mathrm{ml}$ & $640 \mathrm{ul}$ & $32 \mathrm{ul}$ \\
\hline 12 & $7.16 \mathrm{ml}$ & $2.00 \mathrm{ml}$ & $800 \mathrm{ul}$ & $40 \mathrm{ul}$ \\
\hline
\end{tabular}


Appendix 6

\section{Reversibility of Protein Synthesis Inhibition.}

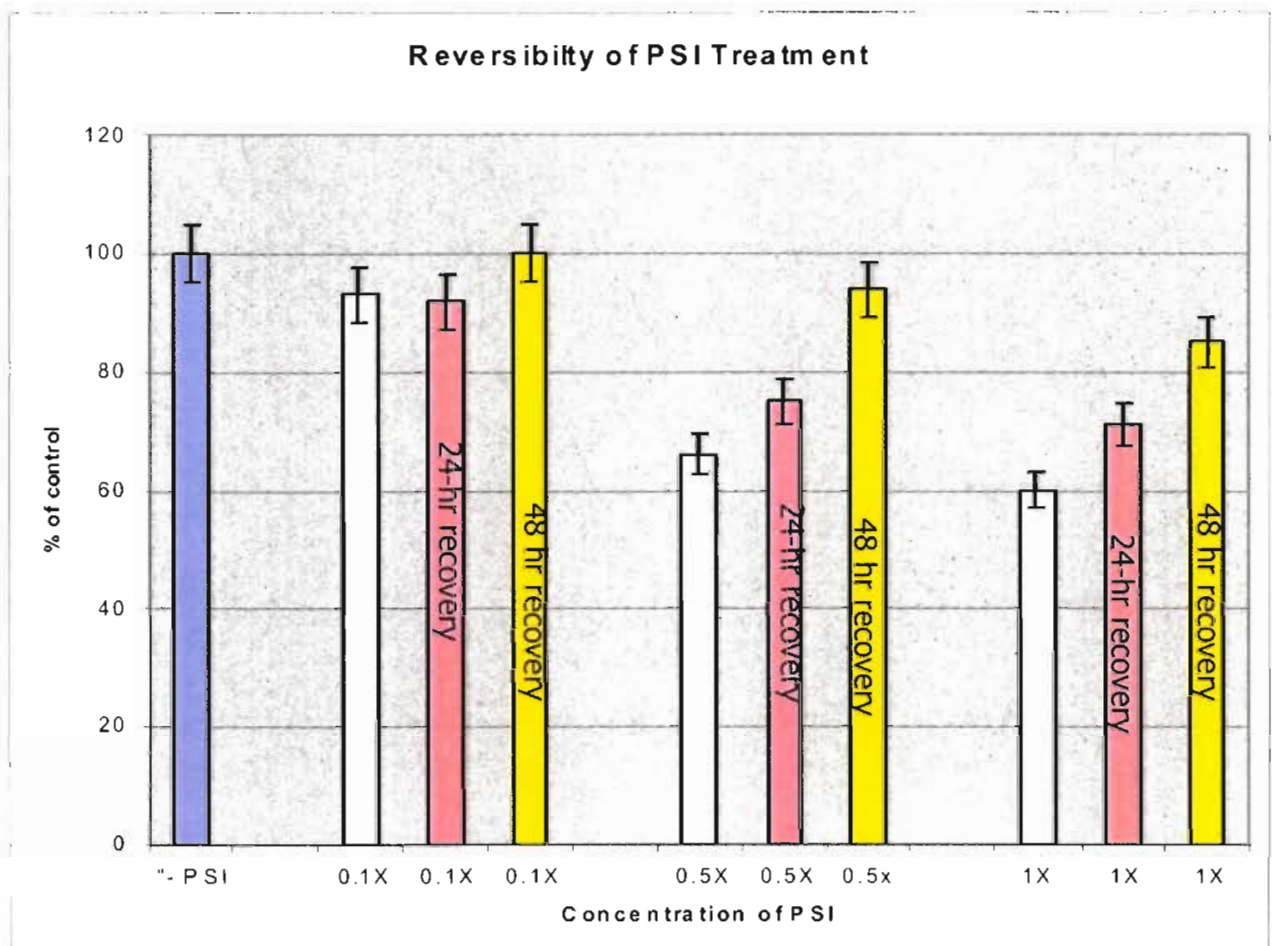

$$
\text { 1XPSI = 1LMPuramyain + 0.25uMArisomyain }
$$

Appendix 6: A time course of $\mathrm{HMEC}-1$ recovery after exposure to $0.1 \mathrm{X}, 0.5 \mathrm{X}$, and $1 \mathrm{X}$ concentrations of PSI (Puromycin + Anisomycin). [by Quincy Tran]. 


\section{Appendix 7}

FACS Analysis of E-Selectin Expression (J4 quadrant) in HMEC-1 cultured in $2 \%$ of Serum

a. Negative Control $-6.5 \%$

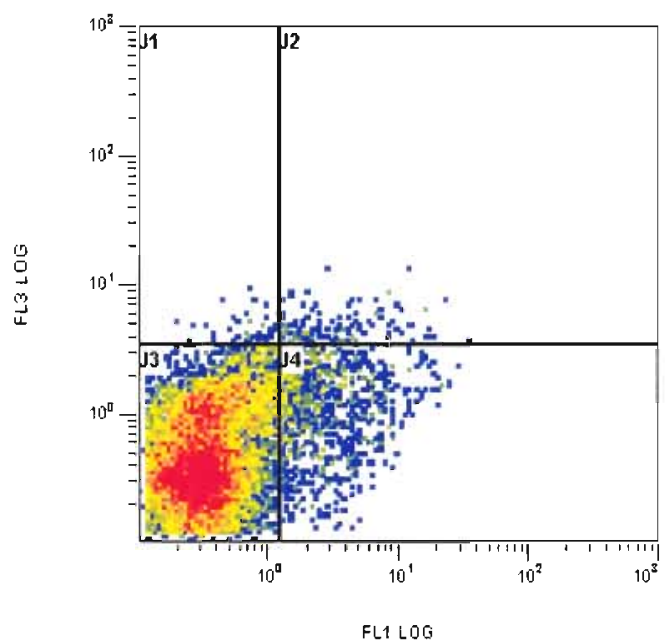

Control (no treatment) $-26 \%$

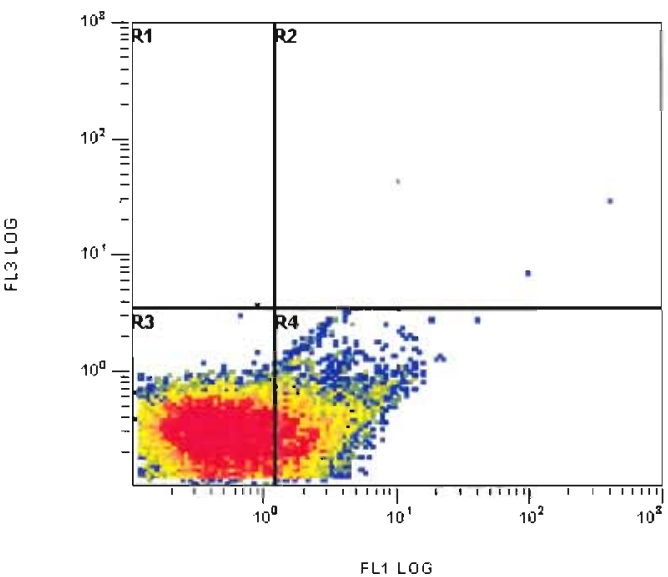

b. TNF(Positive Control) $-29 \%$

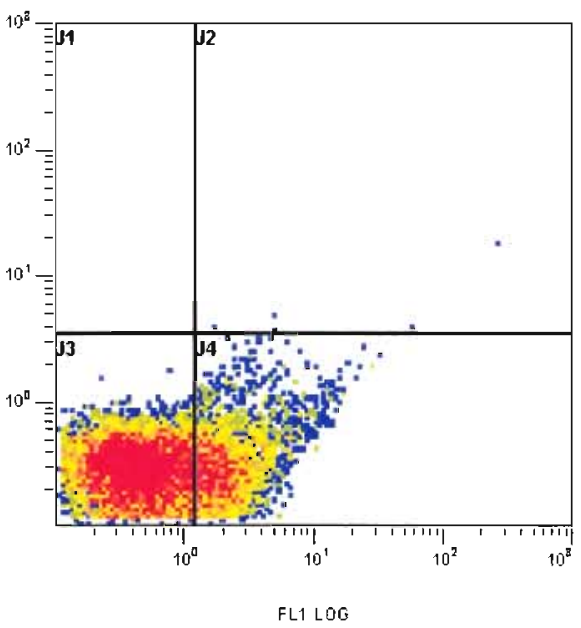

d. PSI $-14.4 \%$

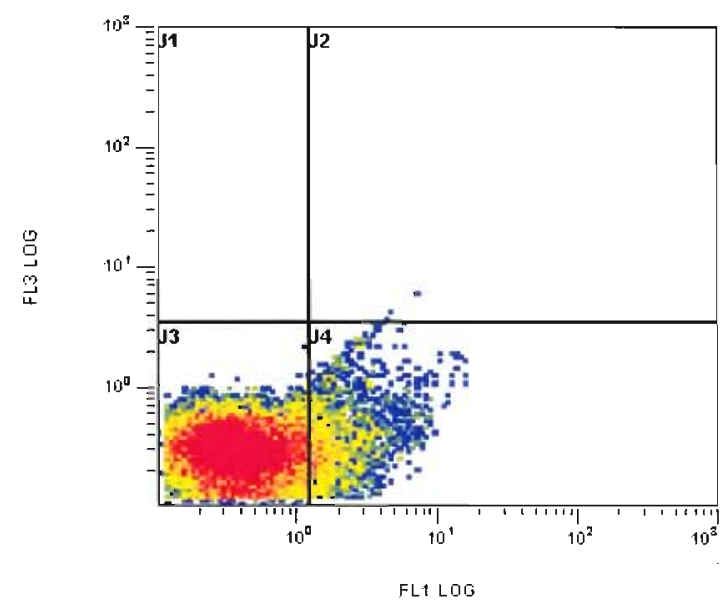


e. PSI-TNF- $10.6 \%$

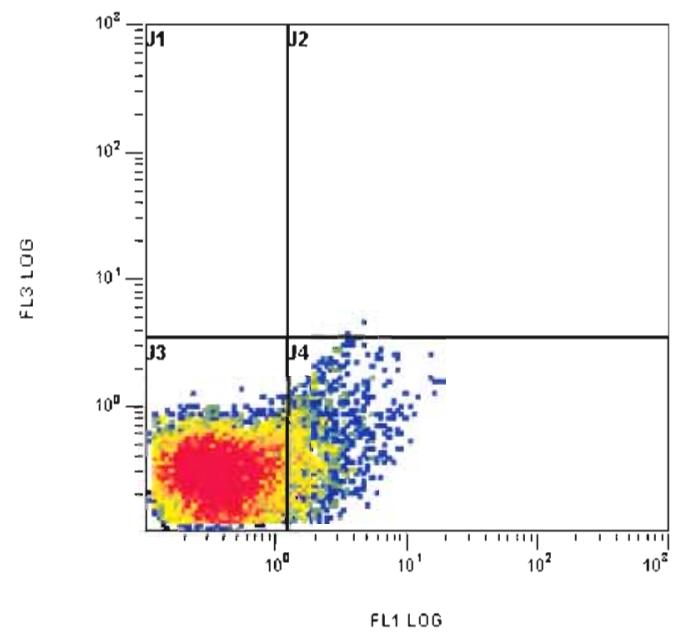

Appendix 7: Illustrations of FACS data on the proportions of E-selectin induced in cells cultured in $\mathbf{2 \%}$ serum: (a) Negative control for non-specific binding, $6.5 \%$, forms the background (b) TNF $\alpha$, positive control- $29 \%$ (c) Control cells with no treatment- $26 \%$ (d) $14.4 \%$ (e) TNFa-PSI $-10.6 \%$ 